VAN WEEZEL, Alex. "Optimización de la autonomía y deberes penales de solidaridad".

Polít. crim. Vol. 13, Nº 26 (Diciembre 2018) Art. 12, pp. 1074-1139.

[http://www.politicacriminal.cl/Vol_13/n_26/Vol13N26A12.pdf]

\title{
Optimización de la autonomía y deberes penales de solidaridad*
}

\section{Autonomy and Solidarity under Criminal Law}

\author{
Alex van Weezel \\ Profesor de Derecho Penal \\ Pontificia Universidad Católica de Chile \\ avw@uc.cl
}

\section{Resumen}

El trabajo es un estudio sobre la solidaridad como fuente de deberes penales. Después de realizar algunas precisiones conceptuales para delimitar su objeto de análisis, expone dos modelos alternativos de fundamentación e incardinación de la solidaridad en el sistema de los deberes jurídico-penales: la estatalización de la solidaridad y la solidaridad como expresión de un "derecho al bienestar" en el proceso de realización del concepto del derecho. Ambos modelos se ponen a prueba en la explicación del régimen legal de la falta de omisión de socorro y de los estados de necesidad justificantes. Este ejercicio permite identificar el lugar de la solidaridad en el sistema de distribución de autonomía y precisar sus límites generales y específicos, que comprenden la autonomía en el origen de la obligación y los presupuestos de surgimiento de la posición de garante. En la tercera y última sección se desarrolla una propuesta de interpretación del artículo $10 \mathrm{~N}^{\circ} 11 \mathrm{CP}$ que es consistente con los hallazgos previos.

Palabras clave: solidaridad, estado de necesidad, omisión de socorro, causas de justificación, amistad.

\begin{abstract}
This work is a study about solidarity as a foundation of criminal responsibility. After some conceptual precisions to delimit its object of analysis, it develops two alternative models of foundation and incardination of solidarity in the system of sources of criminal liability: the statization of solidarity and solidarity as an expression of a "right to well-being" in the process of realization of the concept of law. Both models have been tested in the construction of the statutory regulation of the offence of failure to render aid, and the defense of necessity. This exercise allows to identify the place of solidarity in the distribution system of autonomy and to specify its general and specific boundaries, which include the autonomy in the origin of the obligation and the requirements for the emergence of duty to rescue. In the third and last section, a proposal for the construction of article 10 No. 11 Chilean Penal Code is developed, which is consistent with the previous findings.
\end{abstract}

\footnotetext{
${ }^{*}$ Esta contribución ha sido elaborada en el marco del proyecto Fondecyt Regular N 1150264.
} 
Key words: solidarity, necessity, failure to render aid, duty to rescue, defenses, civic friendship.

\section{Introducción}

La palabra "solidaridad" tiene diversos significados, que en el lenguaje ordinario van desde la expresión de un estado del ánimo hasta la formulación de una consigna política ${ }^{1}$. En derecho penal, en cambio, designa por regla general el fundamento común de ciertos mandatos y prohibiciones en orden al favorecimiento de alguien cuyos intereses corren peligro, sin que el obligado se haya vinculado en forma previa y autónoma con tales intereses o con su titular. En esta acepción, la solidaridad alude a uno de los posibles fundamentos de una cierta clase de deber jurídico-penal -una posición de garante, en el sentido que se explica a continuación-, junto al deber de no dañar y a los deberes institucionales más específicos. Así entendida, la solidaridad hace abstracción de actitudes internas de benevolencia o de una cierta comprensión de la fraternidad entre los seres humanos $^{2}$. En lo que sigue llamaremos, pues, "solidaridad", o bien "deberes de solidaridad", a ese fundamento común.

La clarificación del estatus de los deberes de solidaridad en derecho penal exige, al menos en el estado actual de la discusión ${ }^{3}$, dar respuesta a dos cuestiones fundamentales. En primer lugar, es preciso establecer si la solidaridad constituye realmente una fuente de posiciones de garante, es decir, si cuenta como fundamento positivo de la antijuridicidad penal de ciertas conductas, de tal manera que a partir de ella se explica la existencia y configuración de sus respectivas definiciones típicas. A este problema se refieren principalmente las páginas siguientes, pero desde ya se puede advertir que la opinión ampliamente mayoritaria considera a la solidaridad como fuente idónea de posiciones de garante $^{4}$. La interpretación que en la actualidad ${ }^{5}$ se hace de dos institutos sistemáticamente

\footnotetext{
${ }^{1}$ En este sentido, por ejemplo, ya RADBRUCH, Gustav, Gesamtausgabe. Rechtsphilosophie II, edición a cargo de KAUFMANN, Arthur, Heidelberg: C.F. Müller, 1993, pp. 773 y s. El mismo fenómeno observaba también SCHROEDER, Friedrich-Christian, "Die Notwehr als Indikator politischer Grundanschauungen", en: SCHROEDER, Friedrich-Christian; ZIPF, Heinz (eds.), Festschrift für Reinhart Maurach zum 70. Geburtstag, Karlsruhe: Verlag C. F. Müller, 1972, pp. 126-142.

${ }^{2}$ Cfr. von der PFORDTEN, Dietmar, "Zur Rechtfertigung von Hilfeleistungspflichten”, en: von HIRSCH, Andreas; NEUMANN, Ulfrid; SEELMANN, Kurt (eds.), Solidarität im Strafrecht. Zur Funktion und Legitimation strafrechtlicher Solidaritätspflichten, Baden-Baden: Nomos, 2013, p. 104.

3 Véanse al respecto las contribuciones recogidas en HRUSCHKA, Joachim; JOERDEN, Jan C. (eds.), Jahrbuch für Recht und Ethik, Band 22 (2014); von HIRSCH; NEUMANN; SEELMANN (eds.), Solidarität im Strafrecht, cit. nota ${ }^{\circ}$ 2; OTTO, Harro, "Solidarität als Rechtsbegriff”, en: HEGER, Martin; KELKER, Brigitte; SCHRAMM, Edward (eds.), Festschrift für Kristian Kühl zum 70. Geburtstag, München: Verlag C. H. Beck, 2014, pp. 341-362; FRISCH, Wolfgang, "Notstandsregelungen als Ausdruck von Rechtsprinzipien", en: PAEFFGEN, Hans-Ullrich et al. (ed.), Strafrechtswissenschaft als Analyse und Konstruktion. Festschrift für Ingeborg Puppe zum 70. Geburtstag, Berlin: Duncker \& Humblot, 2011, pp. 425-450.

4 Cfr. von HIRSCH, Andreas; SCHORSCHER, Vivian C., "Die Kriminalisierung der unterlassenen Hilfeleistung: Eine Frage von 'Solidarität' oder Altruismus?", en von HIRSCH; NEUMANN; SEELMANN
} 
VAN WEEZEL, Alex. “Optimización de la autonomía y deberes penales de solidaridad”.

relevantes, la falta de omisión de socorro y el estado de necesidad agresivo del artículo 10 $\mathrm{N}^{\circ} 7 \mathrm{CP}$, da cuenta de ello.

En segundo lugar, sin embargo, resulta indispensable esclarecer si la posición de garante basada en solidaridad - en caso de que exista- funda una responsabilidad equivalente a la que emana de los deberes negativos y positivos o, por el contrario, se trata de una responsabilidad de segundo rango. Si una cierta medida de solidaridad resulta indispensable para la cohesión social, ella puede ser exigida por el Estado bajo amenaza de pena; el asunto está en determinar la proporcionalidad de las normas de conducta correspondientes. Pues por una parte existe el riesgo de que la expansión desmesurada de los deberes de solidaridad favorezca una especie de colectivismo que termine por ahogar las posibilidades de realización personal ${ }^{6}$. Por otro lado, y desde el punto de vista sistemático, se corre el peligro de disolver todas las vinculaciones sociales en la solidaridad, con la consiguiente pérdida de capacidad explicativa y de diferenciación. La tarea es reconocer el lugar que corresponde a la solidaridad en el ordenamiento penal y en la reflexión científica sobre él, conservando un sistema de los grados de incumbencia ${ }^{7}$ que permita maximizar la autonomía.

La presente contribución comienza con algunas precisiones conceptuales (1) para luego dar paso a la exposición de dos modelos explicativos: la estatalización de la solidaridad (2.1) y la solidaridad como expresión de un "derecho al bienestar" en proceso de evolución (2.2); este último tiene en cuenta especialmente el régimen de la omisión de socorro. En la tercera sección se esboza una síntesis que considera las particularidades del derecho vigente, especialmente en lo que respecta al estado de necesidad (3). Una herramienta común a todo el análisis será una teoría del derecho y del Estado que intenta captar y reproducir la tensión entre el concepto del derecho como existencia real de la libertad y su realización en la historia ${ }^{8}$.

(eds.), Solidarität im Strafrecht, cit. nota ${ }^{\circ}$ 2, p. 79; véase también, en términos más generales, SIMESTER, A. P.; von HIRSCH, Andreas, Crimes, Harms and Wrongs. On the Principles of Criminalization, Oregon: Hart Publishing, reprint 2014, especialmente los capítulos 4 y 5.

${ }^{5}$ Sobre el abandono o, cuando menos desplazamiento, de la interpretación del estado de necesidad como un asunto de mera ponderación de intereses en la dogmática contemporánea véase PAWLIK, Michael, "Solidarität als strafrechtliche Legitimationskategorie: das Beispiel des rechtfertigenden Aggressivotstandes", en HRUSCHKA; JOERDEN (eds.), Jahrbuch für Recht und Ethik, cit. nota ${ }^{\circ}$ 3, pp. 144 ss.; sobre la incapacidad de la ponderación de intereses para ofrecer criterios confiables y transparentes para la resolución de los conflictos, ampliamente, COCA VILA, Ivó, La colisión de deberes en derecho penal, Barcelona: Atelier, 2016, pp. 223 y ss., y WILENMANN, Javier, Freiheitsdistribution und Verantwortungsbegriff, Tübingen: Mohr Siebeck, 2014, pp. 11 y ss.

${ }^{6}$ Muy enfático sobre la posición secundaria de la solidaridad, complemento de la protección de la libertad, etc. KÜHL, Kristian, "Zur Anwendung des Solidaritätsbegriffs auf die unterlassene Hilfeleistung nach § 323c StGB”, en von HIRSCH; NEUMANN; SEELMANN (eds.), Solidarität im Strafrecht, cit. nota n² 2, pp. 93102.

${ }^{7}$ Cfr. van WEEZEL, Alex, "Injerencia y solidaridad en el delito de omisión de auxilio en caso de accidente" (en evaluación).

${ }^{8}$ Me refiero a HEGEL, G. W. F., especialmente en Grundlinien der Philosophie des Rechts (en adelante, GL) según MOLDENHAUER, E.; MICHEL, K. M. (eds.), Frankfurt a.M.: Suhrkamp, 1970; y a ARISTÓTELES, 
Polít. crim. Vol. 13, Nº 26 (Diciembre 2018) Art. 12, pp. 1074-1139.

[http://www.politicacriminal.cl/Vol_13/n_26/Vol13N26A12.pdf]

\section{La solidaridad en el sistema de las posiciones de garante en derecho penal}

\subsection{El sistema tripartito de las posiciones de garante}

Uno de los principales hallazgos de las teorías normativas de la imputación es, en sí mismo, una obviedad: la causación dolosa de un resultado que se encuadra en la literalidad de la descripción típica no es suficiente para la imputación objetiva de ese resultado, y lo mismo vale mutatis mutandis para la conducta. Para que tal causación o tal conducta puedan imputarse objetivamente a alguien es necesario, en primer lugar, que exista un fundamento jurídico en virtud del cual la correspondiente evitación sea asunto de esa persona, es decir, le concierna jurídico-penalmente hablando. Causalidad y conocimiento no están en condiciones de proporcionar ese fundamento, ni si quiera cuando concurren conjuntamente. Por eso, el deudor que paga una deuda exigible no es interviniente en el delito de tráfico de drogas que, solo gracias a que contaba con ese dinero, cometió luego el acreedor; y no lo es aunque, al momento de pagar, el deudor tuviera perfecto conocimiento de los planes delictivos del acreedor.

Durante mucho tiempo no pareció necesario detenerse en este presupuesto de la tipicidad, tal como cuando Beling formuló su teoría del tipo penal se consideraba superfluo detenerse en la tipicidad como categoría (relativamente) autónoma de la teoría del delito. Beling demostró que no solo resultaba útil hacerlo, sino que era necesario desde una perspectiva sistemática ${ }^{9}$. Análogamente, las teorías formal-objetivas sobre la autoría no plantean algo erróneo, pero llevan a confundir el objeto de la imputación con su fundamento. La teoría del dominio del hecho y otras teorías materiales de la autoría pusieron de relieve que la forma responde a un contenido y que, por lo tanto, nada se clarifica afirmando que es autor el que realiza el tipo penal. En efecto, en muchos casos sencillos de autor solitario parece innecesario preguntarse por el fundamento de la incumbencia o competencia por la realización formal del tipo penal; por ejemplo, cuando A con su propio cuerpo golpea a B provocándole un hematoma. En un caso como este no parece necesario detenerse en si la "propiedad" de A sobre su cuerpo y el golpe propinado a B sirviéndose de él permiten asignar a su ámbito de organización $-\mathrm{y}$ no a otro- la conducta lesiva y el resultado de lesiones.

Pero esta simplicidad desaparece de inmediato apenas se aproxima el ejemplo a la complejidad de los sucesos reales. Pues la competencia de A ya no es tan clara si el golpe es la respuesta a una agresión de B; si A ha sido instrumentalizado por C, quien le ha hecho creer por medios muy convincentes que B se aprestaba a darle muerte; si A ha actuado

en particular en Ética a Nicómaco, citada según la edición bilingüe de ARAUJO, María; MARÍAS, Julián, Madrid: Centro de Estudios Políticos y Constitucionales, $9^{\mathrm{a}}$ ed., 2009.

${ }^{9}$ Véase BELING, Ernst, Die Lehre vom Verbrechen, Tübingen: J.C.B. Mohr (Paul Siebeck), 1906 (reprint EHV History, 2014), pp. 110 y ss. 
VAN WEEZEL, Alex. “Optimización de la autonomía y deberes penales de solidaridad”.

cumpliendo una orden de la autoridad que puede constitucionalmente impartírsela; si se trata de los golpes que $\mathrm{C}$ propina a $\mathrm{B}$ mientras $\mathrm{A}$ lo inmoviliza; etc.

Debido a los avances tecnológicos y a la creciente complejidad de las estructuras de creación y administración de los riesgos, el derecho penal contemporáneo ha abandonado su antigua fijación en los aspectos fenomenológicos -la aparente causalidad, la malicia, el "conocimiento de causa", etc.- para concentrarse en un asunto previo y fundamental: la determinación de los ámbitos de responsabilidad personal. Las investigaciones al respecto, al menos entre quienes han dedicado al problema un interés reflexivo desde el punto de vista dogmático-penal, han llevado a redescubrir que los deberes relevantes para la fundamentación positiva de la antijuridicidad penal son de tres tipos: negativos, positivos y de solidaridad, donde estos últimos, se dice, ocupan un lugar secundario ${ }^{10}$.

Esta tripartición puede explicarse a partir de la idea -presente de diversas maneras en la filosofía moderna- de que el primer precepto del derecho es "(sé una persona y) ${ }^{11}$ respeta a los demás como personas"(GL § 36), lo cual incluye en un primer momento el respeto de la capacidad jurídica de los demás en cuanto a su propiedad y a su calidad de contraparte en las relaciones contractuales y, en un segundo momento, aquellas instituciones específicas sin las cuales en una determinada sociedad y en una determinada época no existiría derecho, sino solo astucia, ley del más fuerte ${ }^{12}$. Ambos elementos se manifiestan en derecho penal, respectivamente, en preceptos que expresan o se fundan en deberes negativos y en preceptos que expresan o se fundan en deberes positivos. Transgrede por ejemplo un deber negativo la persona que, habiendo asumido la protección de otra frente a un peligro mortal, la abandona sin justificación. Transgrede un deber positivo el padre que

${ }^{10}$ Cfr. JAKOBS, Günther, "Recht und Gut - Versuch einer strafrechtlichen Begriffsbildung”, en FREUND, Georg et al. (eds.), Grundlagen und Dogmatik des gesamten Strafrechtssystems. Festschrift für Wolfgang Frisch zum 70. Geburtstag, Berlin: Duncker \& Humblot, 2013, pp. 81-94 (p. 82); él mismo, System der strafrechtlichen Zurechnung, Frankfurt a.M.: Vittorio Klostermann, 2012, pp. 26 y ss., 83 ss.; con un desarrollo propio a partir de estos planteamientos PAWLIK, Michael, Das Unrecht des Bürgers, Tübingen: Mohr Siebeck, 2012, pp. 159 ss.; WILENMANN, Javier, Freiheitsdistribution, cit. nota n 5, pp. 33 y ss.; KUBICIEL, Michael, Die Wissenschaft vom besonderen Teil des Strafrechts, Frankfurt a.M.: Vittorio Klostermann, 2013, pp. 173 y ss.; sobre el origen y la historia de la teoría de los deberes penales SÁNCHEZVERA, Javier, Pflichtdelikt und Beteiligung, Berlin: Duncker \& Humblot, 1999, pp. 67 y ss. Sobre los deberes de actuar en el Common Law véase ASHWORTH, Andrew, Positive Obligations in Criminal Law, Portland: Bloomsbury, 2015, pp.38 y ss.; él mismo, "Die Rettungspflicht im englischen Recht: Sinnvolle Einschränkungen oder 'island" mentality?", en von HIRSCH; NEUMANN; SEELMANN (eds.), Solidarität im Strafrecht, cit. nota n ${ }^{\circ}$ 2, pp. 115-130 (esp. pp. 119 y ss.) y FLETCHER, George P., Rethinking Criminal Law, New York: OUP, 2000 (reprint), pp. 611-625.

${ }^{11}$ Lo señalado entre paréntesis no debe ser entendido como norma de conducta, sino como atribución de personalidad a aquel a quien se atribuye la capacidad de obrar racionalmente: sobre ello, JAKOBS, Günther, "Person und Subjekt in Hegels 'Grundlinien"”, Rechtsphilosophie - Zeitschrift für Grundlagen des Rechts, 22017, pp. 349-352 (p. 349).

12 De otra opinión ROBLES PLANAS, Ricardo, "Deberes negativos y positivos en derecho penal", en InDret $4 / 2013$, p. 5, para quien el deber positivo tendría por objeto la contribución "al bienestar de los demás". De esta manera, Robles funde los deberes institucionales y los deberes de solidaridad en una sola categoría. 
abandona al peligro mortal a su hijo menor de edad, sin justificación. Recién a continuación de estos deberes negativos y positivos encontraría su lugar la solidaridad.

Este sistema es el resultado del esfuerzo por definir una estructura de razones de obligación que maximice la autonomía personal. Pero también es el resultado de una observación de la sociedad tal como ha llegado a ser. Es en este esfuerzo de observación y reconstrucción conceptual donde se identifican y diferencian los diversos fundamentos jurídicos o grados de la incumbencia personal por un suceso: organización (reconocimiento elemental de la personalidad o capacidad jurídica del otro - “dejar al otro ser”, dirá Hegel), institución (los deberes se tienen por la posición que se ocupa en la sociedad; sin estas instituciones se modificaría sustancialmente la identidad social) y solidaridad.

\section{2. ¿Lesión de la solidaridad sin responsabilidad por el "delito de resultado"?}

La segunda de las cuestiones fundamentales planteadas al comienzo, a saber, si la infracción de deberes de solidaridad y de deberes positivos o negativos funda una responsabilidad equivalente, suele traducirse en la pregunta, algo más simple, acerca de si quien infringe un deber de solidaridad responde por el resultado que se siga de la conducta antijurídica (el que omite prestar socorro responde como homicida, si el no socorrido muere) o, por el contrario, solo por la infracción del deber de solidaridad. Esta última alternativa implica atribuir a la solidaridad el carácter de bien jurídico ${ }^{13}$, mientras que la primera supone que las formas típicas de infracción a un deber de solidaridad protegen indirectamente la vida, la salud u otros intereses del necesitado. Esta última opinión es mayoritaria ${ }^{14}$, pero no parece sostenible de lege lata, pues la falta de omisión de socorro no hace diferencia alguna en función de los resultados que se produzcan (tampoco la hacen por lo general las reglas análogas en el derecho comparado). Por otra parte, la responsabilidad por las consecuencias de la infracción del deber de tolerancia que impone ${ }^{15}$ el estado de necesidad agresivo es justamente uno de los aspectos que se trata de clarificar, de modo que cualquier referencia a ellas en este nivel sería una petición de principio.

En cualquier caso, es evidente que la responsabilidad por un determinado resultado es relativamente independiente de la clase de deber que subyace al tipo penal. El ordenamiento conoce innumerables figuras de mera actividad y de peligro en las que, como es obvio, no se responde por una lesión, y donde la ley considera indistintamente deberes

\footnotetext{
${ }^{13}$ NEUMANN, Ulfrid, "Die Strafbarkeit der Suizidbeteiligung als Problem der Eigenverantwortlichkeit des 'Opfers'”, Juristische Arbeitsblätter, 1987, pp. 244-256 (p. 255).

${ }^{14}$ MAIHOLD, Harald, "Jenseits weltanschaulicher Ideologien? - Zur Einführung und Begründung der allgemeinen Nothilfepflicht im Schweizerischen Strafrecht", en von HIRSCH; NEUMANN; SEELMANN (eds.), Solidarität im Strafrecht, cit. nota ${ }^{\circ}{ }^{2}$, p. 142, nota 51.

15 Aunque sea solo en forma refleja, al desactivar la norma prohibitiva que debía respetar el agente en necesidad; sobre el estatus de los deberes de tolerancia véase MAÑALICH, Juan Pablo, "Normas permisivas y deberes de tolerancia" en Revista Chilena de Derecho, Vol.41, № 2 (2014), pp. 473-522, con ulteriores referencias.
} 
VAN WEEZEL, Alex. "Optimización de la autonomía y deberes penales de solidaridad".

positivos y negativos como fuente de competencia. Además, por lo general la posición de garante es externa a la descripción típica, de modo que una misma descripción puede ser realizada desde posiciones de garante diversas ${ }^{16}$. La explicación de la ausencia de responsabilidad por el resultado debe encontrarse en una consideración distinta.

La cuestión principal no es, por lo tanto, si existe o no responsabilidad por el resultado, sino que dice relación, en términos muy amplios, con la jerarquía o peso relativo del respectivo deber. Si esto es correcto, entonces cuando se discute si la conducta antijurídica da lugar o no a responsabilidad por el resultado, se está aludiendo, en realidad, a la necesidad de realizar un cierto balance entre el peso de la posición de garante y la extensión de las consecuencias de su infracción. Pareciera que en los casos de infracción a deberes de solidaridad la ley impone un deber que en principio no debería recaer sobre la persona en cuestión, pero lo compensa excluyendo la responsabilidad por el resultado, tal como a todas luces ocurre en la omisión de socorro.

\subsection{La hipertrofia de los deberes de solidaridad en la discusión actual}

Una última precisión resulta indispensable para cualquier discusión fructífera en torno al estatus de los deberes de solidaridad en derecho penal: estos deberes solo hacen aparición de modo excepcional en el derecho vigente. La constatación de esta realidad se ha visto algo oscurecida en época reciente por la atribución de un fundamento solidario a numerosas instituciones, desde la obligación de realizar el servicio militar o su equivalente hasta la clásica omisión de socorro ${ }^{17}$. Por eso vale la pena revisar de entrada, aunque sea muy brevemente, las principales manifestaciones de hipertrofia de los deberes de solidaridad. A continuación se explicará por qué la omisión de socorro tampoco es un el punto de partida óptimo para la discusión que aquí interesa.

\subsubsection{La omisión de auxilio en caso de accidente de tránsito.}

La Ley 18.290 o Ley de Tránsito (LT) ${ }^{18}$ establece en su artículo 176 que en todo accidente del tránsito en que se produzcan lesiones o muerte, el conductor que participe en los hechos estará obligado, entre otras cosas, a prestar la ayuda que fuese posible. Conforme al artículo 195 de la misma ley, el incumplimiento de esta obligación se sanciona, entre otras, con la pena de presidio menor en su grado medio. Esta pena se eleva a presidio menor en su grado

\footnotetext{
${ }^{16}$ Al respecto, van WEEZEL, Alex, "Actuar en lugar de otro", en MAÑALICH, J. P. (coord.), La ciencia penal en la Universidad de Chile. Libro Homenaje a los Profesores del Departamento de Ciencias Penales de la Facultad de Derecho de la Universidad de Chile, Santiago: Facultad de Derecho Universidad de Chile, 2013, pp. 283-310.

${ }^{17}$ Una manifestación de ello es el reciente trabajo de NAVAS, Iván, Deberes negativos y positivos en derecho penal. Sobre los deberes de solidaridad y cooperación en un Estado liberal, Valencia: Tirant lo Blanch, 2018, pp. 65 y ss., quien reconduce a la infracción de deberes de solidaridad, por ejemplo, la omisión de denuncia del funcionario y hasta el hurto de hallazgo.

${ }^{18}$ La Ley de Tránsito está contenida actualmente en el Decreto con Fuerza de Ley $\mathrm{N}^{\circ}$ 1, promulgado el 27 de diciembre de 2007.
} 
máximo si "las lesiones producidas fuesen de las señaladas en el número $1^{\circ}$ del artículo 397 del Código Penal o se produjese la muerte de alguna persona”.

Alguna jurisprudencia, incluyendo una sentencia relativamente reciente de la Corte Suprema, parece entender que el delito consiste en la infracción de un deber de solidaridad que se activa por el solo hecho de haber tenido el conductor participación causal en los sucesos del accidente. Según las constataciones de hecho que contiene el fallo, el acusado conducía observando las reglas del tránsito - no hay afirmaciones en contrario- hasta que "el día y a la hora del accidente, (...) vio a una persona que se lanzó al vehículo por el lado del acompañante a la que golpeó con el espejo. Miró por el retrovisor, lo vio de pie y siguió su marcha hacia su casa" ${ }^{19}$. Esta última conducta realizó, a juicio de la Corte, el tipo del delito previsto en el artículo 196 LT en la faceta de omisión de auxilio y en su forma más grave, pues el peatón falleció en el lugar.

Esta interpretación del delito de omisión de auxilio no parece aceptable ${ }^{20}$. Aparte de que no explica por qué este deber penal de solidaridad pesaría solo sobre el conductor y no también, por ejemplo, sobre el pasajero o sobre cualquier otra persona que esté en condiciones de prestar ayuda, la tesis del fallo es abiertamente incompatible con dos elementos centrales de la configuración legal del delito. En primer lugar, no explica en qué casos, entonces, habría de tener aplicación la contravención del artículo $201 \mathrm{~N}^{\circ} 15 \mathrm{LT}$, que establece entre las infracciones o contravenciones menos graves del tránsito la de no cumplir las obligaciones que impone el artículo $176 \mathrm{LT}$. Si, conforme al criterio de la suprema Corte, cada vez que un conductor no realiza lo que se manda en el precepto citado, con total independencia de cualquier otra consideración, comete el delito del artículo 195 LT, entonces simplemente no hay espacio para la aplicación de la figura contravencional. La interpretación de la Corte Suprema vacía por completo de contenido a esta figura.

En segundo término, esta interpretación resulta difícilmente compatible con la magnitud de las penas que establece el artículo $195 \mathrm{LT}$, especialmente para los casos en que una persona resulta muerta o lesionada gravemente. Las penas copulativas de presidio menor en su grado máximo, inhabilidad perpetua para conducir vehículos de tracción mecánica, multa de once a veinte unidades tributarias mensuales y comiso del vehículo con que se ha cometido el delito exceden con creces las consecuencias penales asociadas a la infracción de deberes de solidaridad, cuyo ejemplo paradigmático es la falta de omisión de socorro, sancionada con multa de una a cuatro UTM en el artículo 494 del Código Penal ${ }^{21}$, cuando la víctima se encuentra en despoblado herida, maltratada o incluso en peligro de perecer. Lo único que puede explicar semejante diferencia de tratamiento en uno y otro caso es el hecho

\footnotetext{
${ }^{19}$ SCS 20.IX.2017, Rol N ${ }^{\circ} 35.715-17$, considerando $7^{\circ}$.

${ }^{20}$ Más en detalle van WEEZEL, Alex, "Injerencia y solidaridad en el delito de omisión de auxilio en caso de accidente", cit. nota $n^{\circ} 7$.

${ }^{21}$ Las citas de artículos sin otras especificación corresponden al Código Penal chileno, en adelante, "CP".
} 
VAN WEEZEL, Alex. "Optimización de la autonomía y deberes penales de solidaridad”.

de que en la omisión de auxilio de la LT el que omite es el conductor de un vehículo, es decir, quien estaba creando el riesgo especial inherente a esa actividad.

En realidad, el tipo penal protege la vida y la salud o integridad corporal de quien ha sacado la peor parte en un accidente de tránsito. Por eso debe existir, tal como exige el tipo penal al circunscribir a los conductores el círculo de posibles autores del delito, una relación entre la conducción y los resultados de muerte o lesiones que condicionan el surgimiento del deber penal de auxilio. Esta es una relación de imputación objetiva, que existe también cuando el conductor se mantiene dentro del riesgo permitido, pues atendida su regulación la conducción de vehículos constituye lo que se denomina un riesgo especial. La injerencia basada en la creación de un riesgo especial permitido no genera responsabilidad por las lesiones o la muerte que resulten de la conducción conforme a derecho, pero determina una competencia preferente del conductor por la neutralización de las consecuencias ulteriores evitables de la conducta permitida. La responsabilidad que surge de la infracción de este deber de neutralización adquiere la forma, en el artículo 195 LT, de un deber de auxiliar a quienes resulten lesionados, cuya infracción dolosa anticipa la punibilidad -al modo de una figura de peligro- en relación con la efectiva concreción de un riesgo consecuencial de la conducción.

Por lo tanto, el delito de omisión de auxilio -uno de los delitos de omisión propia más relevantes del ordenamiento chileno- nada tiene que ver con un la infracción de un deber general de solidaridad ${ }^{22}$.

\subsubsection{La omisión de dar cuenta a la autoridad en caso de accidente de tránsito.}

Los mismos artículos de la LT citados en el apartado anterior establecen la obligación del conductor que haya participado en el accidente de dar cuenta a la autoridad, y amenazan la infracción de esta obligación con las mismas penas que la omisión de auxilio.

Tampoco en este caso se trata de una obligación basada en deberes de solidaridad sino, como demuestra Rojas, en el interés del Estado en recibir información de cierta calidad sobre las circunstancias del accidente con miras a su procesamiento por la administración de justicia. Por lo mismo, existe una relación complementaria entre el deber de dar cuenta a la autoridad y el deber de detener la marcha. El deber de detener la marcha tiene por objeto contrarrestar la tendencia del tráfico a recuperar su dinámica. En palabras de Rojas: "Como el accidente implica ya de facto una interrupción del tráfico, el cumplimiento de dicho deber [de detención] adquiere el sentido de mantener estático el tráfico hasta que la autoridad policial recabe por sí misma la información necesaria"23.

\footnotetext{
${ }^{22}$ Cfr. van WEEZEL, Alex, "Injerencia y solidaridad en el delito de omisión de auxilio en caso de accidente", cit. nota $\mathrm{n}^{\circ} 7$.

${ }^{23}$ ROJAS, Luis, "Fundamento y estructura del delito contemplado en el art. 195 de la Ley de Tránsito", p. 16 (cit. pro manuscripto).
} 
Polít. crim. Vol. 13, Nº 26 (Diciembre 2018) Art. 12, pp. 1074-1139.

[http://www.politicacriminal.cl/Vol_13/n_26/Vol13N26A12.pdf]

Todo ello contrasta, por ejemplo, con los deberes de denunciar ciertos delitos graves antes de que se cometan, cuando el sujeto -que no es funcionario público- ha adquirido conocimiento de su futura perpetración por medios dignos de verosimilitud. Los delitos de omisión de denuncia de esta especie, como los que están previstos en los $\S \S 138$ y 139 $\mathrm{StGB}$, tienen efectivamente su fundamento, cuando menos en parte, en la infracción de deberes de solidaridad ${ }^{24}$. Sin embargo, nuestro ordenamiento jurídico no contempla esta clase de figuras.

\subsubsection{Abandono de niños y personas desvalidas.}

Los artículos 346 a $351 \mathrm{CP}$ regulan el delito de abandono de niños, mientras que el artículo 352 tipifica el delito tradicionalmente conocido como "abandono de personas desvalidas". La regulación es minuciosa: la ley distingue si el niño es menor de diez o menor de siete años; en este último caso, si el abandonante reside a más o a menos de cinco kilómetros del pueblo; si como consecuencia del abandono se produce su muerte o lesiones graves y, desde luego, si el abandono es realizado por los padres o por quien tiene formalmente el niño a su cuidado.

Pues bien, las infracciones de deber que se encuentran definidas en estos preceptos nada tienen que ver con la infracción de deberes de solidaridad. Pues para que una persona que no se encuentra institucionalmente vinculada al niño -padres, guardadores o quien tenga el cuidado personal- cometa el delito es indispensable que haya asumido previamente su custodia $^{25}$. El ejercicio eficaz de la custodia da lugar a una posición de garante organizacional, basada en un deber negativo, que se conoce usualmente como asunción. Esta posición de garante desplaza cualquier consideración de solidaridad.

Por su parte, el abandono de personas desvalidas - es decir, "enfermas" o "imposibilitadas" en el lenguaje de la ley-, solo puede ser cometido por el cónyuge o por un ascendiente o descendiente que previamente haya asumido el cuidado de la víctima, sea al modo de la asunción como posición de garante organizacional, sea al modo de la confianza especial en el ámbito de las posiciones de garante institucionales. En este último caso, el autor debe haber creado con su propia conducta precedente la justificada confianza de que iba a hacerse cargo de la víctima en situación de necesidad. La confianza especial exige una competencia practicada previamente, expresada en la adopción de medidas para subvenir a la necesidad para el caso de que sobrevenga. Esta competencia practicada da lugar a un deber institucional basado en el principio de non venire contra factum proprium.

\subsection{4. ¿Complicidad por infracción de un deber de solidaridad?}

\footnotetext{
${ }^{24}$ Véase al respecto también ROJAS, Luis, "Grundprobleme der allgemeinen Verbrechenslehre bei der unterlassenen Verbrechensanzeige - $\S \S 138,139$ StGB”, en GA 2017, pp. 147-161.

${ }^{25}$ Cfr. de modo ejemplar ETCHEBERRY, Alfredo, Derecho Penal, IV, Santiago: Ed. Jurídica de Chile, $3^{\text {a }}$ ed., 1997, p. 13; GARRIDO, Mario, Derecho Penal, III, Santiago: Ed. Jurídica de Chile $4^{a}$ ed., 2009, p. 235.
} 
VAN WEEZEL, Alex. "Optimización de la autonomía y deberes penales de solidaridad”.

El problema de las denominadas "conductas neutrales" probaría según Frisch que la infracción de un deber de solidaridad también puede convertir a alguien en cómplice de otro que, por su parte, infringe un deber negativo o institucional. Concretamente, a su juicio puede haber responsabilidad por el delito de resultado cuando el sujeto realiza una conducta que carece de sentido delictivo - no hay comunicación con el autor, el aporte es revocable-, pero es contraria a una restricción que imponen a la libertad del sujeto los principios del estado de necesidad ${ }^{26}$.

En el clásico ejemplo de los conspiradores de Roxin ${ }^{27}$, imaginemos a los conspiradores acechando la casa del político al atardecer. Según este punto de vista, por muy revocable que sea la conducta de abrir la puerta del jardín o de no cerrarla, si el vecino se va a dormir sin haber cerrado la puerta, aplicando los principios del estado de necesidad habrá vulnerado su deber. $\mathrm{Y}$ en tal caso, si los conspiradores matan al político -supuesta la imputación subjetiva-, el vecino sería cómplice.

Sin embargo, esta argumentación no es de recibo. No existen tales "principios del estado de necesidad" más allá del "arreglo institucional" 28 en virtud del cual se resuelve exigir a cada ciudadano que asuma pequeños sacrificios de su libertad de comportamiento en orden a la salvaguarda de ciertos bienes jurídicos. Por lo tanto, si no se definen previamente los términos de tal arreglo, el argumento es una petición de principio; y si los términos ya se encuentran definidos, el argumento es tautológico.

El principal problema, no obstante, radica en que la accesoriedad de la intervención delictiva, en cualquiera de sus formas, consiste en la imputación de una responsabilidad mancomunada, que es incompatible con diferencias sustanciales entre los intervinientes a nivel del fundamento de su competencia por el hecho total. Por la misma razón que no puede haber intervención delictiva entre quien es garante por organización y quien lo es en virtud de una posición institucional -el particular que paga un soborno no es inductor o coautor del funcionario en un delito de cohecho-, tampoco puede haberla entre quien infringe un deber negativo o positivo y quien, por su parte, transgrede un deber de solidaridad. Por lo tanto, si el vecino del político ha de ser cómplice en el homicidio cometido por los conspiradores, el fundamento de su responsabilidad solo puede ser organizacional; es decir, si su contribución cuenta como colaboración a la ejecución del hecho por actos anteriores o simultáneos.

\subsubsection{Interacciones con personas inimputables.}

${ }^{26}$ FRISCH, Wolfgang, Tatbestandsmäßiges Verhalten und Zurechnung des Erfolgs, Heidelberg: C. F. Müller, 2012 (reimpresión de la edición de 1988), pp. 256 y ss.; él mismo, "Beihilfe durch neutrale Handlungen. Bemerkungen zum Strafgrund (der Unrechtskonstitution) der Beihilfe", en PRITTWITZ, Cornelius et al. (eds.), Festschrift für Klaus Lüderssen, Baden-Baden: Nomos, 2002, pp. 539 y ss.

${ }^{27}$ ROXIN, Claus, Täterschaft und Tatherrschaft, Berlin: De Gruyter, $9^{\mathrm{a}}$ ed. 2015, p. 485.

${ }^{28}$ En tal sentido PAWLIK, Das Unrecht, cit. nota n ${ }^{\circ} 10$, pp. 249 y ss. 
Un deber de solidaridad podría invocarse también como fundamento para prohibir las conductas de interacción colaborativa con niños o con personas que sufren de una severa discapacidad psicosocial, cuando la conducta de estas personas califica como autolesión. Todos seríamos garantes de no colaborar en la autolesión de un niño o de un enfermo mental $^{29}$. Salvo que concurra alguna posición de garante institucional, alguna forma de asunción o se esté ante una excepcional hipótesis de deber negativo de impedir autolesiones, el fundamento de aquella prohibición sería un deber de solidaridad.

En realidad, su fundamento es la injerencia. Pues ni el niño ni quien padece una enfermedad mental severa actúan para el derecho penal, de modo que la interacción con estas personas cuenta, a efectos penales, como una interacción con la naturaleza. No se está en presencia de una autolesión, sino de una lesión mediada por un acontecimiento natural, como ocurre por lo demás con casi todas las lesiones penalmente relevantes. La cointervención humana en el suceso no es más que una apariencia, desde el punto de vista de las reglas y criterios de imputación. Por eso, el que con su conducta responsable ocasiona la lesión es garante por injerencia.

\subsection{6. ¿Límites a la legítima defensa basados en deberes de solidaridad?}

La legítima defensa se caracteriza por que el afectado por la reacción defensiva -la conducta típica- es personalmente competente por la situación que da lugar a dicha reacción. Su responsabilidad por las consecuencias es la contrapartida de su libertad para configurar la situación de conflicto. Por eso la afectación del agresor se reconduce a su propia competencia por la situación. Desde el punto de vista jurídico, el agresor injusto se lesiona a sí mismo a través de la reacción defensiva - o bien: quien se defiende administra un asunto del agresor. Por lo tanto, en principio son de cargo del afectado todos los costos que implique la defensa ${ }^{30}$. Esta distribución de competencias $-o$, si se prefiere, de autonomía- recibe una ulterior concreción principalmente a través de dos elementos. En primer lugar, la renuncia a la autotutela hace que se trate de una situación excepcional y extrema. Por otro lado, en los ordenamientos modernos la institución de la legítima defensa no solo debe adecuarse a la personalidad del agresor, sino que también debe atender en cierto modo a su bienestar; esto ocurriría a través del límite, generalmente aceptado, de la solidaridad mínima.

\footnotetext{
${ }^{29}$ JAKOBS, Günther, "Strafrecht und Sitte. Zur Pönalisierung exzessiven Freiheitsgebrauchs", en FREUND, Georg; MURMANN, Uwe (eds.), Siebzig Jahre Frisch, Tübingen: Mohr Siebeck, 2014, p. 14.

${ }^{30}$ Sobre este punto de vista, más recientemente, PAWLIK, Das Unrecht, cit. nota ${ }^{\circ} 10$, pp. 237 y ss.; WILENMANN, Javier, La justificación de un delito en situaciones de necesidad, Madrid, Marcial Pons, 2017, pp. 129 y ss.
} 
VAN WEEZEL, Alex. “Optimización de la autonomía y deberes penales de solidaridad”.

En efecto, en otro lugar ${ }^{31}$ he esbozado la posibilidad de que la legítima defensa tenga o haya ido adquiriendo en nuestro sistema una configuración marcadamente solidaria, en particular debido a la interpretación doctrinal y jurisprudencial de la necesidad racional del medio de defensa como un deber de utilizar el medio menos lesivo. Sugería entonces que esta interpretación alcanza bastante más lejos que las tradicionales limitaciones de proporcionalidad y de subsidiariedad de la legítima defensa -en casos excepcionales, como ante los ataques de inimputables-, pues puede llegar a negar la justificación, por ejemplo, al que disponiendo de un cuchillo se defiende con una pistola. Agregaba que el fundamento de semejante restricción a la defensa legítima no puede ser la autorresponsabilidad del que se defiende, sino que debe buscarse en alguna otra institución y que había buenas razones para pensar que esta consiste en una forma particularmente intensa de lo que en ocasiones se denomina "solidaridad".

Sin embargo, la teoría y la praxis de la legítima defensa en Chile se explican de un modo más coherente desde una tradición que enfatiza el carácter excepcionalísimo de la autorización y que, desde esta perspectiva, concibe la proporcionalidad de la reacción defensiva como una exigencia de moderación. En efecto, la idea de solidaridad mínima es la que menos restringe el derecho de defensa, pues un deber de mínima solidaridad solo puede imponer sacrificios menores para la salvaguarda de bienes muy relevantes. Por lo tanto, el defensor estaría justificado siempre, salvo que el uso de un medio menos lesivo fuera inocuo para sus derechos $\mathrm{y}$, como contrapartida, permitiera salvar bienes muy relevantes del agresor. Esta perspectiva podría llegar a aceptar la huida como alternativa, pero siempre que ella no implique una pérdida o postergación de derechos para el $\operatorname{agredido}^{32}$.

Por su parte, la proporcionalidad como fundamento del deber de moderación de la defensa no dice relación con el tipo o la clase de los medios de ataque -como la entiende Cousiño, quien por lo mismo critica la idea de proporcionalidad como comparación de medios ${ }^{33}$-, sino con la excepcionalidad de la autorización que el derecho confiere a los ciudadanos para defenderse por sí mismos haciendo uso de la fuerza. El carácter excepcional y limitado de esta autorización obliga a aplicar estrictos criterios de proporcionalidad en su uso ${ }^{34}$.

Desde este punto de vista, es la situación en su conjunto la que debe considerarse para estimar si el medio empleado fue racionalmente necesario, por lo que cobran relevancia, por ejemplo, la presencia de otras personas, el lugar del hecho, las posibilidades de auxilio

\footnotetext{
${ }^{31}$ van WEEZEL, Alex, "Necesidad justificante y solidaridad", en CÁRDENAS, Claudia; FERDMAN, Jorge (coords.), El derecho penal como teoría y como práctica. Libro en homenaje a Alfredo Etcheberry Orthusteguy, Santiago: Legal Publishing, 2016, pp. 213-230.

32 Próximo a este punto de vista BALDÓ LAVILLA, Francisco, Estado de necesidad y legítima defensa, Barcelona: J.M. Bosch Editor, 1994, pp. 313 y s.

${ }^{33}$ COUSIÑO, Luis, Derecho Penal Chileno, II, Santiago: Ed. Jurídica de Chile, 1979, p. 270.

${ }^{34}$ Menciona aunque no desarrolla en absoluto esta idea SEELMANN, Kurt, en "Ideengeschichte des Soliaritätsbegriffs im Strafrecht", en von HIRSCH; NEUMANN; SEELMANN (eds.), Solidarität im Strafrecht, cit. nota ${ }^{\circ} 2$, pp. 35 y ss. (p. 37).
} 
por parte de terceros, las relaciones entre agredido y agresor, la circunstancia de si el agresor está armado o no lo está, etc. No se trata de reaccionar con cierto medio de defensa ante ciertos medios de ataque, sino de responder la siguiente pregunta: atendido el carácter excepcional de esta autorización para la autotutela y las circunstancias del caso, ¿puede entenderse todavía justificado el uso este concreto medio de defensa? Esta aproximación es mucho más flexible que cualquiera otra, pues puede obligar al uso de los medios menos lesivos incluso a costa de ciertos derechos del que se defiende. En el extremo, puede llevar a aceptar un deber de tolerar ciertos ataques o, en la más polémica de sus consecuencias, a considerar la huida como camino obligatorio para ciertas situaciones.

Así razonan la doctrina y la jurisprudencia ampliamente mayoritarias en Chile ${ }^{35}$. La exigencia de que se utilice el medio menos lesivo no responde, desde esta perspectiva, a un deber de solidaridad mínima, sino a consideraciones de proporcionalidad.

\subsection{7. ¿La usura como delito contra la solidaridad?}

El artículo 472 CP castiga como autor del delito de usura al que "suministre valores, de cualquiera manera que sea, a un interés que exceda del máximo que la ley permita estipular". A pesar de su antigüedad, o tal vez precisamente debido a ella, la figura no resulta fácil de fundamentar en las coordenadas del derecho penal moderno. Entre otras consideraciones, se sostiene que se trata de un delito sin víctima, pues quien recibió el préstamo carecía de otras alternativas de financiamiento - de lo contrario, habría recurrido a ellas-, de modo que la conducta del usurero vino a ampliar y no a restringir su libertad. Por lo tanto, el prestamista expande las posibilidades de organización de la víctima en lugar de arrogarse un ámbito de organización ajeno. Por otro lado, incluso bajo la lógica de la acumulación resulta difícil fundar la prohibición en la estabilidad del sistema financiero o en la protección de sus instituciones, entre otras razones, porque la ley no prohíbe prestar dinero a interés. De esta forma, no solo se excluye una competencia basada en deberes negativos, sino también una específica competencia institucional.

Estas dificultades han llevado a algunos autores a proponer un fundamento solidario para el delito, especialmente en aquellos casos, que serán los más frecuentes, en que el usurero

\footnotetext{
35 Véanse por ejemplo, SCS 9.IV.2001, Rol 4336-2000: "La racionalidad requiere la necesidad del medio empleado, en el sentido de que el sujeto no disponga de otra forma menos enérgica para defenderse con éxito"; SCS 16.I.2006, Rol 2594-2003: "La racionalidad del medio empleado deriva de su razonabilidad, así como del hecho que el imputado intentó utilizar otros medios para repeler la agresión ilegítima". En todo caso, es preciso valorar la defensa teniendo en cuenta la totalidad de la reacción; SCS 3.V.2007, Rol 64662005 ("la racionalidad no debe entenderse como equivalencia matemática, sino como razonabilidad del medio empleado en virtud de las circunstancias del caso concreto"). Cfr. COUSO, Jaime; HERNÁNDEZ, Héctor, Código Penal Comentado. Parte General, Santiago: LegalPublishing, 2011, p. 217; ETCHEBERRY, Derecho Penal, I, cit. nota ${ }^{\circ}$ 25, p. 256; CURY, Enrique, Derecho Penal: Santiago, Editorial Jurídica de Chile, $7^{a}$ ed. 2005 , pp. 375 y ss.; GARRIDO, Derecho Penal, I, cit. nota $n^{\circ} 25$, p. 133; y desde luego COUSIÑO, Derecho Penal Chileno, II, cit. nota n ${ }^{\circ} 33$, p. 270.
} 
VAN WEEZEL, Alex. "Optimización de la autonomía y deberes penales de solidaridad”.

aprovecha una situación de necesidad en que se encuentra la víctima. Aunque el autor no tenga responsabilidad alguna por la situación, le estaría prohibido explotar esta necesidad de un conciudadano, prohibición que se materializa en el deber de negar el préstamo o ajustarse a las tasas de interés reguladas. Sin embargo, esta apelación a la humana fraternidad del prestamista parece girar sobre sí misma. Y sobre todo: ¿Existe en este ámbito algún deber de solidaridad respecto de la persona que rechaza sus manifestaciones $\mathrm{y}$, por el contrario, las considera expresión de un paternalismo inaceptable?

En realidad, la usura en situaciones de necesidad es un delito que atenta contra las "buenas costumbres", es decir, contra las condiciones de subsistencia del orden jurídico en su actual identidad ${ }^{36}$, tal como la mutilación de miembros importantes aunque sea consentida, y por las mismas razones por las cuales el derecho no confiere validez a la compraventa de órganos. Se trata de atentados contra la aceptabilidad del ordenamiento jurídico. Todo orden necesita mostrarse como preferible a otros posibles, y el orden de libertades no es la excepción. El ejercicio de la libertad en una forma socialmente disfuncional es considerado como un atentado contra las "buenas costumbres" en el sentido de "condiciones de la subsistencia del derecho" ${ }^{37}$.

Por lo tanto, el delito nada tiene que ver con la salvaguarda de los intereses de quien consiente en el préstamo usurero y, por lo mismo, con una infracción de deberes de solidaridad.

\subsubsection{Deberes institucionales}

También deben descartarse como punto de partida de estas reflexiones los deberes institucionales específicos, tanto los que conciernen a quienes ocupan una determinada posición en la estructura social (funcionarios de la administración, padres y madres de hijos menores, jueces, etc.), como quienes son llamados circunstancialmente a desempeñar una función indispensable para las instituciones que configuran la identidad de la sociedad: el ciudadano convocado a declarar como testigo, el conscripto, el que en caso de catástrofe o emergencia es requerido por la autoridad para prestar colaboración, etc.

Aunque todos estos casos podrían agruparse bajo un concepto muy amplio de solidaridad en el sentido de vinculación del individuo con la generalidad-, los deberes que emanan de cada una de estas posiciones no dicen relación, salvo contingencias, con el fundamento común a los mandatos y prohibiciones penales en orden al favorecimiento de alguien cuyos intereses corren peligro, sin que el obligado se haya vinculado en forma previa y autónoma con tales intereses o con su titular; es decir, con los deberes de solidaridad en el sentido jurídico-penal que aquí interesa.

\footnotetext{
${ }^{36}$ Cfr. JAKOBS, “Strafrecht und Sitte”, cit. nota n 29, p. 15.

${ }^{37}$ JAKOBS, Günther, Nötigung, Paderborn: Ferdinand Schöningh, 2015, pp. 28 y ss.
} 
Aunque pueda resultar paradojal, tampoco la omisión de socorro -incluyendo la prevista en la Ley de Navegación ${ }^{38}$ - es un punto de partida óptimo para la discusión. Esto se debe, en primer lugar, a que la ley no hace responsable al omitente por el potencial delito de resultado, sino que le impone una sanción muchísimo menor. La aceptación de un deber de solidaridad mínima tan poco exigente no es en absoluto problemática. De allí que, en segundo lugar, exista una amplia variedad de argumentos liberales, contractualistas, personalistas, comunitaristas y utilitaristas que funcionan adecuadamente ${ }^{39}$ cuando se trata de fundar la exigencia de un sacrificio nimio para salvar bienes de gran trascendencia.

Lo anterior no menoscaba en absoluto la importancia sistemática de la omisión de socorro y de los deberes de solidaridad en que se sustenta. Para advertirlo basta considerar que la posición de garante basada en solidaridad amplía sustancialmente el segmento de la realidad que es relevante para la determinación del riesgo permitido. En el conocido caso del ayudante de garzón que es un estudiante avanzado de biología con mención en botánica, ${ }^{40}$ la solución que rechaza una transgresión del riesgo permitido en relación con una posición de garante organizacional (injerencia, deberes de aseguramiento), la afirma en cambio en relación con una posición de garante basada en solidaridad, la cual sí obliga al estudiante a activar sus conocimientos especiales. ${ }^{41}$ Esto es importante, pues de este modo se amplía el ámbito de responsabilidad -el riesgo permitido se define mediante un parámetro más exigente, que incluye más aspectos de la realidad-, pero se compensa liberando al sujeto de la responsabilidad por el resultado, es decir, haciéndolo responsable solo por una omisión de socorro.

Por todas las consideraciones anteriores, el punto de partida más idóneo para una discusión fructífera sobre el rango y alcance de los deberes de solidaridad en derecho penal la consideración de un estado de necesidad defensivo donde el mal solo se encuentra causalmente vinculado con quien resultará afectado por la acción de salvaguarda o, alternativamente, la de un estado de necesidad agresivo con autorización para afectar intereses personalísimos.

\footnotetext{
38 “Art. 102. Toda nave tiene la obligación de acudir en auxilio de otra en peligro, salvo que ello represente un grave riesgo para su propia seguridad, la de su dotación o la de sus pasajeros. Esta obligación cesa en cuanto se haya logrado asegurar la vida de la dotación y de los pasajeros de la nave en peligro. El capitán que no cumpliere con este deber, será sancionado con la cancelación de su título, sin perjuicio de la responsabilidad penal que le afecte, a menos que justifique haber tenido una causa que razonablemente le haya impedido hacerlo. El armador o naviero no será responsable en este caso por el hecho de su capitán" (Decreto Ley 2222 de 31.V.1978).

${ }^{39}$ Una visión panorámica al respecto puede consultarse en von HIRSCH, Andreas; SCHORSCHER, Vivian C., "Die Kriminalisierung der unterlassenen Hilfeleistung: Eine Frage von 'Solidarität' oder Altruismus?", en von HIRSCH; NEUMANN; SEELMANN (eds.), Solidarität im Strafrecht, cit. nota n 2, pp. 77-92.

${ }^{40}$ Últimamente JAKOBS, Zurechnung, cit. nota ${ }^{\circ} 10$, p. 33.

${ }^{41}$ JAKOBS, Günther, "Altes und Neues zum strafrechtlichen Vorstazbegriff", en Rechtswissenschaft, Heft 3, 2010, pp. 291 y ss. (nota 104).
} 
VAN WEEZEL, Alex. "Optimización de la autonomía y deberes penales de solidaridad".

\section{Modelos de optimización de la autonomía con reconocimiento de deberes de solidaridad}

\subsection{Estatalización de la solidaridad}

Michael Pawlik ha ofrecido una propuesta de fundamentación de los tipos penales que consisten en infringir deberes de solidaridad ${ }^{42}$. A su juicio, las obligaciones de solidaridad son el reflejo de un consenso social en orden a ampliar las esferas de libertad de cada uno por la vía de garantizar una asistencia y colaboración mínimas de los otros ciudadanos en casos de genuina necesidad. Tal consenso no se refiere al Estado de Bienestar, sino, en palabras de Feinberg, a las "random and unpredictable emergencies of life" 43 que provocan desigualdades inmerecidas y que, por lo mismo, el Estado y el ordenamiento jurídico estarían llamados a compensar.

Este consenso social adopta una forma análoga a la de un contrato de aseguramiento recíproco, donde cada uno compromete una parte menor de su libertad con miras a la obtención de una cierta cobertura. Este compromiso se concreta principalmente en el pago de los impuestos, de modo que la obligación de auxilio que recae sobre el particular es excepcionalísima. Sin embargo, aunque en principio es el Estado el que debe subvenir directamente a las necesidades de sus miembros, cuando en el momento de la necesidad ello no es posible, el ciudadano más próximo debe "representar" al Estado en esta función, actúa como una estación de paso $^{44}$. La pretensión de ser socorrido en una situación de necesidad no se dirige, pues, al conciudadano en cuanto tal -y por lo tanto no da lugar a un conflicto entre el necesitado y el que puede inmediatamente asistirlo-, sino a la totalidad de los miembros de la comunidad. Esta fundamentación sería válida cum grano salis tanto para el estado de necesidad agresivo como para la omisión de socorro. ${ }^{45}$

El individuo tiene derecho a que el Estado -y no el conciudadano- lo ayude en la necesidad, de modo que el ciudadano individual solo cumple un rol subsidiario (i) cuando el Estado formalmente no puede estar presente, y (ii) en la medida en que se trate de sacrificios indemnizables en su totalidad (cualquier renuncia no indemnizable queda excluida). Consecuentemente, la indemnización (i) debe ser cubierta por el mismo Estado y no por el beneficiario del auxilio; (ii) por lo tanto, el sacrificio ha de mantenerse dentro de lo que el Estado proveería y no puede extenderse a más que eso.

\footnotetext{
${ }^{42}$ Más recientemente en PAWLIK, Das Unrecht, cit. nota n 10, pp. 190 y ss.; él mismo en "Solidarität als strafrechtliche Legitimationskategorie", cit. nota $\mathrm{n}^{\circ}$ 5, pp. 137 y ss. Además están disponibles dos extensas reconstrucciones de la propuesta de Pawlik: WILENMANN, Javier, Freiheitsdistribution, cit. nota $\mathrm{n}^{\circ}$ 5, pp. 122 y ss., y KÜHNBACH, Lena, Solidaritätspflichten Unbeteiligter, Baden-Baden, Nomos: 2007, pp. 73 у ss.; 223 y ss.

${ }^{43}$ FEINBERG, Joel, Freedom and Fulfillment, Princeton, New Jersey: Princeton University Press, 1992, p. 193.

${ }^{44}$ PAWLIK, "Solidarität als strafrechtliche Legitimationskategorie", cit. nota n 5, p. 155.

${ }^{45}$ PAWLIK, Das Unrecht, cit. nota n ${ }^{\circ} 10$, pp. 248 y ss.
} 
Así, por ejemplo, si alguien ha sido mordido por una víbora venenosa pero el Estado no provee el antídoto a los ciudadanos - por ejemplo, porque esa clase de víboras solo aparece muy raramente-, tampoco queda obligado el vecino a proporcionarlo, aunque a causa de un viaje reciente cuente con abundantes reservas del antídoto.

El planteamiento de Pawlik se inserta en un esfuerzo por explicar la institucionalización de la solidaridad. En los tiempos modernos, tal proceso puede observarse en la evolución del así llamado "derecho a la seguridad personal" y en los "derechos sociales". El tránsito hacia la institucionalización de la solidaridad puede fundarse con mayor o menor fortuna desde una perspectiva comunitarista -en Hegel, solo puede tener lugar a nivel de la eticidad- o individualista -sustituyendo al homo socialis por el homo calculans ${ }^{46}$, pero, más allá de su fundamentación, puede afirmarse que la institucionalización de la solidaridad es un hecho que ha terminado por modificar sustancialmente el concepto, pues una solidaridad que el Estado puede imponer o exigir coactivamente es, en realidad, una cuasi-solidaridad ${ }^{47}$. Probablemente en este sentido Hegel afirmaba, ya a comienzos del siglo XIX, que "el individuo se ha convertido en hijo de la sociedad civil"48. Esta expresión no es solo una metáfora, sino que tiene importantes consecuencias: lo que antes era una comunidad de destino con ayuda mutua pasa a ser un conjunto de derechos y deberes exigibles en forma coactiva.

Sin embargo, la institucionalización de la solidaridad se convierte en el planteamiento de Pawlik en una verdadera "estatalización" de la solidaridad, una consecuencia que no resulta necesaria desde el punto de vista de la filosofía del derecho de Hegel. La incorporación de la moralidad en la eticidad no es la supresión de la primera, sino su conservación; en la estructura de las Grundlinien, lo incorporado es, al mismo tiempo, algo conservado ${ }^{49}$, aun más, algo que es llevado, precisamente en su particularidad, a la perfección mediante su integración en lo universal. En Pawlik, sin embargo, la solidaridad parece transplantada desde la intersubjetividad al plano de las relaciones del sujeto con el Estado. En ello podrían residir también las debilidades de este planteamiento:

a) En primer lugar, es evidente que allí donde es necesaria la acción del agente de necesidad el Estado no llega con su cobertura de rescate. Entonces, ¿en qué sentido se puede decir que la intervención del samaritano es subsidiaria del Estado o, más aun, que el deber de tolerancia o de auxilio se tiene frente al Estado? Y si la cobertura estatal en un determinado ámbito es muy deficiente, ¿no tiene el ciudadano mejor preparado que así lo advierte el deber de poner algo de su parte? Allí donde el Estado no ha previsto asistencia,

\footnotetext{
${ }^{46}$ PAWLIK, "Solidarität als strafrechtliche Legitimationskategorie", cit. nota nº 5, p. 148 y s.

${ }^{47}$ BAYERTZ, Kurt, "Begriff und Problem der Solidarität", en él mismo (ed.), Solidarität, Frankfurt a.M.: Suhrkamp, 1998, pp. 11-53 (p. 37).

${ }^{48}$ HEGEL, G.W.F., GL $\S 238$ (cursivas añadidas).

${ }^{49}$ Cfr. RITTER, Joachim, "Moralität und Sittlichkeit. Zu Hegels Auseinandersetzung mit der Kantischen Ethik", en RIEDEL, Manfred (ed.), Materialien zu Hegels Rechtsphilosophie, Frankfurt a.M.: Suhrkamp, 1975, pp. 217-244 (p. 219).
} 
VAN WEEZEL, Alex. "Optimización de la autonomía y deberes penales de solidaridad”.

o donde esta es muy escasa, no existiría el deber de auxilio, aunque el ciudadano más próximo pudiera prestar ayuda sin ninguna dificultad, como en el ejemplo del antídoto ${ }^{50}$.

b) En sentido similar, el planteamiento estatalista parece legitimar la pena simplemente cuando el Estado es ineficiente o, incluso por razones meramente circunstanciales, no está en situación de prestar asistencia. En el primer caso, compensaría la ineficiencia con sanciones penales. En el segundo, otorga preferencia a la víctima de un acaso -la amenazada por el mal- por sobre la víctima de otro, el obligado al sacrificio por la incapacidad circunstancial del Estado para intervenir. Con otras palabras, una versión moderada del argumento clásico de que "no se ha de jugar a ser Dios" puede adquirir fuerza contra este planteamiento, bajo la forma secularizada que expresa el aforismo casum sentit dominus.

c) La propuesta bajo análisis tiene el gran mérito de que, en principio, proporciona un límite consistente a los deberes de solidaridad, especialmente en relación con el modelo tripartito que ha surgido de los esfuerzos por optimizar la autonomía: solo resulta aceptable que se exija el sacrificio transitorio de bienes indemnizables que, de poder hacerlo, el mismo Estado proveería al necesitado.

Sin embargo, las estatalización de la solidaridad podría terminar por sobre exigir al ciudadano. En efecto, cada vez con mayor frecuencia el Estado se considera obligado, bajo ciertas condiciones, a realizar prestaciones de alto costo a favor de ciudadanos que las requieren para apartar de sí un peligro relevante para su vida o su salud. Así, por ejemplo, si el Estado debe financiar un costoso tratamiento para una persona que no puede hacerlo por sí misma, ¿estaría legitimada una grave afectación patrimonial de un tercero con el consuelo normativo de que debe ser indemnizada en el futuro?

d) El ejemplo del antídoto pone de relieve cómo las expectativas sociales asociadas a la solidaridad parecen ser mayores que las que está en condiciones de explicar la tesis estatalista. Pero esta constatación también podría ser válida respecto de una tendencia bastante generalizada a legitimar las acciones de salvaguarda de los bienes jurídicos en términos más amplios que lo aceptado hasta ahora. Así, por ejemplo, se advierte en la evolución del estado de necesidad defensivo, donde -con buenas o malas razones- se tiende a incluir casos en que la vinculación del peligro con la persona que sufre las consecuencias de la acción de salvaguarda es poco más o menos que causal ${ }^{51}$. Otro tanto puede decirse de la tendencia a ampliar el estado de necesidad agresivo a casos de afectación de intereses

\footnotetext{
${ }^{50}$ Cfr. MAIHOLD, Harald, “Jenseits weltanschaulicher Ideologien?”, cit. nota n ${ }^{\circ}$ 14, p. 147.

${ }^{51}$ Sobre esta tendencia véase el agudo análisis de CONINX, Anna, "Restriktives Solidaritätsverständnis und extensive Gefahrenzuständigkeit", en HRUSCHKA; JOERDEN (eds.), Jahrbuch für Recht und Ethik, cit. nota ${ }^{\circ} 3$, pp. 117-136.
} 
distintos de la propiedad, apartándose así de lo que correspondería de acuerdo a la raigambre histórica ${ }^{52}$ y filosófica ${ }^{53}$ de la institución.

e) Pero posiblemente el principal flanco abierto de esta propuesta sea de índole filosófica. La estructura de la teoría del derecho y el Estado de Hegel, de la cual es tributario el planteamiento estatalista, consta de tres grandes planos de realización del concepto del derecho, que Hegel denomina respectivamente "derecho abstracto", "moralidad" y "eticidad". Entre estos diversos planos existe una relación dialéctica, de modo que el plano siguiente incorpora al anterior pero al mismo tiempo lo eleva a un nivel superior de realización del concepto. Más allá de las particularidades de esta concepción, lo que aquí interesa destacar es que la síntesis que constituye la eticidad ${ }^{54}$, y que a su vez contiene en sí a la familia, la sociedad civil y el Estado, necesariamente incorpora la moralidad, que contiene la subjetividad individual realizada en la acción. De este modo, Hegel mantiene la distinción entre legalidad y moralidad ${ }^{55}$, pero evita separar ambas categorías, con lo que se aparta tanto de la noción griega de ethos -que se realiza en la forma de vida de la polis, con independencia de la reflexión subjetiva-, como de la separación entre lo moral y lo legal que había proclamado Kant pocos años antes.

Lo interesante es que Hegel ubica el problema del estado de necesidad -se refiere explícitamente solo al conflicto entre vida y propiedad (GL § 127)- en el plano de la moralidad y afirma que quien se encuentra en él tiene derecho a realizar la acción de salvaguarda, afectando bienes ajenos. La razón es muy simple: la privación de la vida del necesitado afecta al derecho en cuanto tal, mientras que la afectación de la propiedad perturba solo una forma limitada de existencia de la libertad. No se trata, pues, de una ponderación de bienes o males, sino de que la vida -como dimensión real de la personalidad- tiene un derecho verdadero y preferente frente al derecho formal.

Conforme al planteamiento estatalista de los deberes de solidaridad, lo sistemáticamente correcto habría sido situar el problema del estado de necesidad en el plano de la eticidad. En efecto, es recién en este plano donde se resuelve el conflicto entre las dos pretensiones el derecho formal del propietario y la salvaguarda de la vida- en el marco del ordenamiento jurídico estatal. Esta solución consiste en que corresponde al Estado subvenir a la necesidad de los ciudadanos, esta sería una de sus principales razones de ser, mientras que a estos solo puede tocarles una función subsidiaria o de representación de la generalidad en esta función

\footnotetext{
${ }^{52}$ Un esfuerzo de compatibilización puede verse en WILENMANN, La justificación de un delito, cit. nota $\mathrm{n}^{\circ} 30$, pp. 622 y ss., quien sugiere extender el permiso de afectación de la propiedad a ciertas hipótesis de robo.

${ }^{53}$ Cfr. RENZIKOWSKI, Joachim, "Solidarität in Notsituationen. Ein historischer Überblick von Thomas v. Aquin bis Hegel“, en von HIRSCH; NEUMANN; SEELMANN (eds.), Solidarität im Strafrecht, cit. nota $\mathrm{n}^{\circ} 2$, pp. 13 y ss.

${ }^{54}$ Sobre ello SCHNÄDELBACH, Herbert, Hegels praktische Philosophie, Frankfurt a.M.: Suhrkamp, 2000, p. 244.

${ }^{55}$ RITTER,"Moralität und Sittlichkeit“, cit. nota n 49, pp. 226 y ss.
} 
VAN WEEZEL, Alex. "Optimización de la autonomía y deberes penales de solidaridad".

auxiliadora. Esta lectura puede tener su principal explicación en que las GL no consideran explícitamente la idea de intersubjetividad, es decir, que en principio Hegel parece trabajar solo con la alternativa entre sujeto y substancia (sobre esto, enseguida). En este entendido, la única forma de superar la mera subjetividad propia de la moralidad y el "atomismo" individualista que subyace a los planteamientos de Kant y Fichte ${ }^{56}$, es convertir al sujeto en accidente de una sustancia de índole colectiva (GL $\& 145 \mathrm{Z})^{57}$. Como consecuencia necesaria, esta lectura de Hegel transforma las relaciones interpersonales en relaciones de la sustancia con esos sujetos o personas ${ }^{58}$. El planteamiento estatalista parece conectar con esta línea de razonamiento, y de este modo sustrae los deberes de solidaridad -como deberes jurídicos, sobre ello no hay duda-del plano de las relaciones intersubjetivas.

El apartado siguiente se dedica principalmente a mostrar que existe una lectura alternativa, conforme a la cual es posible conciliar el carácter jurídico de los deberes de solidaridad con su dimensión intersubjetiva. Pues lo que sí está presente en las GL es la idea de que las instituciones son más que relaciones intersubjetivas. Las instituciones son totalidades de comportamiento intersubjetivo que existen en los sujetos que actúan conforme a ellas, y que, al mismo tiempo, complementan su existencia ${ }^{59}$.

\subsection{Un "derecho al bienestar" individual}

La otra alternativa es entender que Hegel no se equivocó al tratar el estado de necesidad en el plano de la moralidad, y que el individuo no solo posee una autonomía personal y un derecho de la personalidad, sino también un derecho al bienestar, que comprende el mínimo necesario para el despliegue de su libertad, pero también elementos asociados a su realización personal, lo que Hegel llama “objetivos propios de la finitud” (GL § 123).

\subsubsection{Eticidad y moralidad}

El proceso histórico de transformación del Estado liberal o guardián hacia el Estado de bienestar, igual que el debate entre las posiciones neoliberales y progresistas, tanto en la arena política como en el plano de las ideas, ha sido abundantemente descrito en lo que respecta al significado de las exigencias de solidaridad ${ }^{60}$. Aquí interesa destacar solo dos aspectos. En primer lugar, que conviene distinguir los deberes de solidaridad con relevancia

\footnotetext{
${ }^{56}$ Sobre el problema del "atomismo" en las concepciones liberales véase FORST, Rainer, Kontexte der Gerechtigkeit, Frankfurt a.M.: Suhrkamp, 1996, pp. 23 ss.

${ }^{57}$ HÖSLE, Vittorio, Hegels System. Der Idealismus der Subjektivität und das Problem der Intersubjektivität, Hamburg: Verlag Felix Meiner, 1998, pp. 473 y ss.

58 THEUNISSEN, Michael, "Die verdrängte Intersubjektivität in Hegels Philosophie des Rechts", en: HENRICH, D.; HORSTMANN R.-P. (eds.), Hegels Philosophie des Rechts. Die Theorie der Rechts-formen und ihre Logik, Stuttgart: Klett-Cotta, 1982, pp. 317 ss. (327 y ss.).

${ }^{59}$ HÖSLE, Hegels System, cit. nota n ${ }^{\circ}$ 57, p. 475.

${ }^{60}$ Cfr. entre muchos otros BAYERTZ, Kurt, "Staat und Solidarität", en él mismo (ed.), Politik und Ethik, Stuttgart: Reclam,1996, pp. 305-329; KÜBLER, Friedrich (ed.), Verrechtlichung von Wirtschaft, Arbeit uns sozialer Solidarität, Frankfurt a.M.: Suhrkamp, $2^{\mathrm{a}}$ ed., 2016, pp. 7 y ss., RORTY, Richard, Solidarität oder Objetivität. Drei philosophische Essays (trad. Joachim Schulte), Stuttgart: Reclam, 1988.
} 
Polít. crim. Vol. 13, Nº 26 (Diciembre 2018) Art. 12, pp. 1074-1139.

[http://www.politicacriminal.cl/Vol_13/n_26/Vol13N26A12.pdf]

penal, definidos ya al comienzo de estas líneas, de los múltiples deberes ciudadanos que surgen del principio del Estado social como base del fin estatal de garantizar la libertad, desde la función social de la propiedad hasta la obligación de realizar determinadas prestaciones personales en beneficio de la administración de justicia o la seguridad exterior del Estado ${ }^{61}$. Todos estos son deberes positivos, los pilares del edificio social, indispensables para una existencia en libertad.

En segundo término interesa destacar el avance de cierto tipo de pretensiones en lo que respecta a su reconocimiento jurídico. Buena parte del proceso de materialización del derecho $^{62}$ se explica por la complejidad asociada a este reconocimiento, que va desde la mención y regulación de un "nuevo" derecho hasta su justiciabilidad. Ya no se trata solo del derecho de los trabajadores a un mínimo bienestar material, sino, para mencionar tres ejemplos significativos, del derecho del niño a una familia, del derecho de una persona transexual a expresar plenamente su identidad, o del denominado right to security como derecho humano de nuevo cuño.

Conforme al artículo $1^{\circ}$ de la Ley 19.620 sobre Adopción, el menor tiene “derecho a vivir y desarrollarse en el seno de una familia que le brinde el afecto y le procure los cuidados tendientes a satisfacer sus necesidades espirituales y materiales". La Ley 20.609, que Establece Medidas contra la Discriminación, tiene el potencial de obligar a una institución educacional o empresa a reorganizar su sistema de beneficios y prestaciones laborales. El derecho a la seguridad, por su parte, ha pasado de estar exclusivamente asociado a la protección frente al Estado en la tradición liberal, a incluir también el derecho a ser protegido por la autoridad estatal. Incluso si se lo interpreta en términos restrictivos -como acertadamente proponen Waldron y Lazarus ${ }^{63}$-, el derecho a la seguridad ha llegado para instalarse, al menos como condición para el ejercicio de los derechos específicos ${ }^{64}$.

Estos desarrollos no son otra cosa que el despliegue del concepto del derecho, su realización a partir de los principios dinámicos que lo constituyen, el derecho formal y la moralidad, cuya interacción da lugar constantemente a nuevas síntesis en el plano de la eticidad. Algunos de los principales derechos de las minorías sexuales y étnicas, de los niños, de los adultos mayores, de los objetores de conciencia, no proceden de deberes negativos puros, ni de deberes institucionales, sino que son formas de aparición del derecho al bienestar individual. En cualquier sistema político que admita la reconfiguración de las instituciones en función de esta dialéctica del concepto del derecho, como ocurre con el

\footnotetext{
${ }^{61}$ Sobre ello, PAWLIK, Das Unrecht, cit. nota n ${ }^{\circ} 10$, p. 119 con nota ${ }^{\circ} 225$.

${ }^{62}$ Cfr. HABERMAS, Jürgen, "Recht und Moral", en: Faktizität und Geltung. Beiträge zur Diskurstheorie des Rechts und des demokratischen Rechtsstaats, Frankfurt a. M.: Suhrkamp, 1992, p. 542; TEUBNER, Günther, Recht als autopoietisches System, Frankfurt a. M.: Suhrkamp, 1989, pp. 102 y ss.

${ }^{63}$ Véase al respecto LAZARUS, Liora, "The Right to Security", en CRUFT, Rowan et al. (eds.), Philosophical Foundations of Human Rights, New York: OUP, 2015, pp. $423-441$ (p. 439 y s.).

${ }^{64}$ Véase, por ejemplo, la fundamentación de los delitos de peligro abstracto en KINDHÄUSER, Urs, Strafrecht. Allgemeiner Teil, Baden-Baden: Nomos, $7^{\mathrm{a}}$ ed., 2015, p. 70, con referencias ulteriores.
} 
VAN WEEZEL, Alex. “Optimización de la autonomía y deberes penales de solidaridad”.

orden democrático ${ }^{65}$, el "derecho de rebelión" tenderá a ser superfluo. En un sistema así existe también un mecanismo institucional para afrontar las situaciones en que las instituciones vigentes intersubjetivamente llegan a considerarse injustas ${ }^{66}$.

Los progresos del espíritu objetivo en la historia de la Humanidad se deben a una disolución de parte de la eticidad imperante por obra de la crítica desde la moralidad. Los "potenciales" morales son conflictivos en el proceso de su universalización ${ }^{67}$. La forma en que Hegel presenta el conflicto entre moralidad y eticidad imperante en la antigua Grecia es particularmente ilustrativa al respecto ${ }^{68}$. En el proceso contra Sócrates, tanto la ciudad como el acusado tienen razón: aquella debe insistir en que nadie puede ponerse por sobre sus autoridades (razón formal), este plantea el paso desde un ethos inmediato e irreflexivo hacia uno que incorpore la primacía de la conciencia individual. Aunque Hegel no toma partido explícitamente y habla de un conflicto "trágico", parece claro que Sócrates es el Héroe, y que su sacrificio es el comienzo de una nueva y superior época en el despliegue histórico del espíritu. Otro tanto afirmará luego sobre el potencial "revolucionario" del Evangelio, ilustrándolo con el ejemplo de la abolición de la esclavitud.

El reconocimiento del heroísmo de Sócrates contrasta, sin embargo, con la condena de San Crispín (GL zu § 126: “deberían haberlo encarcelado”), de quien se cuenta que hurtaba cuero para hacerles zapatos a los pobres. Una acción que expresa una contradicción con los presupuestos elementales de la libertad plasmados en el derecho vigente no puede hallarse justificada, aunque se realice con una buena intención. En esto no puede haber concesiones al sentimentalismo, pues una acción como la descrita es incompatible con aquello que garantiza la libertad, es decir, termina por destruir los presupuestos de su posibilidad como acción libre.

Sin embargo, Hegel advierte que tanto el bienestar individual como el derecho formal o abstracto están subordinados al bien superior del Estado, a lo que es mejor para la generalidad y para cada uno (GL $\S 126$ A). Por lo tanto, tampoco existe una razón necesaria para preferir, en un caso determinado, el derecho formal del propietario. El caso más claro en el cual goza de preferencia el bienestar individual es el del estado de necesidad vital.

La pregunta que se impone es, entonces, si no existen también otros casos en que resulta posible razonar de un modo análogo y donde, en consecuencia, la realización de una conducta de salvaguarda de un bien que en principio resulta contraria a derecho se encuentra justificada, es decir, donde al necesitado le asiste el derecho (aunque sea en un

${ }^{65}$ HONNETH, Axel, Das Recht der Freiheit. Grundriß einer demokratischen Sittlichkeit, Berlin: Suhrkamp, 2011, pp. 81 y ss.; 470 y ss.

${ }^{66}$ Por eso a mi juicio es equivocado sostener, como hace HÖSLE (Hegels System, cit. nota ${ }^{\circ}$ 57, p. 477), que Hegel "esquiva" el problema del derecho de rebelión.

${ }^{67}$ HONNETH, Axel, Kampf um Anerkennung, Frankfurt a.M.: Suhrkamp, 2003 (edición ampliada), p. 27.

${ }^{68}$ Cfr. HEGEL, G. W. F., Vorlesungen über Geschichte der Philosophie, ed. a cargo de K. L. MICHELET, revisada por Eva MOLDENHAUER y Karl Markus MICHEL, Frankfurt a.M.: Suhrkamp, 1986 (aquí: t. 18, p. 498 y ss.); HÖSLE, Hegels System, cit. nota ${ }^{\circ} 57$, pp. 477 y ss. 
sentido débil) de realizar la conducta prohibida en general. Considerando la fuerza motriz de la moralidad, que es, en palabras de Hösle, como una prolepsis de la filosofía, capaz de remover el orden consuetudinario para introducir un principio superior en la realización de la libertad, la respuesta a esta pregunta debería ser positiva. Por eso Hegel no se equivoca al tratar el estado de necesidad en este plano cuando quiere defender, en su época y nada menos que contra Kant, el derecho a salvar la propia vida afectando la propiedad ajena. Desde entonces, el eje de la discusión se ha desplazado considerablemente, pero el problema es el mismo.

La síntesis de la eticidad es necesaria, pues su rendimiento es la institucionalización. La moralidad llega únicamente a fundar la ayuda al necesitado como parte de un cálculo egoísta y, sobre todo, contingente: el sujeto considera que ha hecho algo bueno, pero también que podría perfectamente haberlo omitido (GL $§ 126$ hZ y $§ 26$ hZ). Los deberes de solidaridad que aquí interesan solo pueden encontrar en este estadio un precursor. Sin embargo, sería un error pasar demasiado rápido por este precursor, pues, aunque en su nivel se mantiene la contradicción, sin ella no hay eticidad. Sin conflicto entre el bienestar individual y el derecho formal, no hay regla sobre estado de necesidad. Es la moralidad la que identifica el conflicto y le da relevancia, lo sitúa en el lugar que le corresponde y lo renueva históricamente.

Una de las más importantes contribuciones de las GL es precisamente el reconocimiento de la moralidad como realización de la idea del derecho. Esta realización de la idea no es un ciclo ya cerrado, petrificado en una determinada forma ética, en una cierta institucionalidad estatal. Por el contrario, el despliegue histórico de la idea del derecho es un proceso en movimiento que produce constantemente esta "segunda naturaleza"69, puesta por el espíritu -la "libertad consciente de sí misma"70 - que constituye el derecho real. La fuerza motriz de este despliegue es justamente la tensión entre la abstracción de la forma jurídica exterior del derecho abstracto y la moralidad, que es la reflexión de la voluntad sobre sí misma y sus necesidades ${ }^{71}$. Dicho de otro modo: no hay que confundir el desarrollo del concepto -que es más bien lineal- con su realización, que es dialéctica.

${ }^{69}$ HEGEL, G. W. F., Vorlesungen über die Philosophie der Geschichte (ed. K. Hegel), revisada por MOLDENHAUER, E.; MICHEL, K. M. (eds.), Frankfurt a.M.: Suhrkamp, 1986, p. 57.

${ }^{70}$ HEGEL, G. W. F., Enzyklopädie der philosophischen Wissensachaften, III (ed. K. L. Michelet), revisada por MOLDENHAUER, E.; MICHEL, K. M. (eds.), Frankfurt a.M.: Suhrkamp, 1986, p. 318.

${ }^{71}$ HÖSLE, Hegels System, cit. nota ${ }^{\circ}$ 57, p. 464. Hegel trata también una de las modalidades que adopta esta configuración de la eticidad desde la moralidad en GL $\S 207$, que se refiere a la ética de la profesión o estamento al cual cada uno pertenece conforme al sistema de las necesidades en la sociedad civil. En esta esfera de las necesidades particulares y del bienestar, explica, la moralidad tiene también "su lugar propio", pues allí la contingencia inherente a la satisfacción de al menos una parte de esas necesidades "convierte en deber una ayuda contingente e individual". En efecto, la ayuda no programada -y en este sentido, casual o contingente- del necesitado forma parte de los deberes de estado de ciertas profesiones u oficios. Lo interesante es que esta "etificación" del deber -su conversión en un deber positivo- no excluye para Hegel su carácter moral. Sobre el significado general de esta reaparición de la moralidad en el contexto de la sociedad civil en las GL véase SCHNÄDELBACH, Hegels Praktische Philosophie, cit. nota n 54, pp. 280 y s. 
VAN WEEZEL, Alex. "Optimización de la autonomía y deberes penales de solidaridad”.

\subsubsection{Solidaridad intersubjetiva y penalmente garantizada.}

Como ha puesto de relieve Ritter ${ }^{72}$, resulta prácticamente imposible no relacionar esta explicación de las GL con la forma en que Aristóteles concibe la continuidad entre ética y política. La Ética a Nicómaco termina -de un modo sorprendente para quien se enfrenta a ella por primera vez- con las palabras que rezan: "Comencemos, pues, con la exposición" $(\mathrm{EN} \mathrm{1181b24})^{73}$. Aunque se ha discutido mucho sobre el origen de esta expresión, lo más probable es que Aristóteles, como hace a través de todo el Libro X de la Ética, pretendiera establecer un nexo directo con el tratado que dedica a la política. Si la ética es una teoría de la vida buena o feliz para quien actúa, la política es una teoría sobre la mejor forma de organizar la vida en común. La conexión entre ambas deriva de que para Aristóteles es imposible alcanzar la vida buena o plena, que consiste en el despliegue de las potencias del alma racional, sin la ordenada interacción con los demás que tiene lugar en la comunidad política. Para vivir al margen de esta comunidad se requeriría un grado de autosuficiencia que se encuentra muy por debajo o muy por encima de lo humano: quien no necesita de la comunidad es una bestia o un dios (Pol. 1253a27-29).

Aristóteles valora la vida por sí misma (Pol. 1278b23-31), pero la vida plenamente humana es la vida buena, que solo es posible en la comunidad política. El paralelo con las GL es impresionante: "La ciudad es la comunidad, procedente de varias aldeas, perfecta, ya que posee, para decirlo de una vez, la conclusión de la autosuficiencia total, y que tiene su origen en la autoconservación, pero subsiste para la vida buena" (Pol. 1252b8). De entre todos los seres vivos, el hombre es el único que posee la capacidad de la palabra (Pol. 1253a12; EN 1170b11) y por lo tanto está naturalmente -en el sentido teleológico que es característico de la filosofía aristotélica ${ }^{74}$ - a vivir en la comunidad política, donde se produce el intercambio de pensamientos y discursos. Cuando este intercambio se refiere a las condiciones de la vida buena o plena, lo que tiene lugar en casi toda conversación que trascienda lo inmediato, entonces surge la reflexión que Hegel conoce como la perspectiva de la moralidad. Al reconocimiento del otro que es propio del derecho formal o abstracto, y que se encuentra próximo a la inmediatez, sucede el reconocimiento del otro como sujeto moral, incluyendo su "derecho al bienestar"

${ }^{72}$ RITTER, "Moralität und Sittlichkeit", cit. nota n ${ }^{\circ}$ 49, pp. 235 y ss.; también llaman la atención sobre el paralelismo (y sus diferencias) Ilting y Honneth: al respecto véase, por ejemplo, HONNETH, Kampf um Anerkennung, cit. nota $\mathrm{n}^{\circ} 67$, pp. 20 y ss.

${ }^{73}$ Las obras de ARISTÓTELES se citan utilizando las abreviaturas habituales y la numeración de la edición griega de Bekker. En las citas textuales de la Política (Pol.) y de la Ética Eudemia (EE) la traducción es libre.

${ }^{74}$ Sobre ello WIELAND, Wolfgang, Die aristotelische Physik, Göttingen: Vandenhoeck \& Ruprecht, $3^{\mathrm{a}}$ ed. 1992, pp. 110 y ss.; VIGO, Alejandro, Aristóteles. Una introducción, Santiago: Instituto de Estudios de la Sociedad, 2006, p. 216.

${ }^{75}$ Más detalles desde la perspectiva de la teoría del reconocimiento en HONNETH, Kampf um Anerkennung, cit. nota $\mathrm{n}^{\circ}$ 67, pp. 20 y ss., incluyendo la explicación (ya presente en SIEP y en WILDT: p. 29, nota $\mathrm{n}^{\circ} 19$ ) sobre la forma en que Hegel aplica y desarrolla la idea de reconocimiento de Fichte sobre su anterior base en la ontología aristotélica. Este proceso da lugar a una particular teleología, característica de la interpretación hegeliana de la comunicación. 
Sin embargo, entre la moralidad y la justicia política en la ciudad existe un tránsito necesario, una fase intermedia: "Habrá, pues, una cierta comunidad y una cierta justicia, aun cuando no exista la ciudad, pues la familia es una amistad" (EE 1242a25-30). Este ámbito, donde existe una cierta justicia sin leyes y una cierta comunidad sin ciudad ${ }^{76}$, tiene su origen en lo que Aristóteles llama amistad (philía) en el ámbito familiar. Amistad y justicia están entrelazadas, "pues la amistad es una virtud o algo acompañado de virtud y, además, es lo más necesario para la vida" (EN 1155a1-5). La eticidad de la polis surge así precisamente en el terreno y sobre el fundamento de la amistad. El estudio ético-político de la amistad en Aristóteles resulta, por lo mismo, fundamental. Por una parte, la amistad precede incluso a lo humano en el plano de los afectos -pues en este nivel es común a ciertos animales: EE 1236b5-, pero por otro lado es una coronación de lo humano y completa la estructura jurídica de la polis. La amistad precede a la comunidad política estructurada en la polis, pero la polis no es posible sin la amistad. Igual como ocurre con los demás aspectos de la moralidad, la amistad es incorporada y llevada a su perfección en el plano de la eticidad: "Parece además que la amistad mantiene unidas a las ciudades, y que los legisladores consagran más esfuerzos a ella que a la justicia” (EN 1155a22-25).

La comunidad política no es meramente territorial o física, sino que responde a una cierta constitución, es decir, se trata de una comunidad de fines orientada a la vida buena. Todas las formas de asociación que dan origen a la comunidad política, desde la familia hasta las sociedades benéficas y los clubes deportivos, son obra de diversas formas de amistad. Sin esta densa red de relaciones de amistad, a cada una de las cuales corresponde una cierta forma de justicia que el Estado reconoce e incorpora, la supervivencia de la comunidad política sería imposible (EN 1155a22-23), pues faltarían incluso los presupuestos mínimos de la cohesión social ${ }^{77}$. Ni para la realización de la plenitud humana ni para la subsistencia de la comunidad política es suficiente con la naturaleza social del hombre; este potencial debe actualizarse en la praxis de la intersubjetividad. Por eso podría decirse que el reconocimiento e institucionalización de las relaciones de amistad es el primer acto de la justicia política. Esto no significa que el Estado ponga fin a la guerra por la subsistencia ${ }^{78}$, pues la lucha por el reconocimiento es justamente el medio para llevar a la eticidad a un nivel superior. Pero un mínimo de amistad entre los ciudadanos, precisamente bajo la forma de mínima solidaridad, pertenece al núcleo de lo que constituye la identidad social. Por eso, un mínimo de solidaridad puede exigirse bajo amenaza de pena.

Si lo anterior es correcto, entonces el deber de solidaridad no está mediado por el Estado, sino que existe ya en la relación interpersonal. Por cierto que, en el ámbito del derecho, esta

\footnotetext{
${ }^{76}$ FARRÉS, Oriol, "La amistad cívica en Aristóteles", en Anales del Seminario de Historia de la Filosofía, Vol. 32, $\mathrm{N}^{\circ} 1$ (2015), pp. 41-67 (p. 45).

77 "Los ciudadanos buscan retribuir el mal con el mal y, cuando no pueden hacerlo, les parece que la comunidad no es más que una reunión de esclavos. O bien buscan retribuir el bien con el bien y, cuando no pueden hacerlo, es imposible que surja la reciprocidad. Y la cohesión entre los ciudadanos descansa precisamente en la reciprocidad" (EN, 1132b-1133a) Cfr. al respecto RHONHEIMER, Martin, Die Perspektive der Moral, Berlin: Akademie Verlag, 2001, pp. 222 y ss.

${ }^{78}$ HONNETH, Kampf um Anerkennung, cit. nota ${ }^{\circ}$ 67, p. 31.
} 
VAN WEEZEL, Alex. "Optimización de la autonomía y deberes penales de solidaridad".

relación nunca es inmediata, sino que se encuentra mediada, precisamente, por la correspondiente forma de relación jurídica. Tratándose de los deberes de solidaridad, esta forma es la de la moralidad. En este sentido, los deberes de solidaridad se encuentran posiblemente más próximos a los deberes negativos que a los deberes institucionales. El deber de solidaridad es una concreción ulterior del reconocimiento del otro, dotada al mismo tiempo de mayor complejidad ${ }^{79}$. La moralidad se presenta así como el verdadero tránsito desde el derecho abstracto hacia la eticidad. Dicho de un modo muy impreciso, y solo con fines explicativos: si los deberes negativos encuentran su origen en las relaciones del derecho abstracto y los deberes positivos o institucionales solo aparecen en el plano de la eticidad, entonces los deberes de solidaridad tienen su raíz en la moralidad, y por eso Hegel los trata precisamente en este lugar.

Dicho ahora de un modo más preciso: en la esfera del derecho nunca está un sujeto "frente al otro" ${ }^{\circ 0}$, su relación siempre está mediada por la respectiva relación jurídica; así, el contrato media la respectiva autorrepresentación de los contratantes (GL § 72), el derecho de necesidad media la relación entre el propietario y el necesitado (GL § 127), la ética estamental convierte en deber lo que sería la mera satisfacción contingente de una necesidad (GL § 207). Pero la mediación definitiva a través del Estado en el plano de la eticidad no cancela ni suprime, sino que incorpora en una síntesis las formas de relación jurídica propias del derecho formal y de la moralidad ${ }^{81}$.

Esto tiene importantes consecuencias para el estatuto de los deberes de solidaridad. En primer lugar, significa que la solidaridad es parte del sistema de distribución de ámbitos de

79 Próximos, aunque desde otro enfoque, von HIRSCH, Andreas; SCHORSCHER, Vivian C., "Die Kriminalisierung der unterlassenen Hilfeleistung: Eine Frage von 'Solidarität' oder Altruismus?", en von HIRSCH; NEUMANN; SEELMANN (eds.), Solidarität im Strafrecht, cit. nota ${ }^{\circ}$ 2, pp. 86 y ss., quienes recurren a una fundamentación según la doctrina del altruismo de NAGEL. El sujeto tiene el deber de ayudar pues eleva la pretensión de que sus intereses también sean tomados en serio por los otros. Si él no toma en serio los intereses importantes de otros, entonces no tendrá ninguna razón para exigir que otros tomen en cuenta los suyos. De este modo no se requiere pasar por el colectivo -altruismo entre individuos-, ni apelar a la propia utilidad en el largo plazo. Conforme a esta fundamentación, las fronteras de la solidaridad altruista serían las siguientes: (i) ningún altruismo exige el sacrificio de bienes personalísimos (pues si el punto de partida es la consideración del propio interés como algo relevante, al igual que los intereses de los demás, el output final no puede ser un sacrificio total (es decir, el punto de partida es el sujeto que ayuda y sus intereses, no los intereses del auxiliado); (ii) un límite que sería común a todos los mandatos: como el mandato estrecharía más la libertad de conducta que la prohibición, deben evitarse deberes excesivamente comprehensivos; (iii) debe considerarse la exposición a una experiencia traumática y la postergación de los propios planes que implica prestar ayuda a una persona necesitada, y (iv) la afectación del auxiliador depende de la inclinación que otros tengan por el riesgo.

${ }^{80}$ Cfr. JAKOBS, "Person und Subjekt in Hegels 'Grundlinien'”, cit. nota $n^{\circ} 11$, pp. 346 y s., quien explica además (p. 348) cómo la realización de la voluntad libre está ligada a personas que ya han sido socializadas y han construido relaciones entre ellas. La realización de la libertad es tan originaria como el surgimiento de instituciones objetivamente válidas en la relación interpersonal.

${ }^{81}$ RITTER, "Moralität und Sittlichkeit“", cit. nota $\mathrm{n}^{\circ} 49$, p. 232; el olvido de este aspecto es el que ha llevado a tantos malentendidos con GL $\S 260$; véase también al respecto SIEP, Ludwig, "Selbstverwirklichung, Anerkennung und politische Existenz. Zur Aktualität der politischen Philosophie Hegels”, en: SIEP, Ludwig, El legado político europeo en la filosofía política de Hegel (trad. de Ángela DE LA TORRE y Alex van WEEZEL), Bogotá: Universidad Externado de Colombia, 2005. 
responsabilidad que mira a la preservación de un estado de libertades y no un asunto de cálculo utilitarista o ponderación de conveniencias, plasmado en una cláusula del contrato social. Cada ciudadano es responsable ante el otro de auxiliarlo en situaciones de necesidad. La existencia y cumplimiento de este deber es parte de una convivencia social ordenada, sin la cual nadie puede desarrollar una vida plenamente humana. Lo que vincula intersubjetivamente es la racionalidad del reconocimiento del otro como sujeto moral con derecho al bienestar. Quien no comparta las concreciones técnicas o legales de este principio puede intentar modificar esas concreciones ejerciendo sus derechos políticos, pero esta discrepancia no suprime la racionalidad y libertad de la sujeción. ${ }^{82}$

De este modo se aprecia también con mayor claridad que la solidaridad solo tiene cabida allí donde se ha dejado atrás el cálculo utilitarista como primer criterio de decisión en caso de conflicto $^{83}$. Si lo decisivo fuera el valor relativo de los bienes y la intensidad de su respectivo menoscabo, entonces los deberes de solidaridad serían superfluos, pues siempre primaría la regla de conducta que, en el caso concreto, protege el bien más valioso. La existencia de deberes de solidaridad presupone que existen distribuciones de autonomía que desplazan el cálculo utilitarista a un plano inferior.

El fundamento esbozado permite explicar el carácter delictivo de la infracción del deber de solidaridad $^{84}$, pero al mismo tiempo limitarlo a aquellos casos en que no se afecta en forma relevante la autonomía de la víctima de la acción de salvaguarda. Si el fundamento racional de los deberes de solidaridad es el reconocimiento del otro como sujeto moral unido a las exigencias de cohesión social, todo ello en el marco de distribución de ámbitos de responsabilidad que mira a la preservación de un estado de libertades, entonces el cumplimiento del deber nunca puede arrasar con la distribución de ámbitos de responsabilidad (ordo amoris), ni destruir la autonomía del afectado o sus fundamentos.

Este mismo fundamento obliga a concentrar la atención en la responsabilidad por la situación de necesidad -en sentido fuerte y en sentido débil-, para distinguir con la mayor precisión posible cuándo se está ante deberes de solidaridad y cuándo, en cambio, la

\footnotetext{
${ }^{82}$ Por eso no es pertinente el clásico ejemplo de Hume, donde una persona es llevada a bordo de un barco mientras duerme y luego, una vez en alta mar, está "obligada" a someterse a la autoridad del capitán (el ejemplo es recordado por PAWLIK en "Solidarität als strafrechtliche Legitimationskategorie", cit. nota $\mathrm{n}^{\circ} 5$, p. 151, tomando la cita de KERSTING, Wolfgang, Die politische Philosophie des Gesellschaftsvertrags, Darmstadt: Wiss. Buchgesellschaft, 1994, p. 139). El sueño y la vigilia son contingentes en relación con el momento en el cual concurren. La sociabilidad humana, en cambio, no es contingente sino necesaria. No es posible una vida humana fuera de la sociedad.

${ }^{83}$ PAWLIK en "Solidarität als strafrechtliche Legitimationskategorie", cit. nota ${ }^{\circ}$ 5, pp. 144 y ss.; similar FRISCH, Wolfgang, "Derecho penal y solidaridad", en InDret 4/2016, pp. 1-24 (12 y ss.).

${ }^{84} \mathrm{La}$ importancia de distinguir entre la fundamentabilidad del deber de auxilio en general y la consideración de su infracción como delito es destacada acertadamente por von der PFORDTEN, "Zur Rechtfertigung von Hilfeleistungspflichten", cit. nota $\mathrm{n}^{\circ}$ 2, p. 112. Sobre los deberes de solidaridad como fuente de responsabilidad específicamente penal cfr. también PIÑA, Juan I., "La solidaridad como fuente de deberes" (cit. pro manuscripto), II.4 y IV.
} 
VAN WEEZEL, Alex. “Optimización de la autonomía y deberes penales de solidaridad”.

situación de necesidad no es más que la consecuencia de la autonomía del necesitado. En este último caso también está en juego el reconocimiento del otro como sujeto moral, pero en primer lugar se trata del reconocimiento de su personalidad formal. La principal manifestación de este reconocimiento es la atribución de responsabilidad por el conflicto y la obligación de cargar con sus consecuencias. De allí que cualquier teoría del estado de necesidad que pretenda hacer justicia a este fundamento debe estar en condiciones de distinguir las consecuencias jurídicas aplicables en uno y otro caso. La precisión con que el sistema de las causas de justificación basadas en la necesidad es capaz de dar cuenta de estas distinciones constituye un buen indicador del grado de realización del concepto del derecho en una sociedad determinada. Otro tanto vale para las relaciones entre autonomía, solidaridad y deberes institucionales.

El mismo fundamento vuelve indispensable explicitar una dimensión del principio de autonomía que es clave para la articulación entre los criterios fundamentales para resolver los conflictos emanados de la necesidad -autonomía, deberes institucionales y solidaridady la ponderación de las afectaciones o menoscabos en conflicto. Ya se ha visto una razón negativa para atender a esta ponderación: la solidaridad autoriza únicamente afectaciones menores de la autonomía; cualquiera otra afectación debe basarse en la propia autonomía del afectado o en un deber institucional de mayor jerarquía. Las razones positivas dicen relación con las formas de injusto distributivo o de responsabilidad débil ${ }^{85}$. Pues bien, el elemento que falta en esta construcción es la dimensión de la autonomía que habitualmente se conoce como casum sentit dominus.

La distribución de los bienes terrenos que da lugar a la propiedad privada es un postulado de la razón práctica ${ }^{86}$, pues toda persona goza de un derecho originario a la adquisición de aquellos bienes que requiere para la realización de su libertad. Este derecho no depende de quienes nos han precedido en la historia, sino que se renueva en cada persona que llega al mundo. Por esta misma razón -se trata de un derecho universal y no de un "derecho a todo", en la expresión hobbesiana-, la apropiación individual cede ante la necesidad vital de otro ${ }^{87}$. Pero la distribución de bienes también es necesaria para la vida social -lo mismo que el gobierno democrático, donde la mayoría decide en qué medida serán exigibles los deberes de solidaridad-, y por lo tanto siempre es el punto de partida de correcciones como las que surgen de los deberes de solidaridad. La pregunta acerca de por qué el daño o la afectación deben ser asumidos por el que casualmente los sufre o, con otras palabras, la idea de que el azar no puede ser un buen criterio de justicia política ${ }^{88}$, se encuentra, en este contexto, totalmente fuera de lugar. No es el azar el que distribuye los daños, sino que estos se distribuyen exactamente según la distribución de los bienes: casum sentit dominus.

\footnotetext{
${ }^{85}$ Véase al respecto WILENMANN, Freiheitsdistribution, cit. nota ${ }^{\circ}$ 5, pp. 207 y ss.; van WEEZEL, "Necesidad justificante y solidaridad", cit. nota ${ }^{\circ} 31$, pp. 215 y ss.

${ }^{86}$ KANT, Immanuel, Metaphysik der Sitten, en: Kants gesammelte Schriften, ed. por la Königliche Preußische Akademie der Wissenschaften. Erste Abteilung, Tomo VI, Berlin, 1907, pp. 245 y ss.

${ }^{87}$ Veánse infra las notas $n^{\circ} 103$ y ss.

${ }^{88}$ Así no obstante PAWLIK en "Solidarität als strafrechtliche Legitimationskategorie", cit. nota n 5 , p. 155.
} 
Quien goza de las ventajas de esta distribución, entre ellas la facultad de exclusión de todos los demás, debe cargar con sus desventajas. Esta dimensión de la autonomía complementa al reconocimiento del otro como sujeto moral con derecho al bienestar, a los deberes institucionales y a la solidaridad en el sistema de distribución de ámbitos de responsabilidad que gobierna la resolución de conflictos en situaciones de necesidad. Esta dimensión juega un rol clave en una variable central de los arreglos institucionales que permiten resolver estos conflictos: la aceptabilidad del sacrificio para quien debe sufrirlo ${ }^{89}$. Los principios anteriores pueden graficarse en la siguiente tabla, donde: A=Autonomía (algo análogo valdrá para los deberes institucionales) y $\mathrm{S}=$ Solidaridad. Los números representan la intensidad con que concurre cada categoría. La combinación entre estos criterios de distribución de responsabilidad determina la relevancia del criterio subordinado, la ponderación de intereses o menoscabos:

\begin{tabular}{c|c|c|c} 
A 3-S 0 & A 2 -S 1 & A 1 - S 2 & A 0-S 3 \\
\hline No & No & Balance & Balance \\
total & (grave) & (sustancialmente) & absolutamente \\
desproporción & desproporción & positivo & positivo
\end{tabular}

Desde luego que se trata de una presentación meramente esquemática, donde los valores de 0 a 3 son aproximativos y queda espacio para un afinamiento posterior mediante las expresiones entre paréntesis. Sin embargo, la estructura de la tabla precedente es necesaria. Que el deber de solidaridad sea una contribución de la moralidad al tránsito desde el derecho abstracto hacia la eticidad tiene también como consecuencia que resulte indispensable distinguir entre el deber y su contenido. Por cierto que en rigor no se debe algo a otro sino en cuanto se trata de un ciudadano, es decir, en el Estado y, por lo tanto, en el plano de la eticidad. Pero esto no significa que solo se deba lo mismo que el Estado debe conforme a la decisión de la voluntad general, y que puede corresponder a un rol importante o menor en la superación de las situaciones particulares de necesidad. Las concreciones de lo que debe el Estado y lo que cada uno debe al conciudadano serán también legislativas, pero el Estado, la ley, puede ordenar al ciudadano dar más o algo diverso de lo que el mismo Estado daría. En el ejemplo del antídoto, el vecino puede estar obligado a hacer más de lo que haría la asistencia pública. Esto se debe precisamente a que el fundamento del deber de solidaridad es intersubjetivo y hunde sus raíces en una existencia previa al Estado, la del sujeto moral con necesidades que reflexiona sobre sus acciones.

En este mismo sentido, el Estado no carga al ciudadano con el deber que al Estado le corresponde cumplir -y lo amenaza con penas en caso de que no colabore-, sino que le asiste en el cumplimiento de un deber originario o, en un sentido dialéctico, previo. Aunque la institucionalización de este deber se produzca recién en el Estado, en el plano de la eticidad - por lo demás, igual que en el caso del pacta sunt servanda y de los demás deberes

\footnotetext{
${ }^{89}$ En detalle al respecto COCA VILA, La colisión de deberes, cit. nota ${ }^{\circ}$ 5, pp. 387 y ss.
} 
VAN WEEZEL, Alex. "Optimización de la autonomía y deberes penales de solidaridad”.

que tienen su raíz en el derecho abstracto-, el conflicto está ya resuelto -o debe estarlo- en el plano de la moralidad. Esta visión armoniza también mejor con lo que el más prominente de los defensores contemporáneos de un planteamiento institucionalista de la solidaridad sostiene en su última contribución al respecto:

"Por eso ha de enfatizarse expresamente que ella [la interpretación institucionalista] no prescinde del necesitado y sus intereses ni favorece el retorno a una comprensión colectivista del estado de necesidad, que trate a la generalidad como fin en sí misma y a los ciudadanos individuales como a sus funcionarios. La interposición de la generalidad se produce exclusivamente para descargar al obligado por el estado de necesidad de las consecuencias asociadas a la acción de salvaguarda que le afectan. La generalidad funge, con otras palabras, como sirvienta del destinatario individual del deber de soportar la intervención, no como su patrona. El injusto que este realiza, por tanto, cuando no cumple adecuadamente su deber de tolerancia, no es un injusto frente a la comunidad jurídica como un todo, sino un injusto frente al necesitado mismo que tiene derecho a la solidaridad" 90 .

Este planteamiento es correcto, pero solo es consistente con una fundamentación intersubjetiva del deber de solidaridad en el plano de la moralidad, como exigencia del derecho al bienestar. En cambio, no es compatible con el planteamiento estatalista del ciudadano como representante de la generalidad.

\section{El problema de los límites}

Como sea, una de las principales ventajas de la aproximación estatalista radicaba en la naturalidad con que, al menos prima facie, permitía trazar los límites de los deberes de solidaridad $^{91}$. Para la concepción aquí favorecida esta tarea es algo más ardua y a ella se dedican las consideraciones siguientes.

\subsection{Límites generales}

Ante todo cabe preguntarse si es posible extraer en forma inmediata alguna consecuencia a partir del fundamento propuesto o si, como observa Walzer, el asunto de la constitución del yo (y la filosofía del reconocimiento) no es más que un "campo de batalla" del cual nada se obtiene para la teoría política y, menos todavía, para la ciencia del derecho ${ }^{92}$. Contra esta apreciación, todo indica que el potencial limitativo de la aproximación intersubjetiva no es menor y puede sintetizarse en tres aspectos. En primer lugar, que el cumplimiento de un deber de solidaridad no puede exigir el sacrificio completo de la personalidad abstracta del obligado ni un sacrificio que afecte sustancialmente su autonomía. Luego, que el respeto de la personalidad abstracta no puede exigirse al extremo de justificar el incumplimiento de

\footnotetext{
${ }^{90}$ PAWLIK en "Solidarität als strafrechtliche Legitimationskategorie", cit. nota n’ 5, p. 156.

91 Véase supra, Apartado 2.1.

92 WALZER, Michael, "Die kommunitaristische Kritik am Liberalismus", en HONNETH, A. (ed.), Kommunitarismus, Frankfurt a. M.: Campus Verlag, 1993, p. 179.
} 
deberes de mínima solidaridad en la medida en que, según se vio, una cierta incorporación al ordenamiento jurídico de la justicia propia de las relaciones de amistad es indispensable para la subsistencia de la comunidad y, por lo tanto, forma parte de la justicia política. Por último, se puede concluir que no es aventurado suponer que consideraciones análogas deberían ser válidas para las relaciones conflictivas entre deberes de solidaridad y deberes positivos.

El espectro de situaciones imaginable entre los extremos -mínima solidaridad, conservación de los derechos de la personalidad abstracta- debe definirse con mayor precisión en la regulación contingente $\mathrm{y}$, en efecto, esta regulación contiene definiciones que son perfectamente consistentes con las premisas extraídas de la dialéctica del reconocimiento, según se verá. Sin embargo, la selección de los deberes de solidaridad cuya infracción tendrá relevancia penal, y de la medida de la infracción, es una cuestión de política legislativa, un asunto más bien tecnocrático, aunque dependa de la evolución de la sociedad en cuanto al reconocimiento del otro como sujeto moral con derecho al bienestar.

Hay dos caminos para abordar el problema de los límites de los deberes de solidaridad que, desde la perspectiva aquí adoptada, no parecen transitables y conviene despejar desde ya. En primer lugar, el camino de la exigibilidad, cuando el obligado incumple el deber porque enfrenta un conflicto de motivos que el derecho reconoce y que, bajo determinadas circunstancias, permite configurar una excusa. En estos casos, el deber subsiste en toda su amplitud y la limitación se refiere a la imposición de las consecuencias jurídicas de la infracción. Se trata, por lo tanto, de un límite inmanente al sistema de imputación pero extrínseco al deber ${ }^{93}$, y por lo tanto no es pertinente al objeto de estas reflexiones. Sobre todo, el límite de la exigibilidad poco o nada dice acerca del sistema de distribución de autonomía y responsabilidades en una sociedad determinada.

A ello debe añadirse que los límites tampoco pueden provenir de una supuesta preferencia de los deberes de abstenerse (prohibiciones) respecto de los deberes de realizar una determinada actividad (mandatos). Aunque pueda aceptarse que existen diferencias en la imputación del actuar y del omitir, de estas diferencias no se sigue un orden de prelación basado simplemente en el operador deóntico. En efecto, en cuanto se asume que los deberes negativos y positivos pueden ser infringidos por acción y por omisión, resulta imposible establecer juicios de prioridad estables basados en el operador deóntico de la obligación: ni los mandatos exigen siempre contribuciones solidarias, ni las prohibiciones sirven en todo caso al mantenimiento de una separación dada de esferas de libertad ${ }^{94}$.

\subsection{Límites específicos}

\footnotetext{
93 MOMSEN, Carsten, Die Zumutbarkeit als Begrenzung strafrechtlicher Pflichten, Baden-Baden: Nomos, 2006, pp. 139 y ss..

${ }^{94}$ Recientemente y en detalle al respecto, COCA VILA, La colisión de deberes, cit. nota n ${ }^{\circ} 5$, pp. 381 y ss.
} 
VAN WEEZEL, Alex. "Optimización de la autonomía y deberes penales de solidaridad”.

Son dos los límites que derivan de la génesis y estructura de los deberes de solidaridad en el derecho contemporáneo. En primer lugar, la intensidad de un deber de garante depende del ejercicio de autonomía relativa en el momento de la asunción de la obligación. Esta intensidad del deber se manifiesta luego en la extensión de la responsabilidad por su infracción (¿responsabilidad por el resultado?) y en la solución de las colisiones de deberes. En segundo término, el deber de solidaridad se encuentra limitado por los presupuestos específicos de su surgimiento, que deben buscarse en el tenor de las reglas de omisión de auxilio y estado de necesidad, y en la tradición filosófica y jurídica en la que ellas se inscriben.

\subsubsection{Autonomía en el origen e intensidad del deber}

Ya se han esbozado las razones por las cuales el Estado garantiza a cada persona un cierto nivel de reconocimiento como sujeto moral con derecho al bienestar y cómo este reconocimiento es indispensable para la cohesión social. Sin embargo, la fundamentación de la existencia de deberes heterónomos no resuelve automáticamente, en el marco valorativo predominante de individualismo moral, la pregunta sobre la intensidad con la que un determinado ciudadano queda vinculado por tales deberes. Este problema ha sido abordado en detalle por Pawlik en su investigación sobre el injusto del ciudadano ${ }^{95}$. En las coordenadas del individualismo moral, el carácter vinculante del deber respecto del sujeto obligado se funda y legitima en la auto-obligación: el surgimiento del deber debe estar vinculado a un acto voluntario del sujeto del mismo deber.

En el caso de los deberes negativos es relativamente simple advertir el carácter autoimpuesto de los deberes correspondientes, pues estos deberes operan con el esquema básico del sinalagma "libertad de comportamiento / responsabilidad por las consecuencias". En ellos, la autovinculación del sujeto se refiere además específicamente a la situación concreta en que incide el deber, o a una cierta clase de situaciones análogas: deberes de aseguramiento y asunción. En el caso de los deberes positivos, en cambio, es preciso distinguir entre aquellos deberes en cuyo origen es reconocible un acto original de voluntad del obligado - los deberes funcionariales, la confianza especial, la relación paterno-filial, el matrimonio- y aquellos en que ese acto no es reconocible, como en el caso del deber de comparecer y declarar verazmente como testigo, o el de realizar el servicio militar. Pawlik subdistingue aquí entre los deberes que se tienen por solo el hecho de ser súbdito de un Estado, como este último, y los que se imponen en razón de la mera capacidad para realizar la prestación, como los deberes del testigo presencial de un hecho delictivo. ${ }^{96}$

\footnotetext{
95 PAWLIK, Das Unrecht, cit. nota ${ }^{\circ}$ 10, pp. 187 y ss.; él mismo, en "Solidarität als strafrechtliche

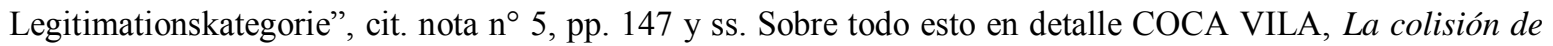
deberes, cit. nota $\mathrm{n}^{\circ} 5$, pp. 276 y ss., quien destaca acertadamente cómo esta idea ya estaba presente en SILVA SÁNCHEZ, Jesús-María, El delito de omisión. Concepto y sistema, Montevideo-Buenos Aires: B de F, $2^{\mathrm{a}}$ ed. 2003, p. 470, pp. 476 y ss. y en ROBLES PLANAS, Ricardo, Garantes y cómplices: la intervención por omisión y en los delitos especiales, Barcelona: Atelier, 2007, p. 33.

96 PAWLIK, Michael, "Las competencias del ciudadano", en: él mismo, Ciudadanía y derecho penal, Barcelona: Atelier, 2016, p. 99.
} 
Pues bien, desde una perspectiva moral individualista la intensidad relativa de los deberes el ordo amoris - depende radicalmente de la autonomía de su imposición, pues justamente aquí reside el principio de su legitimación en relación con el concreto sujeto obligado. El deber de auxilio que subyace a la omisión de socorro corresponde, en este contexto, al prototipo de los deberes heterónomos. Por lo tanto, aunque por las razones vistas es perfectamente posible fundar su existencia en abstracto, en un Estado liberal y bajo la primacía de una moral individualista, la intensidad del deber no puede ser equiparable a la de los deberes negativos ni a la de los deberes positivos cuyo surgimiento importa la realización de un acto voluntario de asunción por parte del obligado. Por la misma razón, entre estas últimas clases de deberes tampoco es posible establecer a priori una jerarquía, sino que será preciso indagar con mayor detalle en la intensidad del compromiso de la libertad individual en cada caso. Así, por ejemplo, un deber negativo basado en la injerencia imprudente tendrá menor intensidad que el deber positivo de un policía en orden a impedir la comisión de cierto delito. Y así sucesivamente ${ }^{97}$. Esta misma lógica del compromiso gradualmente creciente de la autonomía subyace a la gradualidad descrita precedentemente y sintetizada en la tabla que se incluye más arriba.

De esta forma se construye el equilibrio entre la necesidad de los deberes de solidaridad para la mantención del edificio social y la autonomía individual. Para determinar la proporcionalidad de las normas de conducta correspondientes a cada clase de deber, evitando el riesgo de que una expansión desmesurada de los deberes de solidaridad ahogue los espacios de realización personal, es preciso combinar los fundamentos de su existencia -incluyendo la relevancia abstracta de la institución- con el principio de autonomía en el origen de la vinculación. Todo esto hace posible el surgimiento de un sistema de los grados de competencia que maximiza la autonomía, pero que al mismo tiempo da cuenta de los presupuestos institucionales de su existencia y ejercicio.

La principal consecuencia de ello consiste en que la infracción del deber de solidaridad -en cuyo surgimiento, por definición, no tiene parte la asunción voluntaria- exhibe una gravedad menor que la infracción de un deber negativo o positivo. Para un grupo significativo de autores ${ }^{98}$, esto implica en primer lugar que la infracción de un deber de solidaridad es incompatible con la imputación de los resultados lesivos que pudieran atribuirse a tal infracción. Efectivamente, en la discusión sobre el alcance de las posiciones de garante en los delitos de omisión, uno de los tópicos centrales es el de la equivalencia de la omisión a la acción en orden a la imputación de un delito de comisión por omisión ${ }^{99}$. Por otro lado, excluir la imputación por el resultado en el caso de la infracción de deberes heterónomos parece una forma adecuada de establecer un balance entre el peso relativo de

${ }^{97}$ El problema ha sido tratado y resuelto en base a distinciones altamente plausibles en COCA VILA, $L a$ colisión de deberes, cit. nota ${ }^{\circ} 5$, pp. 281 y ss.

${ }^{98}$ Referencias supra, en nota ${ }^{\circ} 95$.

${ }^{99}$ Cfr. SILVA SÁNCHEZ, El delito de omisión, cit. nota n 95, pp. 471 y ss. 
VAN WEEZEL, Alex. "Optimización de la autonomía y deberes penales de solidaridad”.

la posición de garante y la extensión de las consecuencias de su infracción. Al carácter subordinado de los deberes de solidaridad correspondería así una exclusión de la responsabilidad por el resultado, según se observa claramente en la omisión de socorro.

Este punto de vista parece convincente. Del contexto de fundamentación de los deberes de solidaridad y del criterio de autonomía de la vinculación se deduce que las infracciones punibles a esta clase de deberes han de ser algo excepcional, pero también que la pena de la infracción del deber de solidaridad debe ser considerablemente menor. Es cierto que la infracción de deberes positivos y negativos puede dar lugar a delitos de resultado o de mera actividad, de modo que a su respecto la inclusión del resultado en el tipo y la agravación en virtud de los resultados imputables a la infracción es un asunto de política y de técnica legislativa. Pero esto nada dice respecto de los deberes de solidaridad. En primer término, porque ya se ha visto cómo estos se encuentran subordinados a aquellos; y luego, porque entre los deberes positivos y negativos no es posible acordar a priori una jerarquía, de tal manera que la responsabilidad por el resultado puede corresponder a diferentes especies de deber.

Por lo mismo, la figura de omisión de socorro no considera la afectación concreta de la vida o la integridad como resultado del delito al cual subyace la infracción del deber de solidaridad y sería anómalo que la magnitud de la pena de la omisión de socorro dependiera de las lesiones que sufra el no socorrido y que sean atribuibles a la infracción del deber, como ocurre en otros ordenamientos ${ }^{100}$.

La situación es exactamente la misma si se miran las cosas desde el lado de la justificación, es decir, si se atiende a los deberes del afectado por la acción de salvaguarda en el estado de necesidad agresivo. Lo que denominamos "deberes de tolerancia" no es otra cosa que el resultado de la desactivación de la norma prohibitiva para el agente de necesidad por efecto de la causa de justificación que, entre otros aspectos, funciona como norma permisiva. ${ }^{101}$ Producida esta desactivación, la conducta del afectado por la acción de salvaguarda se enjuicia directamente a partir de su contraste con las normas de conducta que protegen el bien amenazado y sus presupuestos de aplicación. Entre estos se encuentra la competencia del afectado por la evitación del daño, que en el caso del estado de necesidad agresivo solo puede fundarse en un deber de solidaridad. Por lo tanto, si el afectado impide con su conducta el salvamento del bien, será responsable en la medida en que su infracción al deber de solidaridad sea el presupuesto positivo de la antijuridicidad de una conducta típica, pero hasta el límite señalado, es decir, sin responsabilidad por el resultado que teóricamente pudiera imputarse a la infracción del deber.

\footnotetext{
${ }^{100}$ Véase, por ejemplo, el $\S 95$ del Código Penal austríaco.

${ }^{101}$ Al respecto MAÑALICH, Juan Pablo, "Normas permisivas y deberes de tolerancia", cit. nota $n^{\circ} 15$, pp. 495 y ss. Las consecuencias de este planteamiento son claras y acertadas respecto de los denominados "deberes de tolerancia", con independencia de que, a nuestro juicio, las causas de justificación no puedan reducirse a su carácter de normas permisivas (al respecto van WEEZEL, "Necesidad justificante y solidaridad", cit. nota $\mathrm{n}^{\circ} 31$, pp. 215 y ss.)
} 
En abstracto, nada impide que la competencia por la realización de una gran parte de las figuras delictivas de la parte especial se funde indistintamente en la infracción de deberes negativos, deberes positivos o deberes de solidaridad ${ }^{102}$, tal como en un mismo hecho pueden concurrir presupuestos de exclusión de la antijuridicidad basados en la autonomía, en consideraciones institucionales o en deberes de solidaridad. Pero la exigencia de autonomía en el origen de la vinculación determina que sea imposible imponer deberes de garante de máxima intensidad, es decir, con responsabilidad por el delito de resultado, sobre la base exclusiva de un fundamento solidario.

La responsabilidad por la infracción de un deber de solidaridad también está subordinada, igual como ocurre con todas las posiciones de garante, a la concurrencia de ciertos presupuestos. Ellos constituyen, tras el criterio de la autonomía en el origen de la obligación, el segundo límite específico a la responsabilidad penal por infracción de deberes de solidaridad.

\subsubsection{Los presupuestos del surgimiento de la posición de garante por solidaridad}

Conforme al fundamento de los deberes de solidaridad su cumplimiento no puede exigir el sacrificio completo de la personalidad abstracta del obligado ni un sacrificio que afecte sustancialmente su autonomía. Por otro lado, la heteronomía en el surgimiento del deber obliga a concluir que los deberes de solidaridad se encuentran por debajo de los deberes negativos y positivos que suponen un acto libre de asunción del deber por parte del obligado. Aparte de lo que significa en materia de colisión de deberes, lo anterior determina que, de acuerdo al principio de proporcionalidad, la responsabilidad penal por infracción de deberes de solidaridad sea excepcional, que no permita fundar responsabilidad por el resultado y que las correspondientes penas hayan de ser también significativamente menores.

El carácter excepcional de la responsabilidad a título de infracción de deberes de solidaridad se observa claramente en la tradición filosófica y jurídica en la cual se inscriben las reglas pertinentes del Código Penal. Conforme a ella, solo se permite (o se excusa) por razones de solidaridad el sacrificio de la propiedad ajena para salvaguardar la vida u otro bien personalísimo de alta significación. Esto se muestra muy sintéticamente a continuación, siguiendo el recorrido histórico propuesto por Renzikowski ${ }^{103}$.

La fundamentación iusnaturalista del derecho de necesidad es, hasta fines del siglo XVIII, la única aproximación que explica por qué en caso de peligro para sí mismo alguien puede echar mano, justificadamente, de bienes ajenos. Lo interesante es que ya en esta época se trata precisamente de un peligro para la vida y, como contrapartida, de la afectación de la

${ }^{102}$ Cfr. van WEEZEL, Alex, "Actuar en lugar de otro", cit. nota n ${ }^{\circ} 16$, pp. 301 y ss.

${ }^{103}$ RENZIKOWSKI, Joachim, "Solidarität in Notsituationen”, cit. nota ${ }^{\circ} 53$. 
VAN WEEZEL, Alex. "Optimización de la autonomía y deberes penales de solidaridad".

propiedad ajena ${ }^{104}$. Para Tomás de Aquino, quien asumía un destino universal de los bienes seguido de una distribución de la propiedad por razones de conveniencia, "en la necesidad todo es común (...) Una cosa sustraída subrepticiamente para superar la extrema necesidad nada tiene que ver, en rigor, con el hurto. Pues una situación de necesidad de ese tipo produce que aquello que alguien toma para sí con el fin de conservar su vida se convierta en su propiedad" ${ }^{\prime 05}$. Así, en el máximo peligro -el peligro de muerte- revive el destino universal de los bienes conforme al derecho natural.

Esta línea de argumentación se mantiene entre los autores iusnaturalistas, algunos de los cuales incorporan elementos contractualistas. Tal es el caso de Grocio:

"En la máxima necesidad revive el antiguo derecho de uso, como si los bienes todavía fueran comunes; porque en todas las leyes humanas y consecuentemente también en las leyes sobre la propiedad se encuentra excluida aquella necesidad extrema (...) Por eso en una travesía marítima, cuando los alimentos se acaban, cada uno debe entregar para el uso común todo lo que posee; y así también puedo yo en caso de incendio echar abajo la casa de mi vecino para proteger la mía; e igualmente puedo cortar las cuerdas y redes entre las que ha ido a parar mi barco, si es que no puede liberarse de otra manera. (...) Pues también entre los teólogos vale la máxima de que no comete hurto quien en tal necesidad toma de otros aquello que es necesario para la conservación de su vida" ${ }^{106}$.

En todo caso, el derecho de necesidad está sometido a una serie de limitaciones: el peligro no debe ser evitable de otro modo y el que realiza la acción de salvaguarda está obligado a la restitución de la cosa y la compensación de los daños ${ }^{107}$.

Una voz discordante en la tradición del derecho natural es la de Pufendorf. A su juicio no existe un derecho natural a afectar la propiedad ajena para salvar la propia vida, aunque el

${ }^{104}$ Aunque sea discutible qué entienden los teóricos iusnaturalistas por "propiedad" y, especialmente, si esta comprende o no intereses distintos de la propiedad o posesión de cosas, es claro a partir de los textos de los autores relevantes que el estado de necesidad se discutía en relación con la afectación de intereses instrumentales y no personalísimos.

${ }^{105}$ Tomás de AQUINO, S.Th. II ${ }^{\mathrm{a}} \mathrm{II}^{\mathrm{ae}}$, q. LXVI, art. 7: "In necessitate sunt omnia communia (...) ... quod uti re aliena occulte accepta in casu necessitatis extremae, non habet rationem furti, proprie loquendo: quia per talem necessitatem efficitur suum id, quod quis accipit ad sustentandam propriam vitam" (se cita según la edición BAC, t. VIII).

106 GROTIUS, Hugo, De Jure Belli ac Pacis. Libri tres, editio nova, Amsterdam 1680, Lib. II, Cap. II, § 6: "Hinc primo sequitur in gravissima necessitate reviviscere jus illud pristinum rebus utendi, tamquam si communes mansissent; quia in omnibus legibus humansi, ac proinde $\&$ in lege dominii, summa illa necessitas videtur excepta. (...) Hinc illud ut in navigatione si quando defecerint cibaria quod quisque habet in comune conferri debeat; sic et defendendi mei causa vicini aedificium orto incendio dissipare possum: et funes aut retia discindere in quae navis mea impulsa est, si aliter explicari nequit (...) Nam \& inter Theologos recepta sententia est, in tali necessitate si quis quod ad vitam suam necessarium est sumat aliunde, eum furtum non committere" (citado según RENZIKOWSKI, Joachim, "Solidarität in Notsituationen", cit. nota n 53, p. 20).

${ }^{107}$ GROTIUS, Hugo, De Jure Belli ac Pacis, cit. nota n 102, p. 21 (Lib. II, Cap. II, § 9): "Ubi fieri poterit faciendam restitutionem. (...) ius hic non fuisse plenum, sed restrictum cum onere restituendi ubi necessitas cessaret. Tale enim ius sufficit ad feruandam naturalem aequitatem contra rigorem dominii”. 
derecho positivo podría establecer un deber jurídico de ayuda mutua en situaciones de extrema necesidad. A falta de una regla positiva, en el mejor de los casos cabría pensar en lo que muchos años después se denominaría "espacio libre de derecho" -el ordenamiento no aprueba ni desaprueba la acción de salvaguarda-, pues el derecho jamás podría prohibir actos directamente tendientes a la autoconservación ${ }^{108}$. Este planteamiento se radicalizará luego en Kant, quien no solo no acepta la existencia de derechos de necesidad ("no puede haber una necesidad que convierta en legal lo que es contrario a derecho" ${ }^{109}$ ), sino que también descartará con razón la tesis del "espacio libre de derecho".

Pese a todas las diferencias entre los planteamientos del derecho natural previo a la Ilustración y al Idealismo Alemán, Fichte se encuentra en una línea de continuidad con los antiguos iusnaturalistas y reconoce un genuino derecho emanado de la necesidad. Este derecho no se basa, sin embargo, en la idea de una original destinación universal de los bienes, sino en consideraciones de teoría del Estado:

"Desde el momento en que alguien sufre necesidad, a nadie pertenece aquella parte de su propiedad que es reclamada como contribución para sacar a alguien de la situación de necesidad; esa parte pertenece jurídicamente al necesitado. Para una tal distribución de los bienes deben adoptarse medidas ya en el contrato ciudadano. Y aquella contribución es una condición de todo lo que es justo en la sociedad, como lo es la contribución a la protección del cuerpo, ya que este apoyo al que sufre necesidad es en sí mismo una parte de la protección necesaria. Cada uno posee su propiedad ciudadana solo bajo la condición de que todos los ciudadanos que componen el Estado puedan vivir de la suya; y por lo tanto esa propiedad termina ante los que no pueden vivir, pues pasa a ser la propiedad de ellos; todo esto se entiende siempre, por cierto, de acuerdo a la sentencia adjudicatoria de la autoridad estatal (...) Todo aquel que ha suscrito el contrato ciudadano tiene un derecho absoluto a exigir ayuda" $" 10$.

Este derecho es, sin embargo, estrictamente subsidiario, pues "nadie tiene derecho a la ayuda del Estado antes de haber probado que él, en su esfera, ha hecho todo lo posible para su auto conservación y que, a pesar de ello, no le ha resultado posible"111. En la concepción de Fichte hay dos aspectos particularmente destacables. En primer lugar, que los derechos de necesidad no constituyen una suspensión parcial de la vigencia del orden estatal sino,

${ }^{108}$ PUFENDORF, De Jure Belli ac Pacis, cit. nota n 103, Lib. II, Cap. VI, § 2, p. 238: "Unde necessitas non id quidem efficit, ut directe lex heic et nunc possit violari, seu peccatum admitti; sed ex benevola legislatorum mente, simulque naturae humanae consideratione praesumitur, casum neccessitatis sub lege generaliter concepta non contineri" (disponible en https://archive.org/stream/samuelispufendor1672pufe\#page/238/mode/ 2up).

${ }^{109}$ KANT, Metaphysik der Sitten, cit. nota ${ }^{\circ}$ 86, p. 236.

110 FICHTE, Johann Gottlieb, Grundlage des Naturrechts nach Principien der Wissenschaftslehre, Hamburgo, Verlag Felix Meiner, reimpresión sobre la base de la 2a edición de 1922 a cargo de MEDICUS, F., 1979, p. 207.

${ }^{111}$ FICHTE, Grundlage, cit. nota n 110, p. 208. 
VAN WEEZEL, Alex. "Optimización de la autonomía y deberes penales de solidaridad”.

por el contrario, un caso paradigmático de su aplicación, precisamente porque la comunidad ha adoptado previamente las medidas del caso, es decir, porque la ayuda en la necesidad es una cláusula del "contrato social". En segundo lugar, la solidaridad en Fichte es, como apunta Renzikowski, una "relación triangular"112: la contribución solidaria es realizada directamente por el ciudadano para con el necesitado y, al mismo tiempo, en la forma de un aporte al Estado para que este cumpla con su función de protección. El Estado de Fichte no agrupa a individuos que existen desvinculados uno junto al otro, sino que la solidaridad recíproca forma parte de sus condiciones constitutivas.

Para concluir este breve recorrido es preciso volver a la concepción que probablemente ha ejercido mayor influencia en la comprensión del estado de necesidad justificante desde su formulación hasta la actualidad. En el pasaje ya citado de GL § 127, Hegel expone en los siguientes términos del derecho de necesidad:

"La particularidad de los intereses de la voluntad natural, tomados conjuntamente en su simple totalidad, es la existencia personal en cuanto vida. Esta, en el máximo peligro y en la colisión con la propiedad conforme a derecho de otro, posee un derecho de necesidad (no como gracia, sino como derecho), en donde por un lado está la lesión infinita de la existencia y con ella la total ausencia de derecho, y por el otro lado solamente la lesión de una única y limitada existencia de la libertad. En el ejercicio de este derecho se reconoce al mismo tiempo el derecho en cuanto tal y la capacidad jurídica de aquel que resulta afectado solamente en esta propiedad puntual”.

Con otras palabras, el estado de necesidad con peligro vital es un caso donde la privación de la vida del necesitado afecta al derecho en cuanto tal, mientras que la afectación de la propiedad incide solo en una forma limitada de existencia de la libertad. No se trata, pues, de una ponderación de bienes o males, sino de que la vida -como dimensión real de la personalidad- tiene un derecho verdadero y preferente frente al derecho formal.

Hay dos asuntos que Hegel deja sin una respuesta explícita. Por una parte, no resuelve el problema del ordo amoris, es decir, qué deberes tienen preferencia frente a otros. Sin embargo, en GL § 127, sobre el estado de necesidad, reconoce el derecho, no la gracia, a afectar el patrimonio ajeno para salvar la propia vida. Si bien con esta especificación se elude el caso más difícil -el conflicto entre bienes equivalentes-, sí se dice algo relevante sobre la jerarquía de los deberes, a saber, que bajo ciertas circunstancias prima el deber de solidaridad por sobre el deber negativo. El agente de necesidad puede afectar la propiedad de uno para socorrer a otro. Por lo tanto, según Hegel no existe una jerarquía absoluta entre las tres clases de deberes.

Por otro lado, Hegel no se pronuncia explícitamente acerca de si el derecho de necesidad se restringe a las afectaciones de la propiedad, o si alcanza a todas las demás posiciones jurídicas, incluso a la integridad corporal, en la medida en que la acción de salvaguarda a su

${ }^{112}$ RENZIKOWSKI, Joachim, "Solidarität in Notsituationen”, cit. nota n 50, p. 29. 
Polít. crim. Vol. 13, Nº 26 (Diciembre 2018) Art. 12, pp. 1074-1139.

[http://www.politicacriminal.cl/Vol_13/n_26/Vol13N26A12.pdf]

vez no conduzca a la pérdida de la vida de quien sufre sus consecuencias y, con ello, a su exclusión del derecho. No obstante, el contexto de sus reflexiones, en especial GL $\S 126$ y la ya mencionada condena de San Crispín, no dejan a mi juicio espacio para dudas en cuanto al absoluto carácter restrictivo del derecho de necesidad en Hegel: afectación de la propiedad para la salvaguarda de la vida. Una extensión solo sería concebible en términos muy próximos a esta hipótesis de base.

Las reglas legales vigentes en Chile y que resultan pertinentes se mantienen rigurosamente en la línea de esta tradición. En primer lugar, la figura del artículo $494 \mathrm{~N}^{\circ} 14 \mathrm{CP}$ define consistentemente los presupuestos de surgimiento de la posición de garante exigiendo que el necesitado se encuentre "herido, maltratado o en peligro de perecer"; que además se halle "en despoblado", es decir, sin posibilidad real de recibir ayuda que no provenga del transeúnte en cuestión; y que este pueda socorrerlo "sin detrimento propio", sin siquiera limitar expresamente esta condición negativa a un detrimento o menoscabo de cierta entidad.

Lo mismo ocurre en el caso del estado de necesidad agresivo del artículo $10 \mathrm{~N}^{\circ} 7 \mathrm{CP}$. La regla autoriza la afectación de la propiedad ajena para la salvaguarda de un bien "mayor" y siempre que no haya otro medio practicable y menos perjudicial para procurar dicha salvaguarda. Aunque no se establece una limitación en cuanto a los bienes susceptibles de rescate -la ley habla simplemente de la evitación de "un mal"-, la limitación de las posibilidades de afectación a la propiedad ajena establece un estándar que armoniza con la tradición descrita previamente pero incorpora, además, una regla para la resolución de conflictos cotidianos de menor entidad.

El estado de necesidad contemplado en el artículo $10 \mathrm{~N}^{\circ} 11 \mathrm{CP}$, en cambio, escapa a esta lógica cuando acepta el sacrificio de un bien mayor que el que se salva. Ello obliga a revisar en profundidad los fundamentos de la institución legal, que podría parecer refractaria a una interpretación en clave de justificación y, más aún, a una que dé cabida al estado de necesidad agresivo en su ámbito de aplicación. Esta regla y sus relaciones con el artículo $10 \mathrm{~N}^{\circ} 7 \mathrm{CP}$ serán objeto de análisis en la sección siguiente.

\subsubsection{Breve recapitulación y conclusiones intermedias}

De lo expuesto es posible concluir que la posición de garante fundada en deberes de solidaridad solo puede surgir para el resguardo inmediato de la vida o ante amenazas muy graves e irrevocables de la autonomía del actualmente necesitado. Por otro lado, el cumplimiento del deber solo puede requerir el sacrificio de bienes instrumentales cuya pérdida no implique un sacrificio grave o irreparable de la autonomía del obligado.

Asimismo, y recapitulando lo señalado en el apartado anterior, la heteronomía que por definición caracteriza a los deberes de solidaridad determina que su estatus sea inferior al 
VAN WEEZEL, Alex. "Optimización de la autonomía y deberes penales de solidaridad".

de los deberes negativos y positivos. Tal estatus subordinado excluye el establecimiento de una responsabilidad por el resultado y obliga a asignar penas considerablemente inferiores en caso de infracción.

En el ordenamiento chileno, la gravedad relativa de las infracciones al deber de solidaridad se encuentra definida en la falta de omisión de socorro del artículo $494 \mathrm{~N}^{\circ} 14$. En la medida en que el deber de solidaridad que fundamenta el deber de tolerancia en el estado de necesidad agresivo ostenta el mismo fundamento, la infracción a este deber solo puede ser sancionada en los mismos términos que la omisión de socorro, que constituye la lex specialis en la infracción de deberes de solidaridad, como lo es el artículo 390 CP respecto de los atentados contra la vida de ciertos parientes. De lo contrario se produciría una distorsión valorativa intolerable para el sistema, pues dos situaciones estructuralmente idénticas recibirían, sin justificación alguna, un tratamiento diverso.

Así, quien impide que un objeto de su propiedad sea utilizado por un tercero para auxiliar a una persona, como consecuencia de lo cual las heridas que esta ha sufrido se agravan, solo puede responder hasta el límite de la omisión de socorro. En efecto, una vez que se ha desactivado la norma prohibitiva en virtud de la causa de justificación, la conducta del afectado por la acción de salvaguarda se enjuicia directamente a partir de su contraste con las normas de conducta que protegen el bien amenazado y sus presupuestos de aplicación. Entre estos presupuestos se encuentra la competencia del afectado rebelde por la evitación del daño, que en el estado de necesidad agresivo se funda precisamente en un deber de solidaridad. Este fundamento de competencia determina la aplicación de la lex specialis, lo cual traslada la hipótesis de subsunción, en el ejemplo, desde el artículo 397 CP hacia el artículo $494 \mathrm{~N}^{\circ} 14 \mathrm{CP}$, cuyos presupuestos típicos, en el caso del mismo ejemplo, no se verificarán ${ }^{113}$.

En estos casos el deber de garante es de menor intensidad, pero existe. Por eso el afectado por la acción de salvaguarda rebelde puede ser obligado a prestar ayuda, o a tolerar que se ayude a su costa, por la vía de considerar, por ejemplo, su inactividad o rebeldía como una forma de agresión ilegítima. Por la misma razón -la posición de garante en virtud de un deber de solidaridad existe y debe ser tomada en serio-, en cada caso será preciso

${ }^{113}$ Este problema es el que subyace a ciertos planteamientos de Baldó (BALDÓ LAVILLA, Estado de necesidad y legítima defensa, cit. nota $\mathrm{n}^{\circ} 32$, pp. 232 y ss.) que fueron desarrollados luego por Silva Sánchez (SILVA SÁNCHEZ, Jesús-María, "Notstandsrechte und Duldungspflichtverletzung”, en GA 2006, pp. 382 y ss.). Como el estado de necesidad agresivo se funda en un deber de solidaridad, quien frustra la acción de salvamento sin abandonar para ello su propia esfera de derechos - por ejemplo, el dueño se aleja en el único bote que otro estaba desatando para salvar a una persona que se ahoga-, debería ser castigado como autor de una omisión de socorro. Silva constata, sin embargo, que según la gran mayoría de los autores el sujeto incurre en una responsabilidad por el delito de resultado, pues su conducta constituye la interrupción de un curso causal salvador, al menos en todos aquellos casos en que ya se inició el salvamento (y siempre que no se esté ante una conducta neutral). Es decir, en casos como el del ejemplo se habría producido una genuina violación del deber negativo de no dañar. Ante la pregunta sobre por qué el afectado rebelde se habría arrogado una esfera de organización ajena, responde Silva con una teoría dinámica de las esferas de derechos, las cuales se relacionan e interfieren entre sí, en conjunto con argumentos basados en la idea de incremento del riesgo. 
determinar cómo inciden en la imputación objetiva de la conducta los institutos dogmáticos correspondientes: riesgo permitido, principio de confianza, prohibición de regreso y actuación a riesgo propio. Así, por ejemplo, la posición de garante resultará desactivada cuando el necesitado rechaza la ayuda que se le ofrece, o cuando la situación de necesidad le es imputable y él está en condiciones de ayudarse a sí mismo.

No obstante, el carácter limitado de los deberes de garante por solidaridad debe necesariamente dejar casos sin resolver desde el punto de vista del sentimiento jurídico. Consideremos el siguiente ejemplo: A va caminando por la calle mientras habla por su teléfono celular cuando B se accidenta gravemente. $\mathrm{C}$ quiere usar el celular de A para llamar a la ambulancia, pero A se niega a entregárselo y lo guarda en su pecho bajo la camiseta ¿Puede legítimamente $\mathrm{C}$ arrebatarle por la fuerza el celular? En este caso ya no se trata de la afectación de la propiedad u otro interés instrumental, sino de la inviolabilidad del cuerpo. Las limitaciones analizadas obligan a responder la pregunta en términos negativos.

Como contrapartida, el modelo aquí presentado deja a salvo la estructura tripartita de los deberes de conducta con relevancia penal, conservando así sus beneficios en cuanto a optimización de la autonomía. Al mismo tiempo, sin embargo, confiere a los deberes de solidaridad un estatuto relativamente autónomo de base intersubjetiva, incorporando en el sistema los fundamentos de una jerarquía de los deberes que armoniza la autonomía con sus presupuestos institucionales y evitando los inconvenientes de su estatalización. El modelo explica también de un modo más claro el carácter evolutivo de los deberes de solidaridad como "moralización del derecho" en el sentido de las GL y, por lo mismo, abre los espacios sistemáticos necesarios para una paulatina revisión de aquel ordo. Finalmente, el modelo tiene la ventaja de que explica la racionalidad de las instituciones positivas basadas en deberes de solidaridad, pero dejándolas en su lugar.

\section{El estado de necesidad en el Código Penal}

\subsection{Los principios de la justificación}

Si se revisa desde el punto de vista histórico, dogmático y jurisprudencial el estatuto de los derechos de defensa y necesidad, se descubre que su "gramática" consta de tres variables principales, cuya combinación da lugar a regímenes de justificación bien diferentes. Estas tres variables, expresadas en términos muy generales, son la autonomía o autorresponsabilidad, la consideración del otro o de la generalidad, y una ponderación de bienes (o, mejor dicho, de males).

La autorresponsabilidad designa la competencia del afectado por la intervención justificada respecto de la situación que exige la intervención. Los ejemplos más extremos corresponden al ámbito de la legítima defensa -el dueño del perro de raza lo azuza contra el 
VAN WEEZEL, Alex. “Optimización de la autonomía y deberes penales de solidaridad”.

valioso jarrón de su vecino- $\mathrm{y}$, de otra parte, el estado de necesidad agresivo, donde el afectado nada tiene que ver con la situación de riesgo: Un hincha va huyendo de la barra brava que lo persigue y, para ponerse a salvo, ingresa por la fuerza en la casa de un tercero, el cual lo repele, como consecuencia de lo cual el hincha sufre graves lesiones a manos de la barra del equipo rival.

La consideración del (bienestar del) otro o de la generalidad -brevemente, si se quiere: "solidaridad" en un sentido muy amplio- designa la integración de elementos no individualistas en la valoración de la conducta. La integración de estos elementos puede obedecer a diversos fundamentos, desde los discursos más colectivistas -como el del utilitarismo- hasta propuestas sofisticadamente liberales, como las que se apoyan en una cierta concepción del contrato social ${ }^{114}$. Esta consideración del otro o de la generalidad se manifiesta, por ejemplo y según doctrina dominante, en la exigencia de que el medio para impedir o repeler la agresión sea "racionalmente necesario", en la legítima defensa. Por otro lado, la misma posibilidad de considerar un estado de necesidad agresivo con efectos justificantes obedece, como se ha visto, a la consideración del otro como sujeto moral con derecho al bienestar en la distribución de ámbitos de competencia.

La tercera variable es la ponderación de bienes o males en la lógica del "mal menor". Como es sabido, incluso planteamientos muy fuertemente deontológicos ${ }^{115}$ reconocen esta lógica del mal menor cuando los principios han agotado su capacidad de rendimiento.

Al observar con atención estas tres variables, se aprecia que las dos primeras responden cabalmente a los fundamentos de la responsabilidad personal por un hecho, es decir, se trata de fundamentos positivos de la ilicitud de la conducta en general. La autorresponsabilidad funda precisamente los denominados deberes negativos, característicos de las formas más básicas de interacción entre personas. La consideración de la generalidad, por su parte, se presenta como una responsabilidad básica para con la sociedad (como abreviatura de una responsabilidad socialmente mediada para con el otro), cuyo objetivo es garantizar las instituciones indispensables para la convivencia en libertad y da lugar a los deberes positivos. La consideración del bienestar del otro da origen a los deberes de solidaridad.

Es útil detenerse en esta reaparición de los fundamentos de toda ilicitud con relevancia penal -deberes negativos, deberes positivos y deberes de solidaridad- en el plano de la justificación. Los mismos elementos o categorías que aparecen con un signo positivo en la tipicidad -es decir, como presupuestos positivos del injusto-, adquieren un signo negativo en el examen de las causas de justificación. Así, por ejemplo, en la legítima defensa es al mismo agresor a quien se imputa la situación de peligro y, por lo tanto, es él quien debe correr con todos los costos del aseguramiento del bien. El que se defiende ejecuta, para

\footnotetext{
${ }^{114}$ Referencias supra en notas $\mathrm{n}^{\circ} 3 \mathrm{y} \mathrm{n}^{\circ} 4$.

115 Cfr. RHONHEIMER, Die Perspektive der Moral, cit. nota n 77, pp. 332 y ss.; SPAEMANN, Robert, Glück und Wohlwollen, Stuttgart: Klett-Cotta, 1988, pp. 157 y ss.
} 
decirlo de un modo gráfico y tradicional a la vez ${ }^{116}$, un negocio del agresor, actúa en su esfera o ámbito de organización.

Esta forma de ver las cosas manifiesta una vez más el carácter subordinado de la tercera variable, pues su relevancia y consistencia depende por completo de la definición previa de competencias positivas y su exclusión. La ponderación de bienes o males solo cumple una función cuando ya se ha determinado, a través de las otras dos variables, qué función debe cumplir. Porque el afectado no es competente por la situación de necesidad es que el art. 10 $\mathrm{N}^{\circ} 7 \mathrm{CP}$ solo autoriza a que se afecte su propiedad, y siempre que sea para evitar un mal mayor. Porque el afectado es competente en cuanto agresor ilegítimo es que el art. $10 \mathrm{~N}^{\circ} 4$ $\mathrm{CP}$-que regula la legítima defensa- es, en principio, indiferente a la ponderación de bienes o males. Tanto en el plano de los presupuestos positivos de la ilicitud como en el plano de la justificación se trata de un asunto de distribución de ámbitos de autonomía y, por lo tanto, de responsabilidad. Por eso, por ejemplo, el estado de necesidad agresivo no tiene su fundamento en el balance final positivo ${ }^{117}$, sino en el derecho al bienestar mínimo del sujeto moral, reconocido por el Estado, que prima por sobre el derecho de propiedad de la personalidad abstracta.

De esto mismo se deriva que el sistema legal de los derechos de necesidad no puede terminar nivelando situaciones que son radicalmente distintas entre sí. En el ámbito del estado de necesidad, por ejemplo, no puede existir una misma regla que comprenda desde el caso del perro amenazante que se escapa a pesar de que se observaron todas las medidas de cuidado, hasta el caso en que el perro se escapa debido a un descuido grave de su dueño. O bien: desde el caso en que el conductor pierde el control del vehículo porque queda inconsciente debido a un ataque cardiaco, hasta el del conductor que pierde el control del vehículo debido a su temeridad en la conducción. Si se concede la justificación al amenazado por el peligro -o al que actúa en su favor- en las hipótesis respectivamente iniciales, entonces el componente de consideración del otro o de la generalidad envuelto en el sacrificio que se exige al afectado por la acción de salvaguarda es incomparablemente mayor. Y si esto es así, entonces la diferencia debe reflejarse necesariamente en la ponderación de bienes o males, que es la tercera y subordinada variable, con lo cual se da origen a una regla adicional.

Entonces, si los estados de necesidad defensivos (END) son causas de justificación que se basan en el principio de autorresponsabilidad respecto del riesgo que dio origen a la intervención justificada; si, por lo tanto, una conducta estará justificada cuando es la reacción proporcionada ante un riesgo por el cual es de algún modo responsable el que resulta afectado por esa conducta de salvaguarda del bien; entonces, el espectro

116 Cfr. verse WILENMANN, La justificación de un delito, cit. nota $\mathrm{n}^{\circ}$ 30, pp. 161 y ss., con abundantes referencias.

${ }^{117}$ Con ello abandono la opinión expresada en van WEEZEL, "Necesidad justificante y solidaridad", cit. nota $\mathrm{n}^{\circ} 31$, p. 228. 
VAN WEEZEL, Alex. "Optimización de la autonomía y deberes penales de solidaridad”.

justificatorio en cada caso dependerá primariamente del grado de competencia por la situación de riesgo y, secundariamente, de una ponderación de los respectivos menoscabos. Si el que sufre las consecuencias de la intervención es personalmente competente y además culpable por la situación de riesgo, pero sin que su creación llegue a constituir una agresión ilegítima, el sujeto debe soportar todos los costos de la intervención de salvaguarda, e incluso está permitido sacrificar más de lo que se salva. Solo se requerirá que no exista una desproporción considerable entre el menoscabo producido y el evitado, y siempre bajo un régimen de subsidiariedad. Este END 1 es una verdadera "pequeña legítima defensa".

Si el que sufre las consecuencias de la intervención es, en cambio, personalmente competente pero no culpable por la situación de riesgo, la acción típica de salvaguarda no estará justificada, a menos que el menoscabo producido por la reacción sea superior al menoscabo evitado en el interés que se salva. El balance debe ser positivo, aunque sea por poco. Desde luego hay también aquí una exigencia de subsidiariedad, y al respecto puede ser útil buscar orientación en el derecho civil ${ }^{118}$. Este END 2 es un "arreglo institucional" a favor del mal menor en caso de conflicto irresoluble y bajo ciertas restricciones.

Una concepción como esta del estado necesidad permite descargar la legítima defensa de una serie de hipótesis en que no puede hablarse de agresión ilegítima en un sentido penalmente relevante y donde, por lo mismo, la amplitud de las autorizaciones que concede esa causa de justificación resulta excesiva, lo que redunda en la búsqueda más o menos inorgánica de correctivos.

En este sentido, cumpliéndose los demás requisitos quedarían cubiertas por el estado de necesidad defensivo justificante las intervenciones:

- contra el sujeto que actúa u omite dentro del riesgo permitido, atípica o incluso justificadamente (en este último caso, no respecto del daño específico que está autorizado a producir), pero creando con su conducta un peligro actual para los intereses de un tercero;

- contra el sujeto que actúa creando un riesgo especial, como la conducción de un vehículo motorizado (por ejemplo, en el caso del que a causa del hielo pierde el control del auto y amenaza atropellar a un peatón, el cual solo se salva porque un camionero atraviesa su vehículo, provocando la muerte del conductor del auto);

- contra el sujeto que actúa u omite en error -cuando menos en error invencible; por ejemplo, el enfermero que por instrucciones del médico va a inyectar al paciente incorrecto- o lo hace de otro modo individualmente inevitable;

- en los casos en que el peligro proviene de la conducta de un inimputable o de un menor de edad;

\footnotetext{
${ }^{118}$ Por ejemplo, en las reglas de responsabilidad por el peligro, como en el caso del daño causado por un animal fiero: artículo 2327 del Código Civil.
} 
Polít. crim. Vol. 13, Nº 26 (Diciembre 2018) Art. 12, pp. 1074-1139.

[http://www.politicacriminal.cl/Vol_13/n_26/Vol13N26A12.pdf]

- en los casos en que el sujeto de quien emana el peligro actúa coaccionado o bajo circunstancias que le hacen inexigible otra conducta (siempre que no haya agresión ilegítima de su parte).

Más discutible es el régimen de las intervenciones que consisten en una defensa anticipada, cuando la necesidad de anticiparla se debe precisamente a la conducta del afectado por la intervención, como en algunas hipótesis de homicidio del tirano doméstico ${ }^{119}$. En estos casos de defensa anticipada el principal obstáculo para la aplicación de la eximente podría estar en un requisito común a los derechos de necesidad, la actualidad o inminencia de la amenaza. Por lo tanto, probablemente la solución pasa por una previsión legislativa expresa.

El estado de necesidad agresivo (ENA), en cambio, se basa en consideraciones diversas de la autorresponsabilidad. Bajo su amparo se afectan los bienes de una persona para proteger bienes de otras personas o de la sociedad que prevalecen sobre los bienes sacrificados, pero el afectado no es en absoluto competente por la situación de riesgo. Por eso, para que la intervención que causa daño se encuentre justificada se requiere que lo positivo sea muy preponderante respecto de lo negativo y que el sacrificio se mantenga dentro de límites muy acotados: no puede afectar severa ni permanentemente la autonomía del que padece la intervención.

En la opinión predominante, el ENA no se encuentra simplemente limitado por consideraciones de solidaridad, sino que se basa precisamente en ella ${ }^{120}$. Esto no es correcto, pues tanto los fundamentos positivos de la antijuridicidad como los fundamentos de su exclusión constituyen criterios de distribución de autonomía o ámbitos de responsabilidad. El ENA no se basa en una ponderación de bienes o males, sino en el derecho al bienestar mínimo del sujeto moral, reconocido por el Estado, que prima por sobre el derecho de propiedad de la personalidad abstracta. La limitación de su alcance no obedece a un supuesto carácter anómalo de la institución, sino a los dos factores ya analizados: la heteronomía en el origen de la obligación y los presupuestos estrictos bajo los cuales el derecho vigente acepta el surgimiento de una posición de garante por solidaridad.

La combinación de las tres variables revisadas da lugar a un modelo de las causas de justificación en comentario que se aparta de la tripartición tradicional -y desde luego, de la

${ }^{119} \mathrm{Al}$ respecto, van WEEZEL, Alex, "Caso del agresor dormido. El problema del 'tirano doméstico' ", en VARGAS, Tatiana (dir.), Casos Destacados. Derecho Penal (Parte General), Santiago: Thomson Reuters, 2015, pp. 337-356.

${ }^{120}$ NEUMANN, Ulfrid, "Die rechtsethische Begründung des 'rechtfertigenden Notstands' auf der Basis von Utilitarismus, Solidaritätsprinzip und Loyalitätsprinzip”, en von HIRSCH; NEUMANN; SEELMANN (eds.), Solidarität im Strafrecht, cit. nota ${ }^{\circ} 2$, pp. 155-173. 
VAN WEEZEL, Alex. “Optimización de la autonomía y deberes penales de solidaridad”.

bipartición usual entre nosotros-, principalmente porque requiere identificar dos estados de necesidad defensivos en lugar de uno solo.

La siguiente tabla completa el esquema presentado anteriormente, indicando las correspondientes causas de justificación ( $\mathrm{LG}=$ legítima defensa; END $1=$ estado de necesidad defensivo con competencia personal por el peligro -pequeña legítima defensa-; END 2= estado de necesidad defensivo sin competencia personal por el peligro; ENA= estado de necesidad agresivo):

\begin{tabular}{c|c|c|c} 
A 3-S 0 & A 2 - S 1 & A 1 - S 2 & A 0 - S 3 \\
\hline $\begin{array}{c}\text { No } \\
\text { total } \\
\text { desproporción }\end{array}$ & $\begin{array}{c}\text { No } \\
\text { grave) } \\
\text { desproporción }\end{array}$ & $\begin{array}{c}\text { Balance } \\
\text { (sustancialmente) } \\
\text { positivo }\end{array}$ & $\begin{array}{c}\text { Balance } \\
\text { absolutamente } \\
\text { positivo }\end{array}$ \\
\hline LG & END 1 & END 2 & ENA
\end{tabular}

\subsection{El estado de necesidad justificante en el Código Penal}

El Código Penal contiene dos reglas directamente relacionadas con el estado de necesidad, el $\mathrm{N}^{\circ} 7$ y el $\mathrm{N}^{\circ} 11$ del artículo $10 \mathrm{CP}$. La amplitud del alcance de este último -que data de 2010 - obliga a desentrañar primero las distintas posibilidades contenidas en el artículo 10 $\mathrm{N}^{\circ} 11 \mathrm{CP}$, para luego indagar si la subsistencia del artículo $10 \mathrm{~N}^{\circ} 7 \mathrm{CP}$ tiene un sentido aprovechable. Según se verá, la clase de contenido que es propio de las circunstancias $3^{\mathrm{a}}$ y $4^{\mathrm{a}}$ del artículo $10 \mathrm{~N}^{\circ} 11$ y el carácter graduable de las valoraciones que subyacen a ellas, hacen posible que en la misma regla estén incluidas las tres causas de justificación asociadas a situaciones de necesidad.

\subsubsection{El artículo $10 \mathrm{~N}^{\circ} 11$ contiene los estados de necesidad justificantes}

Antes de examinar los requisitos generales de la exención de responsabilidad prevista en el artículo $10 \mathrm{~N}^{\circ} 11 \mathrm{CP}$ es necesario, sin embargo, detenerse brevemente en una cuestión elemental: cuáles son las razones para sostener, como aquí se hace, que este precepto no contiene el estado de necesidad exculpante, ${ }^{121}$ sino las reglas de justificación basadas en derechos de necesidad.

${ }^{121}$ Podría considerarse mayoritaria entre nosotros la opinión de que el artículo $10 \mathrm{~N}^{\circ} 11 \mathrm{CP}$ contiene el estado de necesidad exculpante. En este sentido ya HERNÁNDEZ, en COUSO; HERNÁNDEZ, Código Penal Comentado. Parte General, cit. nota n 35, pp. 266 y ss.; igualmente MAÑALICH, Juan Pablo, "El estado de necesidad exculpante. Una propuesta de interpretación del artículo $10 \mathrm{~N}^{\circ} 11$ del Código Penal chileno", en van WEEZEL, Alex (ed.), Humanizar y renovar el derecho penal. Estudios en memoria de Enrique Cury, Santiago: Thomson Reuters, 2013, pp. 715 y ss. (pp. 718 y ss.); CASTILLO, Juan Pablo, "El estado de necesidad del artículo $10 \mathrm{n}^{\circ} 11 \mathrm{del}$ Código penal chileno: ¿Una norma bifronte? Elementos para una respuesta negativa", en Política Criminal, Vol. 11, N 22 (2016), pp. 340-367; WILENMANN, La justificación de un delito, cit. nota $\mathrm{n}^{\circ} 30$, pp. 457 y s. Junto a este planteamiento está el de quienes sostienen que se trataría de una regla bifronte, que opera como causa de justificación (en caso de balance positivo) o de exculpación (en caso de balance negativo). En tal sentido CURY, Enrique, "El estado de necesidad en el Código Penal 
a) En primer lugar, interpretar la regla como causa de exculpación equivale a entregar una "patente de corso" para la perpetración de afectaciones muy relevantes a los derechos e intereses de personas completamente ajenas al conflicto en que se encuentra el autor. Una vez suprimida - ni siquiera reducida o rebajada- la barrera de la "insuperabilidad" o “irresistibilidad" que impone el artículo $10 \mathrm{~N}^{\circ} 9 \mathrm{CP}$, se arroja de lleno el conflicto al juego entre una gruesa ponderación de intereses y la vaga referencia, en la circunstancia $4^{\mathrm{a}}$, a la "razonable exigibilidad" de un "sacrificio" que, jurídicamente hablando, no es otra cosa que la contrapartida del dominio sobre el objeto en cuestión, incluyendo todos los beneficios y las cargas que este conlleva.

Interpretando la regla como causa de exculpación habría que eximir de responsabilidad al médico que, para mejorar la posición de sus pacientes en la lista de espera de receptores de órganos, falsea las fichas médicas agravando su condición. También habría que considerar exento de responsabilidad al administrador de fondos de inversión que ha tenido grandes pérdidas en algunos y ganancias en otros y que, para evitar la debacle de su negocio, realiza operaciones ficticias entre ellos que le permiten compensar las pérdidas (el caso podría considerar, incluso, que las operaciones perjudican a muchos en poco, para salvar la estabilidad económica del administrador y sus dependientes). Lo mismo valdría para pequeños productores atomizados que deciden ponerse de acuerdo en los precios de venta para no sucumbir ante la competencia extranjera o no verse seriamente perjudicados por una contraparte oligopsónica.

Una interpretación de la eximente desde la lógica de la exculpación la convierte en un traje a la medida de quienes optan racionalmente por desplazar sus propias contingencias hacia terceros, en especial en el ámbito patrimonial y económico, pero también respecto de bienes personalísimos. En todos estos casos será excusable realizar tal desplazamiento, incluso si se causa un mal mayor que el que se evita, con tal de que la diferencia no sea sustancial. Todo ello, además, como resultado de un cálculo frío y sosegado, en una especie de consagración legislativa del maquiavelismo.

chileno", en MAÑALICH, J. P. (coord.), La ciencia penal en la Universidad de Chile. Libro Homenaje a los Profesores del Departamento de Ciencias Penales de la Facultad de Derecho de la Universidad de Chile, Santiago: Facultad de Derecho Universidad de Chile, 2013, pp. 249-266; VARGAS, Tatiana; SANTIBÁÑEZ, María Elena, "Reflexiones en torno a las modificaciones para sancionar el femicidio y otras reformas relacionadas (Ley n ${ }^{\circ} 20.480$ )", en Revista Chilena de Derecho, Vol. 38 № 1 (2011), pp. 193-207; ACOSTA, Juan Domingo, "Artículo 10 Nos. $7^{\circ}$ y $11^{\circ}$ del Código Penal. Algunos criterios de delimitación", en van WEEZEL (ed.), Humanizar y renovar el derecho penal, loc. cit., pp. 691 y ss.; VARGAS, Tatiana, "¿Tiene la necesidad cara de hereje? Necesidad justificante y exculpante a la luz del artículo $10 \mathrm{~N}^{\circ} 11$ ", en van WEEZEL (ed.), Humanizar y renovar el derecho penal, loc. cit., pp. 743 y ss.; similar VIDAL, Víctor, "Análisis de las características más relevantes del estado de necesidad establecido por la ley 20.480", en Ars Boni et Aequi (Año 9, $\mathrm{N}^{\circ} 2$ 2, 2013), pp. 237 y ss. 
VAN WEEZEL, Alex. "Optimización de la autonomía y deberes penales de solidaridad”.

b) Aunque el estado de necesidad exculpante no se reduce a ella, uno de sus fundamentos es la inexigibilidad de la conducta conforme a derecho. El contexto en que el sujeto actúa es tan anormal, que la realización de la conducta típica no constituye una toma de posición frente a la norma que sea capaz de desestabilizarla. El hecho no constituye el esbozo de un orden diverso, susceptible de generalización, sino que da cuenta de un conflicto existencial y se explica solo desde sus circunstancias, lo que permite un procesamiento de la situación al margen del derecho penal.

En este contexto, la circunstancia $4^{\mathrm{a}}$ del artículo $10 \mathrm{~N}^{\circ} 11 \mathrm{CP}-$ "que el sacrificio del bien amenazado por el mal no pueda ser razonablemente exigido al que lo aparta de sí"- carece de sentido, pues se limitaría a señalar que "la conducta conforme a derecho es exigible cuando es exigible"; o bien: "no se reconoce inexigibilidad cuando al sujeto se le pudo exigir otra conducta". Una posibilidad, sugerida por Hernández ${ }^{122}$, Mañalich ${ }^{123}$ y Castillo ${ }^{124}$, es interpretar esta cláusula siguiendo el tenor del § $35 \mathrm{I}$, segunda parte StGB, es decir, entendiendo que fracasa la exculpación cuando el mismo necesitado es quien ha causado el peligro o se encuentra en una particular posición jurídica que le obliga a tolerarlo. Bajo esta inteligencia, la circunstancia $4^{a}$ no solo no sería redundante, sino que sería "la parte más rica de la norma desde el punto de vista de las posibilidades que ofrece su interpretación". ${ }^{125}$

Un examen más detenido sugiere, sin embargo, que no es así. La cláusula de inexigibilidad en el § 35 I, segunda parte, StGB no constituye una remisión genérica a una "situación de inexigibilidad", sino que establece criterios definidos para hacer operativa una subexcepción de la excepción, como apunta Weigend ${ }^{126}$. Es cierto que, a primera vista, la regla del § $35 \mathrm{I}$, segunda parte StGB no se encuentra en un nivel inferior respecto de la regla del $\S 35 \mathrm{I}$, primera parte $\mathrm{StGB}$, pues se trata de reglas complementarias; ambas podrían formularse conjuntamente del siguiente modo: "Cuando la aceptación del peligro según el inciso I sea exigible, entonces no se configura la excusa". Sin embargo, las hipótesis del inciso I, segunda parte, no constituyen la mera explicitación de un principio general de inexigibilidad, pues en tal caso su mera concurrencia impediría realizar cualquier otra consideración o ponderación de exigibilidad, lo que no es efectivo, al menos según la amplia mayoría de los autores alemanes. ${ }^{127}$

\footnotetext{
${ }^{122}$ HERNÁNDEZ, en COUSO; HERNÁNDEZ, Código Penal Comentado. Parte General, cit. nota n 35, p. 274.

${ }^{123}$ Con mucha cautela MAÑALICH, "El estado de necesidad exculpante", cit. nota n 121, p. 740.

${ }^{124}$ CASTILLO, "El estado de necesidad del artículo $10 \mathrm{n}^{\circ} 11$ ", cit. nota $\mathrm{n}^{\circ} 121$, p. 354.

${ }^{125}$ CASTILLO, "El estado de necesidad del artículo $10 \mathrm{n}^{\circ} 11$ ”, cit. nota $\mathrm{n}^{\circ} 121$, p. 357.

${ }^{126}$ Así PERRON, Walter, en SCHÖNKE, Adolf; SCHRÖDER, Horst, Strafgesetzbuch, München: C. H. Beck, 29a ed., 2014, § 35, nn. 18 y ss.; JESCHEK, Hans-Heinrich; WEIGEND, Thomas, Strafrecht. Allgemeiner Teil, Berlin: Duncker \& Humblot, 1996, § 44 III 2; MOMSEN, Die Zumutbarkeit, cit. nota n 93 , p. 254.

${ }^{127}$ MOMSEN, Die Zumutbarkeit, cit. nota n ${ }^{\circ} 93$, pp. 253 y ss.
} 
En la clásica formulación de Blei ${ }^{128}$, la regla no dice que se niega la excusa si el autor ha provocado él mismo la situación de necesidad porque en tal caso se le puede exigir que soporte el peligro, sino que se niega la excusa cuando el autor ha provocado la situación de necesidad y si además se le puede exigir, atendidas las circunstancias del caso, que soporte el peligro. Esta interpretación obedece a la comprensión mayoritaria de que el inciso I, segunda parte, utiliza una técnica de ejemplos-regla ${ }^{129}$. Por lo tanto, la existencia de una particular relación jurídica y la causación del peligro no conducen necesariamente a la exclusión de la exigibilidad en el sentido del inciso I, segunda parte, pues, dependiendo de las circunstancias del caso concreto, podría perder eficacia el efecto previsto en abstracto para los ejemplos-regla ${ }^{130}$. La realización formal del tipo del ejemplo-regla puede ser compensada por circunstancias extraordinarias que sustraen nuevamente el caso del ámbito que los ejemplos-regla pretenden cubrir.

Nada de esto se encuentra presente en el artículo $10 \mathrm{~N}^{\circ} 11$, circunstancia $4^{\mathrm{a}}$, donde solo existe una referencia genérica a que, en ciertos casos no especificados en forma alguna, el "sacrificio" del bien amenazado por el mal puede ser razonablemente exigido al que lo aparta de sí. Como alusión genérica a la exigibilidad en una causa de exculpación basada en la exigibilidad, esta referencia es superflua, pues el análisis de la exigibilidad consiste precisamente en lo que el tenor de la circunstancia proclama. En consecuencia, la circunstancia $4^{\mathrm{a}}$ adquiere recién un sentido y deja de ser tautológica cuando se sitúa en un contexto de justificación y puede llenarse de contenido mediante la consideración de la competencia por el peligro o de un deber especial de hacerle frente.

c) La inexigibilidad de otra conducta da lugar a una excusa de carácter personalísimo a favor de quien se encuentra ante un irreductible conflicto existencial o de motivos. Esto no significa que el mal de cuya evitación mediante la conducta típica se trata tenga que amenazar necesariamente los bienes del mismo agente de necesidad. Como afirma Castillo, "la presencia en nuestra legislación penal de instituciones que efectivamente responden a una 'antropología individualista', no implica asumirla como una decisión definitiva y general a la que no sea posible hacer frente en el plano teórico y legislativo"131. Pero, en

${ }^{128}$ En detalle al respecto BERNSMANN, Klaus, Entschuldigung durch Notstand, Köln: Carl Heymans Verlag, 1989, pp. 136 y ss. Cfr. también STRATENWERTH, Günter, Strafrecht Allgemeiner Teil, Köln; Carl Heymans Verlag, $4^{\text {a }}$ ed. 2000, pp. 249 y s., quien en los casos de causación del peligro sugiere que al menos habría que completar la formulación legal con el "wenn und soweit" de Lenckner (véase PERRON, StGB $\S 35$, nn. 20 y 25 , cit. nota $\left.\mathrm{n}^{\circ} 126\right)$.

${ }^{129}$ HIRSCH, Joachim, en Strafgesetzbuch Leipziger Kommentar, Berlin: De Gruyter, $11^{\text {a }}$ ed. 1992, § 35, n. 48 , con ulteriores referencias.

${ }^{130}$ Cfr., por ejemplo, PERRON, StGB $\S 35$, n. 15, cit. nota ${ }^{\circ} 126$; ROXIN, Claus, Strafrecht Allgemeiner Teil, I, München: C. H. Beck, $4^{\text {a }}$ ed. 2006, § 35, nn. 20, 25. En el contexto del derecho español, pero coincidiendo en aplicar la categoría de la inexigibilidad también en los casos en que la posición del afectado le "obliga" a tolerar el mal COUSO, Jaime, Fundamentos del derecho penal de culpabilidad, Valencia: Tirant lo Blanch, 2006, pp. 527 y s.

${ }^{131}$ CASTILLO, "El estado de necesidad del artículo $10 \mathrm{n}^{\circ} 11$ ", cit. nota $\mathrm{n}^{\circ} 121$, p. 357; en el mismo sentido MAÑALICH, "El estado de necesidad exculpante", cit. nota n 121, p. 735. 
VAN WEEZEL, Alex. "Optimización de la autonomía y deberes penales de solidaridad".

todo caso, el conflicto existencial o de motivos debe existir en la persona del que resulta excusado y no (solo) en el afectado por el mal.

En contraste con lo anterior, el artículo $10 \mathrm{~N}^{\circ} 11$ concede la exención de responsabilidad cuando el mal amenaza los intereses de un tercero cualquiera, con el cual el agente de necesidad no tiene ninguna relación. Con ello, la referencia a un contexto de inexigibilidad en la realización de la conducta típica se pierde completamente. Por cierto que pueden verificarse casos de intensa empatía del agente con la situación de un tercero al cual le amenaza un mal grave, pero la eximente está construida de espaldas a esta posibilidad, que le resulta completamente indiferente. La total apertura de la eximente a la salvaguarda de intereses meramente instrumentales de terceros cualesquiera parece asimismo particularmente incompatible con una exculpación basada en un conflicto existencial o de motivos. Y que además se excuse, en este contexto, la causación de un mal mayor que el que se evita, parece todavía más exorbitante.

No se pretende sostener aquí que la salvaguarda de bienes ajenos en estado de necesidad exculpante deba restringirse a las hipótesis de proximidad formal o institucionalmente reconocida ${ }^{132}$. Pero la ausencia de toda vinculación, la prescindencia de toda alusión a algún elemento que permita concluir la existencia de un conflicto de motivos en el agente de necesidad, deja suspendida en el aire a la interpretación del artículo $10 \mathrm{~N}^{\circ} 11 \mathrm{CP}$ en clave de exculpación.

Es interesante constatar cómo incluso los más fervientes opositores a la exigencia doctrinal de una relación formal o institucional de proximidad para la aplicación del $\S 35 \mathrm{StGB}$, asumen que la excusa solo puede concederse allí donde existe alguna relación o vínculo preexistente que origina el conflicto de motivos (la compañera de trabajo, el compañero de deportes ${ }^{133}$ ), la cual, bajo ciertas condiciones, podría preferir a la relación de proximidad institucional. Cuando el argumento se lleva al extremo, sin embargo, pierde toda su plausibilidad. Así por ejemplo, Coninx considera evidente la solución del caso en que el sujeto, para salvar a un niño desamparado con el cual no tiene relación previa alguna, da muerte a su propio padre (quien no es responsable del mal que amenaza al niño). A su juicio, la opinión pública coincidiría en este caso con la valoración jurídica, pues consideraría como un verdadero héroe al que, para salvar al niño, sacrificó a su propio padre "y con ello a una parte de sí mismo"134. Es posible que esta valoración tenga sentido para algunas personas, pero no cabe duda de que para muchas otras resultará simplemente chocante. En todo caso, Coninx parte de la base de que el agente mismo obra en una situación de genuino conflicto existencial, algo que la historia e interpretación uniformes

\footnotetext{
${ }^{132}$ En tal sentido resultan convincentes los argumentos de MAÑALICH, "El estado de necesidad exculpante", cit. nota $\mathrm{n}^{\circ} 121$, pp. 735 y s. y, en el mismo sentido, de CONINX, "Restriktives Solidaritätsverständnis", cit. nota $\mathrm{n}^{\circ} 3$, pp. 123 y ss.

${ }^{133}$ Cfr. PERRON, StGB $\S 35$, n. 15, cit. nota ${ }^{\circ}$ 126; ROXIN, Claus, Strafrecht Allgemeiner Teil, I, München: C. H. Beck, $4^{\text {a }}$ ed. 2006 , p. 976.

${ }^{134}$ CONINX, "Restriktives Solidaritätsverständnis", cit. nota n 3, p. 124.
} 
Polít. crim. Vol. 13, Nº 26 (Diciembre 2018) Art. 12, pp. 1074-1139.

[http://www.politicacriminal.cl/Vol_13/n_26/Vol13N26A12.pdf]

del $\S 35$ StGB no permiten poner en duda. Por eso, junto con rechazar el criterio formalista, debería descartar la concesión de la eximente allí donde no concurre vínculo alguno entre el necesitado y el agente de necesidad ${ }^{135}$.

d) En el estado de necesidad exculpante, igual que en las demás causas de exculpación por inexigibilidad de otra conducta, el derecho se vuelve exclusivamente hacia el sujeto que ha realizado la conducta formalmente antijurídica. Se hace cargo de su particularidad y le concede una excusa extraordinaria aun a riesgo de poner en tela de juicio el tratamiento que el derecho le confiere en cuanto ser racional e igual a los demás. Al proceder de este modo, sin embargo, el derecho deja intactas las posiciones jurídicas de los demás. Por eso, la exculpación por inexigibilidad está más allá de la ponderación de intereses. Su límite no se encuentra -al menos, no directamente- en un cierto umbral del daño que el sujeto puede causar impunemente a terceros, sino en la capacidad del mismo ordenamiento jurídico para seguir siendo el parámetro de orientación válido en un cierto ámbito, a pesar del otorgamiento de la excusa en un caso particular.

Por lo tanto, y aunque nada impide que funcione como criterio general de orientación ${ }^{136}$, la estricta ponderación de males (artículo $10 \mathrm{~N}^{\circ} 11 \mathrm{CP}$, circunstancia $3^{\mathrm{a}}$ : el mal causado no ha de ser sustancialmente superior al que se evita) no encuentra un lugar cómodo como requisito típico de una excusa por razón de inexigibilidad. Ello resulta aún más evidente en los casos, nada infrecuentes (por cierto: dentro de la extrema excepcionalidad de estos supuestos), en que quien realiza la acción de salvaguarda amparado por la excusa se pone a sí mismo en peligro mediante ella, como ocurre paradigmáticamente en el homicidio del tirano doméstico. En esta y otras constelaciones, quien realiza la acción de salvaguarda en estado de necesidad exculpante es, en cierto modo, una víctima de su propia conducta.

\subsubsection{Los requisitos generales de la justificación}

Una justificación por estado de necesidad conforme al artículo $10 \mathrm{~N}^{\circ} 11 \mathrm{CP}$ entra en consideración cuando concurren los siguientes requisitos generales:

a) Mal grave, actual o inminente, que amenaza a la persona o derechos del que interviene o de un tercero cualquiera.

La exigencia de gravedad del mal es relativa y de difícil interpretación. La mención expresa de los "derechos" abre, sin embargo, un amplio campo, pues en la contraposición con la voz "persona" remite inequívocamente a los intereses instrumentales. Esta relatividad del mal y su gravedad, junto a la inclusión de los intereses instrumentales, permiten despejar en

${ }^{135}$ CONINX, "Restriktives Solidaritätsverständnis", cit. nota n 3, p. 126.

${ }^{136}$ Como ocurre en relación con el estado de necesidad exculpante que regula el $\S 35 \mathrm{StGB}$, tan citado por quienes abogan por una interpretación de la eximente en clave de exculpación. La mencionada regla nada establece sobre una ponderación de males, lo cual no impide que el correspondiente balance sea tomado en cuenta para evaluar la viabilidad de la excusa en el sentido expresado en el texto. 
VAN WEEZEL, Alex. "Optimización de la autonomía y deberes penales de solidaridad”.

buena medida una de las objeciones que se han formulado contra la inteligencia del precepto en comentario como regla de justificación, a saber, que su limitación al apartamiento de un "mal grave" excluiría precisamente el principal ámbito de aplicación del estado de necesidad justificante, el de los conflictos pequeños y cotidianos. ${ }^{137}$ Por otra parte, es posible que los "pequeños conflictos derivados de la puesta en peligro de otro por cosas propias" pertenezcan con mayor propiedad al ámbito del derecho de policía y del derecho civil. $\mathrm{Si}$, en cambio, la cosa propia de una persona pone en peligro la integridad corporal de otra, difícilmente seguirá tratándose de un pequeño conflicto.

Bajo este concepto de "mal" caben, en un extremo, todos los peligros o amenazas atribuibles a un ámbito de organización ajeno pero que no constituyen conductas típicas, antijurídicas y culpables, y que por lo tanto no pueden considerarse como "agresiones ilegítimas" en el sentido de la legítima defensa. En este ámbito, el estado de necesidad opera como una pequeña legítima defensa y la reacción defensiva queda sujeta a los requisitos de subsidiariedad de la circunstancia $2^{\mathrm{a}}$ y al límite superior de la ponderación prevista en la circunstancia $3^{\text {a }}$, según se verá. En el otro extremo, quedan comprendidos bajo el concepto de "mal" las amenazas o peligros provenientes de una esfera de organización ajena, aun de un modo inculpable.

La exigencia de actualidad o inminencia del mal, por su parte, hace que por lo general queden excluidas del ámbito de aplicación del artículo $10 \mathrm{~N}^{\circ} 11 \mathrm{CP}$ la situaciones criminológicamente caracterizadas como homicidio del tirano doméstico.

Como contrapartida, y según se vio, el agente de necesidad puede obrar a favor de un tercero cualquiera, pues así lo establece el precepto en razón de que la eximente no mira a la situación individual y extraordinaria en que se encuentra el agente de necesidad, sino que en primer lugar establece un criterio de distribución de autonomía, es decir, define el ámbito de lo permitido o prohibido.

b) Estricta subsidiariedad: que no exista otro medio practicable y menos perjudicial para "evitar" el mal.

La circunstancia $2^{\mathrm{a}}$ establece un requisito muy exigente de subsidiariedad, a diferencia de lo que ocurre con la acción defensiva en la legítima defensa. Esto obedece en primer lugar a que las situaciones de necesidad difieren en un punto esencial de las situaciones de defensa: mientras que la defensa es reacción frente a una agresión ilegítima, en la necesidad se trata -como expresa la ley-de "evitar un mal". Esto hace que la acción de salvaguarda propia de las situaciones de necesidad incluya por definición maniobras de mera elusión o evitación que, en cambio, en el caso de la legítima defensa, solo pueden añadirse desde afuera de la

${ }^{137}$ La objeción es de WILENMANN (La justificación de un delito, cit. nota $\mathrm{n}^{\circ}$ 30, p. 458), para quien la interpretación de la regla como justificante, "dada la limitación a la prevención de males graves, sería completamente contraproducente: el estado de necesidad defensivo encuentra su principal ámbito de aplicación en los 'pequeños conflictos' derivados de la puesta en peligro de otro por cosas propias y no solo en conflictos vitales". 
Polít. crim. Vol. 13, Nº 26 (Diciembre 2018) Art. 12, pp. 1074-1139.

[http://www.politicacriminal.cl/Vol_13/n_26/Vol13N26A12.pdf]

lógica defensiva. Esto vale también para una perspectiva, como la aquí sustentada, según la cual la excepcionalidad de la autorización que el derecho confiere a los ciudadanos para defenderse por sí mismos haciendo uso de la fuerza da lugar a una exigencia de proporcionalidad, que se traduce en la obligación de escoger el medio menos lesivo.

En el caso del artículo $10 \mathrm{~N}^{\circ} 11 \mathrm{CP}$ la exigencia de subsidiariedad es mayor, y ello rige también para el estado de necesidad defensivo que comprende el precepto. Aunque desde luego puede utilizarse la idea de defensa como criterio hermenéutico para graduar las exigencias de subsidiariedad -cuanto menos defensivo es el estado de necesidad, mayor es la exigencia de subsidiariedad y viceversa-, el punto de partida impuesto por la ley es claro: la acción de salvaguarda tiene que ser necesaria. Un medio necesario es aquel que resulta indispensable, y solo es indispensable un medio respecto del cual no hay otra alternativa practicable. Desde esta perspectiva, el medio menos lesivo y el único practicable se confunden en uno solo.

c) Que el sacrificio del bien amenazado no pueda ser exigido al agente de necesidad.

A diferencia de lo que ocurre en otros ordenamientos, la ley deja en suspenso lo que ha de entenderse por exigibilidad del sacrificio, elemento que junto a otras consideraciones permite entender que "esta" exigibilidad no es el foco del precepto, sino solo un dispositivo para limitar su alcance.

El sentido de la circunstancia $4^{\mathrm{a}}$ se entiende mejor a luz de otra de las objeciones que se han dirigido contra la comprensión del precepto como regla de justificación: si fuera una regla de esta clase, contendría alguna referencia a la responsabilidad por el peligro ${ }^{138}$. Esta objeción sorprende en alguna medida, si se tiene en cuenta que tampoco el artículo $10 \mathrm{~N}^{\circ} 7$ $\mathrm{CP}$ contiene tal referencia y ello no ha impedido que se lo interprete como una regla sobre estado de necesidad agresivo, precisamente a partir del contexto en que se encuentra y el sentido de los presupuestos de aplicación que establece expresamente.

La principal causa de la "omisión" legislativa en ambos casos radica, probablemente, en que en la tradición doctrinal chilena (y española) el asunto de la responsabilidad por el peligro era uno de los aspectos que entraba a formar parte de la ponderación de los males ${ }^{139}$. Lo que la doctrina contemporánea ha dado en identificar y aislar como una de las vigas maestras del sistema de los derechos de necesidad era, en esa tradición, un elemento integrante del macro-juicio de ponderación. Así, por ejemplo, cuando Cury interpreta la circunstancia $4^{a}$ como el establecimiento de una obligación de tolerancia basada en la provocación intencional del peligro, afirma precisamente que no es necesario explicitar este

${ }^{138}$ Así WILENMANN, La justificación de un delito, cit. nota n ${ }^{\circ}$ 30, p. 458; en el mismo sentido, CASTILLO, "El estado de necesidad del artículo $10 \mathrm{n}^{\circ} 11$ ", cit. nota ${ }^{\circ} 121$, p. 347; igualmente MAÑALICH, "El estado de necesidad exculpante", cit. nota $\mathrm{n}^{\circ} 121$, pp. 718 y s.; las demás objeciones a la posibilidad de interpretar la regla en clave de justificación pueden verse en HERNÁNDEZ, en COUSO; HERNÁNDEZ, Código Penal Comentado. Parte General, cit. nota n ${ }^{\circ} 35$, pp. 270 y s.

${ }^{139}$ Con amplias referencias al respecto COCA VILA, La colisión de deberes, cit. nota n ${ }^{\circ}$ 5, pp. 223 y ss. 
VAN WEEZEL, Alex. “Optimización de la autonomía y deberes penales de solidaridad”.

fundamento en la ley, pues se trata de una consideración implícita, ampliamente reconocida por la doctrina y la jurisprudencia ${ }^{140}$.

Esta misma observación de Cury sugiere que la circunstancia $4^{\mathrm{a}}$, así interpretada, puede constituir precisamente un modo implícito de incorporar el elemento de competencia por el peligro que algunos autores echan en falta. Así, lo que la ley califica como una posibilidad de "exigir razonablemente" el sacrificio del bien no sería una remisión a genéricas consideraciones de exigibilidad de otra conducta, sino la incorporación del principio de responsabilidad por el peligro: el sacrificio del bien puede ser exigido, en mayor o menor medida, precisamente a aquel que es responsable, también en mayor o menor medida, del mismo peligro ${ }^{141}$ que ahora lo amenaza ${ }^{142}$. En cualquier caso, y con independencia de su plausibilidad, esta interpretación de la circunstancia $4^{\mathrm{a}}$ no es necesaria para sostener que el sistema de los derechos de defensa y necesidad obedece al principio de competencia o autorresponsabilidad, pues así ocurría también con anterioridad a la introducción del nuevo artículo $10 \mathrm{~N}^{\circ} 11 \mathrm{CP}$.

\subsubsection{Elemento distintivo: que el mal causado no sea sustancialmente superior al que se evita}

La interpretación de la circunstancia $3^{\text {a }}$ de la eximente fluye de todo lo expuesto precedentemente, tanto en esta misma sección como en las secciones anteriores. La existencia de genuinos deberes de solidaridad con relevancia penal, junto a otras consideraciones, demuestra que la solución de los conflictos entre bienes jurídicos de titulares diversos no se resuelve simplemente según un criterio individualista -pues en tal caso no existirían deberes ante el otro como sujeto moral con derecho al bienestar-, y los límites a tales deberes manifiestan que los conflictos tampoco se superan desde la lógica colectivista de protección de bienes - de ser así, siempre triunfaría el interés que se considera en sí mismo más valioso. El sistema de los derechos de necesidad surge, en realidad, a partir de un entendimiento sobre la distribución de ámbitos de autonomía. Así,

140 CURY, "El estado de necesidad", cit. nota n 121, p. 255. En tal sentido COUSIÑO, Derecho Penal Chileno, II, cit. nota $\mathrm{n}^{\circ}$ 33, pp. 402 y ss.; POLITOFF, Sergio, Derecho Penal, Santiago: Conosur, 1996, p. 388; ETCHEBERRY, Derecho Penal, I, cit. nota ${ }^{\circ} 25$, pp. 265 y ss.

${ }^{141}$ CASTILLO, "El estado de necesidad del artículo $10 \mathrm{n}^{\circ} 11$ ”, cit. nota $\mathrm{n}^{\circ} 121, \mathrm{p} .353$, argumenta que un mal auto-producido no es un mal en el sentido de la ley, y para ello se funda en una serie de preceptos de los cuales se desprendería que, en el Código Penal, la expresión "mal" tiene la connotación de algo injusto o inmerecido, opuesto al derecho. La observación es interesante, pero choca con el uso que en la dogmática de la justificación se da a las expresiones que designan el peligro o amenaza que se trata de conjurar. En la misma tradición hispanoamericana (véase supra nota $\mathrm{n}^{\circ} 140$ ), la ponderación de los males incluye precisamente aquellos que son atribuibles a quien luego pretende apartarlos de sí.

${ }^{142}$ Cuando el necesitado no es el agente de necesidad, la competencia por el peligro sigue estando radicada en él. Por eso la parte final de la circunstancia $4^{\mathrm{a}}$ aclara que el necesitado es la persona relevante y contempla una regla especial sobre estado de necesidad putativo con efecto eximente. Como en la realidad puede ser muy complejo para el agente conocer la relación de competencias por el peligro, el ordenamiento opta por concederle la exención aún con prescindencia del requisito, si para el agente era imposible conocer esa relación de competencias. Con todo, la solución correcta habría sido la concesión de una eximente distinta (artículo $10 \mathrm{~N}^{\circ} 9 \mathrm{CP}$ ) y no la mera prescindencia de uno de los requisitos de esta. 
las causas de justificación son la otra cara de la medalla de los deberes que fundan posiciones de garante como presupuestos positivos de la antijuridicidad de una conducta, todos los cuales se insertan en un sistema ordenado a la maximización de la autonomía. La intensidad de los deberes y de los principios que gobiernan su neutralización depende de su consistencia con la razón de ser de ese sistema y, por lo tanto, del grado de ejercicio de autonomía en el origen de la vinculación.

De este modo, y en primer término, los estados de necesidad defensivos (END) se basan en el principio de responsabilidad respecto del riesgo que dio origen a la intervención justificada, de modo que su espectro justificatorio en cada caso depende primariamente del grado de competencia por la situación de riesgo y, en forma subordinada, de una ponderación de los respectivos menoscabos. Aunque teóricamente sería posible establecer soluciones diferenciadas para cada grado de competencia, la función del ordenamiento jurídico en orden a la reducción de la complejidad obliga a limitar estas distinciones. Sin embargo, el mínimo de complejidad aceptable obliga a distinguir dos END, uno con competencia personal culpable ${ }^{143}$ por un peligro cuya creación no alcanza a constituir una agresión ilegítima (END 1), y otro con competencia personal no culpable por el peligro (END 2).

El estado de necesidad agresivo (ENA), en segundo lugar, autoriza a afectar los bienes de una persona que no es en absoluto competente por la situación de riesgo, para proteger bienes de otras personas o de la sociedad que, en un juicio de ponderación, prevalecen ampliamente sobre los bienes sacrificados. En la tradición jurídica y filosófica en que se inscribe nuestro ordenamiento jurídico, esto solo significa, en principio, afectar la propiedad del inocente para salvar la vida del necesitado. No obstante, ya el Código Penal acepta en el artículo $10 \mathrm{~N}^{\circ} 7$ la afectación de la propiedad del inocente para salvaguardar un bien "mayor". En cualquier caso, para que opere la justificación que puede proveer el ENA es necesario que lo positivo sea muy preponderante respecto de lo negativo y que el sacrificio sea menor. Un criterio útil pero no excluyente es que se trate de un bien susceptible de indemnización en naturaleza ${ }^{144}$. El sacrificio para el obligado por el deber solidaridad, que es heterónomo en su origen, no puede ser irreparable. Por la misma razón, el incumplimiento del deber no puede acarrear responsabilidad por el correspondiente delito de resultado.

143 Los fundamentos de la competencia personal en uno y otro caso pueden consultarse, con amplia coincidencia en lo sustancial, en WILENMANN, La justificación de un delito, cit. nota $\mathrm{n}^{\circ}$ 30, pp. 488 y ss., y en COCA VILA, La colisión de deberes, cit. nota $\mathrm{n}^{\circ}$ 5, pp. 335 y ss.

144 También debe ser objeto de un estudio específico la determinación de quién es el obligado a indemnizar. De acuerdo a la concepción aquí planteada, el primer obligado es el beneficiario de la acción de salvaguarda (como está regulado en el caso de la echazón de mercaderías para salvar el barco y las vidas de la tripulación: artículo 1095 y siguientes del Código de Comercio) -atendido el carácter primariamente intersubjetivo del deber de solidaridad- $\mathrm{y}$, en subsidio, el Estado. 
VAN WEEZEL, Alex. "Optimización de la autonomía y deberes penales de solidaridad”.

Consecuentemente, conforme a la circunstancia $3^{\mathrm{a}}$ del artículo $10 \mathrm{~N}^{\circ} 11 \mathrm{CP}$, cuando se está ante un estado de necesidad defensivo, el precepto puede aplicarse en su límite: siempre que el afectado por la intervención sea personalmente competente y culpable por la situación de riesgo (pero sin ser agresor ilegítimo: END 1), el hecho estará justificado, incluso si el mal causado es superior al que se evita, salvo que sea sustancialmente superior a él. Si el afectado, en cambio, es competente pero no culpable por la situación de peligro (END 2), entonces el hecho estará justificado solo si el balance final es, al menos, mínimamente positivo.

En cambio, cuando se está ante un estado de necesidad agresivo, solo habrá justificación en la medida en que lo positivo sea muy preponderante respecto de lo negativo. Tal es el caso cuando se sacrifican intereses instrumentales o intereses personales de muy menor entidad para salvar la vida o la salud de una persona - pero también, por ejemplo, su indemnidad sexual o su libertad ambulatoria- frente a amenazas que pueden implicar su destrucción o grave afectación.

El artículo $10 \mathrm{~N}^{\circ} 11 \mathrm{CP}$ no tiene el sentido de equiparar el estado de necesidad defensivo con el estado de necesidad agresivo, que solo se explica por consideraciones de mínima solidaridad. Por lo tanto, hay que entender que la circunstancia $3^{\mathrm{a}}$ funciona como reguladora: en su límite opera solo en caso de estado de necesidad defensivo; para que justifique en los casos de estado de necesidad agresivo, en cambio, se requiere que el balance sea mucho mejor que ese límite mínimo. Con otras palabras, el precepto tiene un "techo" -la no afectación de un interés sustancialmente superior que el que se salva-, pero el "piso" es variable dependiendo del fundamento de la justificación en el plano de la competencia por el peligro.

En este esquema, podría estar justificada la conducta del que pasa por el jardín del vecino para cortar el agua del que vive más allá y cuyo sistema de riego descompuesto amenaza inundación, pues se afecta un interés de menor consideración; el vecino no tendría legítima defensa en contra. Pero sería discutible si tuviera que pasar por su casa. En el caso del que mata al perro del vecino diligente para salvar su valioso jarrón el asunto también se decide a favor de la justificación, pues forma parte de la posición jurídica del tenedor de un perro aceptar que este sea sacrificado cuando se convierte en fuente incontrolable de peligros para los intereses de terceros.

El ENA queda así limitado a la afectación de bienes instrumentales como la propiedad o de bienes personales de significación muy menor (como en el ejemplo del paso por el jardín ajeno), y además sujeto a la exigencia de gravedad del mal amenazante, salvo que el bien afectado por la acción de salvaguarda sea la propiedad, pues en ese caso operará la regla de justificación más amplia contenida en el artículo $10 \mathrm{~N}^{\circ} 7 \mathrm{CP}$, que no solo prescinde de la exigencia de un mal grave, sino también de un balance final muy sustancialmente positivo. Ambas características diferenciales respecto del ENA regulado en el artículo $10 \mathrm{~N}^{\circ} 11 \mathrm{CP}$ 
justifican la conservación de aquel precepto, o su derogación únicamente en conjunto con una modificación de este.

Tal como de acuerdo a esta interpretación del artículo $10 \mathrm{~N}^{\circ} 11 \mathrm{CP}$, el artículo $10 \mathrm{~N}^{\circ} 7 \mathrm{CP}$ sigue cumpliendo una función relevante, también conforme a ella resulta reforzado el rol del artículo $10 \mathrm{~N}^{\circ} 9 \mathrm{CP}$, el cual sigue regulando, entre otros supuestos, lo que en el derecho comparado se conoce como estado de necesidad exculpante. Tradicionalmente se decía que el fundamento de la eximente estaba en que el sujeto había actuado con menor libertad. Es posible que haya algo de esto, pero hoy se reconoce que no es todo. Tal fundamentación no explica, por ejemplo, por qué no se concede sin más la eximente a personas que por su oficio deben afrontar ciertos peligros; es decir, no se mira al estado anímico del bombero o del policía, sino que se hace una ponderación más generalizadora. Tampoco explica por qué no se exime en los casos de error fácilmente evitable sobre el estímulo; cuando, por ejemplo, uno de los náufragos mata al otro para quedarse con la tabla de Carnéades, pero luego advierte que en ese lugar las aguas tenían muy baja profundidad y podría haberse puesto de pie, o que poco más allá podía divisarse una isla tras la niebla.

La explicación real de la eximente pasa por determinar cuándo la sociedad puede permitirse atender a las particularidades individuales del ánimo en el proceso de imputación. Solo si la solución del conflicto al margen del sujeto excusado no desestabiliza la vigencia de la norma de un modo intolerable, se puede psicologizar la imputación; si no, el ordenamiento se aferra al mínimo de motivación de respeto al derecho que se atribuye a toda persona imputable. Exactamente de esto se trata en el estado de necesidad exculpante. El sujeto realiza la descripción típica sin estar amparado por una causa de justificación, pero lo hace en un conflicto existencial insuperable o irresistible. En estas condiciones, la conducta no constituye una verdadera toma de posición sobre la vigencia del derecho. La insuperabilidad y la irresistibilidad son la clave de la eximente, y no una ponderación de intereses ${ }^{145}$.

\subsection{El caso de Karina}

El 27 de marzo de 2013, la Corte de Apelaciones de San Miguel resolvió un caso al que subyacían los siguientes hechos ${ }^{146}$ : el 17 de octubre de 2011, Karina dio muerte a su conviviente mientras este dormía. El día anterior, el conviviente había atacado al hijo menor de la pareja, en un episodio más de violencia intrafamiliar de entre los muchos que se sucedían en la familia desde hacía años. Respecto de la motivación de su acto, los antecedentes permiten concluir que el propósito de Karina fue prevenir futuros hechos de violencia de su conviviente.

${ }^{145}$ Cfr. MOMSEN, Die Zumutbarkeit, cit. nota n 93, p. 141.

${ }^{146}$ SCA San Miguel, 27.III.2013, Rol Ingreso de Corte N ${ }^{\circ}$ 133-2013. 
VAN WEEZEL, Alex. "Optimización de la autonomía y deberes penales de solidaridad”.

Lo sustancial del fallo, posiblemente el más emblemático hasta ahora en relación con el artículo $10 \mathrm{~N}^{\circ} 11 \mathrm{CP}$, es conocido: la Corte rechazó la eximente invocada por la defensa y anuló la sentencia del Tribunal Oral en lo Penal que la había acogido ${ }^{147}$. Menos conocido es, sin embargo, que en su sentencia la Corte de San Miguel realiza una interpretación a primera vista muy particular del artículo $10 \mathrm{~N}^{\circ} 11 \mathrm{CP}$. Entiende así, por ejemplo, contra el tenor literal de la circunstancia $3^{\text {a }}$, que el mal que se trata de evitar debe ser equivalente al mal que se provoca, al menos cuando la acción de salvaguarda afecta la vida de otras personas. Por otro lado, establece una exigencia de subsidiariedad particularmente intensa, ya que considera aceptable la autotutela solo cuando no existe la alternativa de acudir a la policía o a terceros en un momento distinto de los episodios críticos de violencia intrafamiliar. Finalmente, el fallo parece dejar completamente de lado el requisito de ausencia de una razonable exigibilidad del sacrificio.

La explicación de todas estas particularidades se encuentra en que la Corte, a pesar de lo alegado por la defensa y de lo sostenido por el tribunal del fondo, interpreta el artículo 10 $\mathrm{N}^{\circ} 11$ CP como una regla sobre estado de necesidad justificante. Dicho con más precisión: el fallo parece oscilar intelectualmente entre la interpretación alegada en el juicio que considera la regla como causa de exculpación, y lo que el análisis de la misma regla parece imponer al intérprete.

El considerando $9^{\circ}$ es muy ilustrativo al respecto:

"Conforme a lo ya reseñado, necesariamente ha de entenderse entonces, que al momento de cometerse la acción no existía respecto de ella una situación de tal naturaleza que hiciera peligrar su vida o la de sus hijos puesto que si bien se demostró que llevaba una relación conflictiva de muchos años, marcada por hechos violentos, la reacción que tuvo la acusada en dicha oportunidad no se encuentra acorde con el resultado de la misma justificando el actuar de la acusada quien repele ese mal provocando otro de mayor entidad" ${ }^{148}$.

En este contexto, la prescindencia del requisito de ausencia de razonable exigibilidad del sacrificio resulta comprensible, pues desde la lógica de la justificación tal requisito solo puede referirse a la exigencia de que el sujeto que sufre la intervención no haya provocado culpablemente la situación de necesidad, a los límites basados en solidaridad mínima, o a la situación de personas afectadas por especiales posiciones de garante. Nada de esto resultaba pertinente para la decisión del caso concreto en la lógica de la justificación. Solo en la lógica de la exculpación resulta insólito que se prescinda en el fallo del requisito relativo a la exigibilidad.

La estricta subsidiariedad de la acción de salvaguarda se explica también perfectamente desde la lógica de la justificación. El tirano doméstico no es un injusto agresor, y por lo

\footnotetext{
${ }^{147}$ En detalle van WEEZEL, Alex, "Caso del agresor dormido", cit. nota n ${ }^{\circ} 119$, pp. 337 y ss.

${ }^{148}$ SCA San Miguel, 27.III.2013, Rol Ingreso de Corte $N^{\circ} 133-2013$, considerando $9^{\circ}$ (cursivas añadidas).
} 
Polít. crim. Vol. 13, Nº 26 (Diciembre 2018) Art. 12, pp. 1074-1139.

[http://www.politicacriminal.cl/Vol_13/n_26/Vol13N26A12.pdf]

tanto a su respecto no se tiene la autorización casi omnímoda que confiere la legítima defensa. En consecuencia, en la especie solo se trataba de justificar la conducta de quien evita un mal grave, lo que establece por definición un régimen de subsidiariedad que llega hasta la huida como alternativa que, si es practicable, debe ser escogida en lugar de una acción homicida.

La lógica de la justificación por estado de necesidad defensivo alcanza su más evidente demostración cuando el tribunal realiza el análisis de proporcionalidad y, desechando el tenor literal de la circunstancia $3^{\mathrm{a}}$, exige que el menoscabo producido por la acción de salvaguarda no supere en entidad al mal amenazante. En los términos del considerando $9^{\circ}$ recién citado: "La reacción que tuvo la acusada en dicha oportunidad no se encuentra acorde con el resultado de la misma justificando el actuar de la acusada quien repele ese mal provocando otro de mayor entidad". O también, enfáticamente, en el considerando $11^{\circ}$ : "Dicho mal [amenazante] no podía ser mayor que el causado para evitarlo", la muerte del conviviente, lo que excluye la exención de responsabilidad. Cuando el que sufre las consecuencias de la intervención es personalmente competente y además culpable por el curso dañoso, como ocurre en la especie, entonces debe soportar todos los costos de la acción de salvaguarda, pero siempre que no haya desproporción considerable entre el menoscabo producido por la reacción defensiva y el mal evitado. Esta pequeña legítima defensa que es el estado de necesidad defensivo justifica solo bajo estrictas exigencias de proporcionalidad. En principio, el balance final no puede ser negativo; y si lo es, la diferencia a favor de quien usa la justificación solo puede ser muy menor.

Con otras palabras, la Corte de San Miguel se hizo cargo de la alegación de un estado de necesidad exculpante desde la racionalidad del estado de necesidad justificante. Como la regla legal invocada por la defensa fue el artículo $10 \mathrm{~N}^{\circ} 11 \mathrm{CP}$, la Corte estuvo en lo correcto al proceder de este modo. 
VAN WEEZEL, Alex. “Optimización de la autonomía y deberes penales de solidaridad”.

\section{Bibliografía}

ACOSTA, Juan Domingo, “Artículo 10 Nos. $7^{\circ}$ y $11^{\circ}$ del Código Penal. Algunos criterios de delimitación”, en: van WEEZEL, Alex (ed.), Humanizar y renovar el derecho penal. Estudios en memoria de Enrique Cury, Santiago: Thomson Reuters, 2013, pp. 691-713.

AQUINO, Tomás de, Suma Teológica, t. VIII, Edición Bilingüe, Madrid: B AC, 2014.

ARISTÓTELES, Ética a Nicómaco, cit. según la edición bilingüe de ARAUJO, María; MARÍAS, Julián, Madrid: Centro de Estudios Políticos y Constitucionales, $9^{a}$ ed., 2009.

ARISTÓTELES, Aristotelis Opera, ed. a cargo de Emanuel BEKKER, Berolini, apud G. Reimerum, 1831, Vol. I y II, pp. 1214 y ss. (Ética Eudemia); 1252 y ss. (Política), disponible en https://archive.org/details/aristotelisopera01arisrich

ASHWORTH, Andrew, "Die Rettungspflicht im englischen Recht: Sinnvolle Einschränkungen oder 'island" mentality?", en von HIRSCH; NEUMANN; SEELMANN (eds.), Solidarität im Strafrecht, pp. 115-130.

ASHWORTH, Andrew, Positive Obligations in Criminal Law, Portland: Bloomsbury, 2015.

BALDÓ LAVILLA, Francisco, Estado de necesidad y legítima defensa, Barcelona: J.M. Bosch Editor, 1994.

BAYERTZ, Kurt, "Begriff und Problem der Solidarität", en BAYERTZ, Kurt (ed.), Solidarität, Frankfurt a.M.: Suhrkamp, 1998, pp. 11-53.

BAYERTZ, Kurt, "Staat und Solidarität", en él mismo (ed.), Politik und Ethik, Stuttgart: Reclam,1996, pp. 305-329.

BELING, Ernst, Die Lehre vom Verbrechen, Tübingen: J.C.B. Mohr (Paul Siebeck), 1906 (reprint EHV History, 2014).

BERNSMANN, Klaus, Entschuldigung durch Notstand, Köln: Carl Heymans Verlag, 1989.

CASTILlO, Juan Pablo, "El estado de necesidad del artículo $10 \mathrm{n}^{\circ} 11$ del Código penal chileno: ¿Una norma bifronte? Elementos para una respuesta negativa”, en Política Criminal, Vol. 11, N²2 (2016), pp. 340-367.

COCA VILA, Ivó, La colisión de deberes en derecho penal, Barcelona: Atelier, 2016.

CONINX, Anna, "Restriktives Solidaritätsverständnis und extensive Gefahrenzuständigkeit”, en HRUSCHKA; JOERDEN (eds.), Jahrbuch für Recht und Ethik (2014), pp. 117-136.

COUSIÑO, Luis, Derecho Penal Chileno, II, Santiago: Ed. Jurídica de Chile, 1979.

COUSO, Jaime, Fundamentos del derecho penal de culpabilidad, Valencia: Tirant lo Blanch, 2006.

COUSO, Jaime; HERNÁNDEZ, Héctor, Código Penal Comentado. Parte General, Santiago: LegalPublishing, 2011.

CURY, Enrique, "El estado de necesidad en el Código Penal chileno", en MAÑALICH, J. P. (coord.), La ciencia penal en la Universidad de Chile. Libro Homenaje a los Profesores del Departamento de Ciencias Penales de la Facultad de Derecho de la Universidad de Chile, Santiago: Facultad de Derecho Universidad de Chile, 2013, pp. 249-266. 
Polít. crim. Vol. 13, Nº 26 (Diciembre 2018) Art. 12, pp. 1074-1139.

[http://www.politicacriminal.cl/Vol_13/n_26/Vol13N26A12.pdf]

CURY, Enrique, Derecho Penal: Santiago, Editorial Jurídica de Chile, $7^{\text {a }}$ ed. 2005.

ETCHEBERRY, Alfredo, Derecho Penal, I, IV, Santiago: Ed. Jurídica de Chile, $3^{\text {a }}$ ed., 1997.

FARRÉS, Oriol, "La amistad cívica en Aristóteles", en Anales del Seminario de Historia de la Filosofía, Vol. 32, $\mathrm{N}^{\circ} 1$ (2015), pp. 41-67.

FEINBERG, Joel, Freedom and Fulfillment, Princeton, New Jersey: Princeton University Press, 1992.

FICHTE, Johann Gottlieb, Grundlage des Naturrechts nach Principien der Wissenschaftslehre, Hamburgo, Verlag Felix Meiner, reimpresión sobre la base de la $2^{\mathrm{a}}$ edición de 1922 a cargo de MEDICUS, F.,1979.

FLETCHER, George P., Rethinking Criminal Law, New York: OUP, 2000.

FORST, Rainer, Kontexte der Gerechtigkeit, Frankfurt a.M.: Suhrkamp, 1996.

FRISCH, Wolfgang, Tatbestandsmäßiges Verhalten und Zurechnung des Erfolgs, Heidelberg: C. F. Müller, 2012 (reimpresión de la edición de 1988).

FRISCH, Wolfgang, "Beihilfe durch neutrale Handlungen. Bemerkungen zum Strafgrund (der Unrechtskonstitution) der Beihilfe", en PRITTWITZ, Cornelius et al. (eds.), Festschrift für Klaus Lüderssen, Baden-Baden: Nomos, 2002, pp. 539-558.

FRISCH, Wolfgang, "Notstandsregelungen als Ausdruck von Rechtsprinzipien", en: PAEFFGEN, Hans-Ullrich et al. (ed.), Strafrechtswissenschaft als Analyse und Konstruktion. Festschrift für Ingeborg Puppe zum 70. Geburtstag, Berlin: Duncker \& Humblot, 2011, pp. 425-450.

FRISCH, Wolfgang, "Derecho penal y solidaridad”, en InDret 4/2016, pp. 1-24.

GARRIDO, Mario, Derecho Penal, I, III, Santiago: Ed. Jurídica de Chile 4ª ed., 2009.

GROTIUS, Hugo, De Jure Belli ac Pacis. Libri tres, editio nova, Amsterdam 1680.

HABERMAS, Jürgen, "Recht und Moral", en: Faktizität und Geltung. Beiträge zur Diskurstheorie des Rechts und des demokratischen Rechtsstaats, Frankfurt a. M.: Suhrkamp, 1992.

HEGEL, G. W. F., Enzyklopädie der philosophischen Wissensachaften, III (ed. K. L. Michelet), revisada por MOLDENHAUER, E.; MICHEL, K. M. (eds.), Frankfurt a.M.: Suhrkamp, 1986.

HEGEL, G. W. F., Grundlinien der Philosophie des Rechts según MOLDENHAUER, E.; MICHEL, K. M. (eds.), Frankfurt a.M.: Suhrkamp, 1970.

HEGEL, G. W. F., Vorlesungen über Geschichte der Philosophie, ed. a cargo de K. L. MICHELET, revisada por Eva MOLDENHAUER y Karl Markus MICHEL, Frankfurt a.M.: Suhrkamp, 1986.

HIRSCH von, Andreas; SCHORSCHER, Vivia C., "Die Kriminalisierung der unterlassenen Hilfeleistung: Eine Frage von 'Solidarität' oder Altruismus?", en von HIRSCH; NEUMANN; SEELMANN (eds.), Solidarität im Strafrecht, pp. 77-92.

HIRSCH, Andreas von; NEUMANN, Ulfrid; SEELMANN, Kurt (eds.), Solidarität im Strafrecht. Zur Funktion und Legitimation strafrechtlicher Solidaritätspflichten, Baden-Baden: Nomos, 2013.

HIRSCH, Joachim, en Strafgesetzbuch Leipziger Kommentar, Berlin: De Gruyter, $11^{\mathrm{a}}$ ed., 1992.

HONNETH, Axel, Das Recht der Freiheit. Grundriß einer demokratischen Sittlichkeit, Berlin: Suhrkamp, 2011. 
VAN WEEZEL, Alex. “Optimización de la autonomía y deberes penales de solidaridad”.

HONNETH, Axel, Kampf um Anerkennung, Frankfurt a.M.: Suhrkamp, 2003 (edición ampliada).

HÖSLE, Vittorio, Hegels System. Der Idealismus der Subjektivität und das Problem der Intersubjektivität, Hamburg: Verlag Felix Meiner, 1998.

JAKOBS, Günther, "Altes und Neues zum strafrechtlichen Vorstazbegriff", en Rechtswissenschaft, Heft 3, 2010, pp. 291-315.

JAKOBS, Günther, "Person und Subjekt in Hegels 'Grundlinien'”, Rechtsphilosophie Zeitschrift für Grundlagen des Rechts, N² 2 (2017), pp. 349-352.

JAKOBS, Günther, "Recht und Gut - Versuch einer strafrechtlichen Begriffsbildung”, en FREUND, Georg et al. (eds.), Grundlagen und Dogmatik des gesamten Strafrechtssystems. Festschrift für Wolfgang Frisch zum 70. Geburtstag, Berlin: Duncker \& Humblot, 2013, pp. 81-94.

JAKOBS, Günther, "Strafrecht und Sitte. Zur Pönalisierung exzessiven Freiheitsgebrauchs", en FREUND, Georg; MURMANN, Uwe (eds.), Siebzig Jahre Frisch, Tübingen: Mohr Siebeck, 2014, pp. 7-21.

JAKOBS, Günther, Nötigung, Paderborn: Ferdinand Schöningh, 2015.

JAKOBS, Günther, System der strafrechtlichen Zurechnung, Frankfurt a.M.: Vittorio Klostermann, 2012.

JESCHEK, Hans-Heinrich; WEIGEND, Thomas, Strafrecht. Allgemeiner Teil, Berlin: Duncker \& Humblot, 1996, § 44 III 2.

KANT, Immanuel, Metaphysik der Sitten, en: Kants gesammelte Schriften, ed. por la Königlich Preußischen Akademie der Wissenschaften. Erste Abteilung, Tomo VI, Berlin 1907.

KERSTING, Wolfgang, Die politische Philosophie des Gesellschaftsvertrags, Darmstadt: Wiss. Buchgesellschaft, 1994.

KINDHÄUSER, Urs, Strafrecht. Allgemeiner Teil, Baden-Baden: Nomos, 7 a ed., 2015.

KUBICIEL, Michael, Die Wissenschaft vom besonderen Teil des Strafrechts, Frankfurt a.M.: Vittorio Klostermann, 2013.

KÜBLER, Friedrich (ed.), Verrechtlichung von Wirtschaft, Arbeit uns sozialer Solidarität, Frankfurt a.M.: Suhrkamp, $2^{\mathrm{a}}$ ed., 2016, pp. 7 y ss., RORTY, Richard, Solidarität oder Objetivität. Drei philosophische Essays (trad. Joachim Schulte), Stuttgart: Reclam, 1988.

KÜHL, Kristian, "Zur Anwendung des Solidaritätsbegriffs auf die unterlassene Hilfeleistung nach § 323c StGB”, en von HIRSCH; NEUMANN; SEELMANN (eds.), Solidarität im Strafrecht, cit. nota ${ }^{\circ} 2$, pp. 93-102.

KÜHNBACH, Lena, Solidaritätspflichten Unbeteiligter, Baden-Baden, Nomos: 2007.

LAZARUS, Liora, "The Right to Security", en CRUFT, Rowan et al. (eds.), Philosophical Foundations of Human Rights, New York: OUP, 2015, pp. 423-441.

MAIHOLD, Harald, "Jenseits weltanschaulicher Ideologien? - Zur Einführung und Begründung der allgemeinen Nothilfepflicht im Schweizerischen Strafrecht", en von HIRSCH; NEUMANN; SEELMANN (eds.), Solidarität im Strafrecht, pp. 131154.

MAÑALICH, Juan Pablo, "El estado de necesidad exculpante. Una propuesta de interpretación del artículo $10 \mathrm{~N}^{\circ} 11$ del Código Penal chileno", en: van WEEZEL, Alex (ed.), Humanizar y renovar el derecho penal. Estudios en memoria de Enrique Cury, Santiago: Thomson Reuters, 2013, pp. 715-742. 
Polít. crim. Vol. 13, Nº 26 (Diciembre 2018) Art. 12, pp. 1074-1139.

[http://www.politicacriminal.cl/Vol_13/n_26/Vol13N26A12.pdf]

MAÑALICH, Juan Pablo, "Normas permisivas y deberes de tolerancia" en Revista Chilena de Derecho, Vol.41, № 2 (2014), pp. 473-522.

MOMSEN, Carsten, Die Zumutbarkeit als Begrenzung strafrechtlicher Pflichten, BadenBaden: Nomos, 2006.

NAVAS, Iván, Deberes negativos y positivos en derecho penal. Sobre los deberes de solidaridad y cooperación en un Estado liberal, Valencia: Tirant lo Blanch, 2018.

NEUMANN, Ulfrid, 'Die rechtsethische Begründung des 'rechtfertigenden Notstands' auf der Basis von Utilitarismus, Solidaritätsprinzip und Loyalitätsprinzip", en von HIRSCH; NEUMANN; SEELMANN (eds.), Solidarität im Strafrecht, pp. 155-173.

NEUMANN, Ulfrid, "Die Strafbarkeit der Suizidbeteiligung als Problem der Eigenverantwortlichkeit des 'Opfers'", Juristische Arbeitsblätter, 1987, pp. 244256.

OTTO, Harro, "Solidarität als Rechtsbegriff”, en: HEGER, Martin; KELKER, Brigitte; SCHRAMM, Edward (eds.), Festschrift für Kristian Kühl zum 70. Geburtstag, München: Verlag C. H. Beck, 2014, pp. 341-362.

PAWLIK, Michael, "Las competencias del ciudadano", en: PAWLIK, Michael, Ciudadanía y derecho penal, Barcelona: Atelier, 2016.

PAWLIK, Michael, "Solidarität als strafrechtliche Legitimationskategorie: das Beispiel des rechtfertigenden Aggressivotstandes", en HRUSCHKA; JOERDEN (eds.), Jahrbuch für Recht und Ethik (2014), pp. 137-157.

PAWLIK, Michael, Das Unrecht des Bürgers, Tübingen: Mohr Siebeck, 2012.

PERRON, Walter, en SCHÖNKE, Adolf; SCHRÖDER, Horst, Strafgesetzbuch, München: C. H. Beck, $29^{\mathrm{a}}$ ed., 2014, $\S 35$.

PFORDTEN, Dietmar von der, "Zur Rechtfertigung von Hilfeleistungspflichten”, en: von HIRSCH, Andreas; NEUMANN, Ulfrid; SEELMANN, Kurt (eds.), Solidarität im Strafrecht. Zur Funktion und Legitimation strafrechtlicher Solidaritätspflichten, Baden-Baden: Nomos, 2013, pp. 103-113.

PIÑA, Juan I., "La solidaridad como fuente de deberes" (cit. pro manuscripto).

POLITOFF, Sergio, Derecho Penal, Santiago: Conosur, 1996.

PUFENDORF, Samuel, De Jure Belli ac Pacis (disponible en https://archive.org/stream/ samuelispufendor1672pufe\#page/238/mode/ 2up; visitada por última vez el 12.III.2018).

RADBRUCH, Gustav, Gesamtausgabe. Rechtsphilosophie II, edición a cargo de KAUFMANN, Arthur, Heidelberg: C.F. Müller, 1993.

RENZIKOWSKI, Joachim, "Solidarität in Notsituationen. Ein historischer Überblick von Thomas v. Aquin bis Hegel“", en von HIRSCH; NEUMANN; SEELMANN (eds.), Solidarität im Strafrecht, pp. 13-34.

RHONHEIMER, Martin, Die Perspektive der Moral, Berlin: Akademie Verlag, 2001.

RITTER, Joachim, "Moralität und Sittlichkeit. Zu Hegels Auseinandersetzung mit der Kantischen Ethik", en RIEDEL, Manfred (ed.), Materialien zu Hegels Rechtsphilosophie, Frankfurt a.M.: Suhrkamp, 1975, pp. 217-244.

ROBLES PLANAS, Ricardo, "Deberes negativos y positivos en derecho penal", en InDret No 4 (2013), pp. 1-21.

ROBLES PLANAS, Ricardo, Garantes y cómplices: la intervención por omisión y en los delitos especiales, Barcelona: Atelier, 2007. 
VAN WEEZEL, Alex. “Optimización de la autonomía y deberes penales de solidaridad”.

ROJAS, Luis, "Fundamento y estructura del delito contemplado en el art. 195 de la Ley de Tránsito" (cit. pro manuscripto).

ROJAS, Luis, "Grundprobleme der allgemeinen Verbrechenslehre bei der unterlassenen Verbrechensanzeige - $\S \S 138,139$ StGB“", en GA 2017, pp. 147-161.

ROXIN, Claus, Strafrecht Allgemeiner Teil, I, München: C. H. Beck, $4^{\mathrm{a}}$ ed. 2006.

ROXIN, Claus, Täterschaft und Tatherrschaft, Berlin: De Gruyter, 9a ed. 2015.

SÁNCHEZ-VERA, Javier, Pflichtdelikt und Beteiligung, Berlin: Duncker \& Humblot, 1999.

SCHNÄDELBACH, Herbert, Hegels praktische Philosophie, Frankfurt a.M.: Suhrkamp, 2000.

SCHROEDER, Friedich-Christian, "Die Notwehr als Indikator politischer Grundanschauungen", en: él mismo y ZIPF, Heinz (eds.), Festschrift für Reinhart Maurach zum 70. Geburtstag, Karlsruhe: Verlag C. F. Müller, 1972, pp. 126-142.

SEELMANN, Kurt, en: "Ideengeschichte des Soliaritätsbegriffs im Strafrecht", en von HIRSCH; NEUMANN; SEELMANN (eds.), Solidarität im Strafrecht, pp. 35-47.

SIEP, Ludwig, "Selbstverwirklichung, Anerkennung und politische Existenz. Zur Aktualität der politischen Philosophie Hegels", en: SIEP, Ludwig, El legado político europeo en la filosofía política de Hegel (trad. por Ángela DE LA TORRE y Alex van WEEZEL), Bogotá: Universidad Externado de Colombia, 2005, pp. 3968.

SILVA SÁNCHEZ, Jesús-María, "Notstandsrechte und Duldungspflichtverletzung”, en GA 2006, pp. 382-386.

SILVA SÁNCHEZ, Jesús-María, El delito de omisión. Concepto y sistema, MontevideoBuenos Aires: B de F, $2^{\mathrm{a}}$ ed. 2003.

SIMESTER, A. P.; von HIRSCH, Andreas, Crimes, Harms and Wrongs. On the Principles of Criminalization, Oregon: Hart Publishing, reprint 2014.

SPAEMANN, Robert, Glück und Wohlwollen, Stuttgart: Klett-Cotta, 1988.

STRATENWERTH, Günter, Strafrecht Allgemeiner Teil, Köln; Carl Heymans Verlag, $4^{\text {a }}$ ed. 2000.

TEUBNER, Günther, Recht als autopoietisches System, Frankfurt a. M.: Suhrkamp, 1989.

THEUNISSEN, Michael, "Die verdrängte Intersubjektivität in Hegels Philosophie des Rechts", en: HENRICH, D.; HORSTMANN R.-P. (eds.), Hegels Philosophie des Rechts. Die Theorie der Rechts-formen und ihre Logik, Stuttgart: Klett-Cotta, 1982.

VARGAS, Tatiana, "¿Tiene la necesidad cara de hereje? Necesidad justificante y exculpante a la luz del artículo $10 \mathrm{~N}^{\circ} 11$ ”, en van WEEZEL (ed.), Humanizar y renovar el derecho penal, loc. cit., pp. 743-774.

VARGAS, Tatiana; SANTIBÁÑEZ, María Elena, "Reflexiones en torno a las modificaciones para sancionar el femicidio y otras reformas relacionadas (Ley $\mathrm{n}^{\circ}$ 20.480)", en Revista Chilena de Derecho, Vol. 38 № 1 (2011), pp. 193-207.

VIDAL, Víctor, "Análisis de las características más relevantes del estado de necesidad establecido por la ley 20.480", en Ars Boni et Aequi, Año 9, N² 2 (2013), pp. 237253.

VIGO, Alejandro, Aristóteles. Una introducción, Santiago: Instituto de Estudios de la Sociedad, 2006.

WALZER, Michael, "Die kommunitaristische Kritik am Liberalismus", en HONNETH, A. (ed.), Kommunitarismus, Frankfurt a. M.: Campus Verlag, 1993. 
Polít. crim. Vol. 13, Nº 26 (Diciembre 2018) Art. 12, pp. 1074-1139.

[http://www.politicacriminal.cl/Vol_13/n_26/Vol13N26A12.pdf]

WEEZEL, Alex van, “Actuar en lugar de otro", en MAÑALICH, J. P. (coord.), La ciencia penal en la Universidad de Chile. Libro Homenaje a los Profesores del Departamento de Ciencias Penales de la Facultad de Derecho de la Universidad de Chile, Santiago: Facultad de Derecho Universidad de Chile, 2013, pp. 283-310.

WEEZEL, Alex van, "Caso del agresor dormido. El problema del 'tirano doméstico' ”, en VARGAS, Tatiana (dir.), Casos Destacados. Derecho Penal (Parte General), Santiago: Thomson Reuters, 2015, pp. 337-356.

WEEZEL, Alex van, "Injerencia y solidaridad en el delito de omisión de auxilio en caso de accidente" (en evaluación).

WEEZEL, Alex van, "Necesidad justificante y solidaridad", en Cárdenas, Claudia; Ferdman, Jorge (coords.), El derecho penal como teoría y como práctica. Libro en homenaje a Alfredo Etcheberry Orthusteguy, Santiago: Legal Publishing, 2016, pp. 213-230.

WIELAND, Wolfgang, Die aristotelische Physik, Göttingen: Vandenhoeck \& Ruprecht, $3^{\mathrm{a}}$ ed. 1992.

WILENMANN, Javier, Freiheitsdistribution und Verantwortungsbegriff, Tübingen: Mohr Siebeck, 2014.

WILENMANN, Javier, La justificación de un delito en situaciones de necesidad, Madrid, Marcial Pons, 2017. 